Cochrane Database of Systematic Reviews

\title{
Follicular flushing during oocyte retrieval in assisted reproductive techniques (Review)
}

Georgiou EX, Melo P, Brown J, Granne IE

Georgiou EX, Melo P, Brown J, Granne IE.

Follicular flushing during oocyte retrieval in assisted reproductive techniques.

Cochrane Database of Systematic Reviews 2018, Issue 4. Art. No.: CD004634.

DOI: 10.1002/14651858.CD004634.pub3.

www.cochranelibrary.com 
TABLE OF CONTENTS

ABSTRACT

PLAIN LANGUAGE SUMMARY

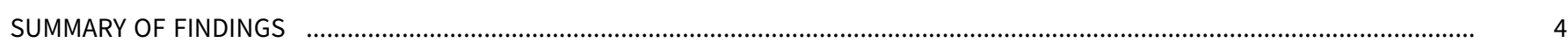

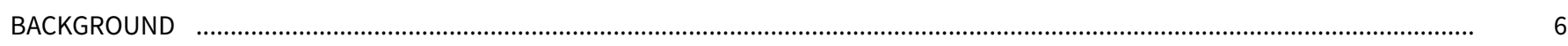

OBJECTIVES

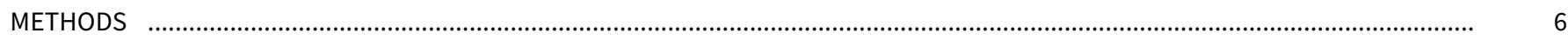

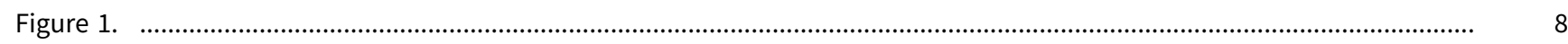

RESULTS

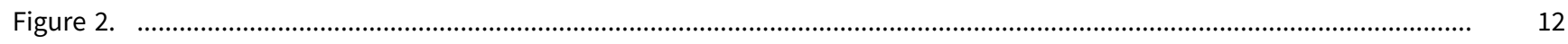

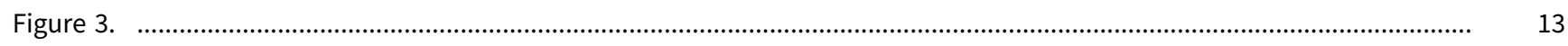

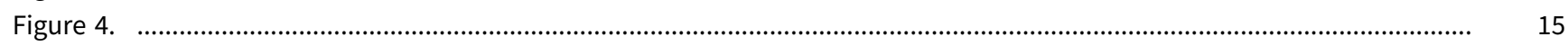

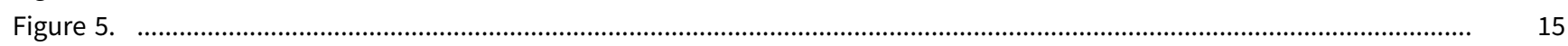

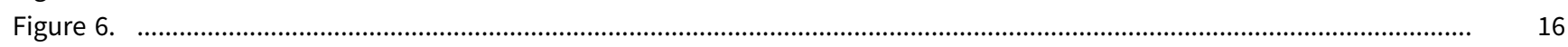

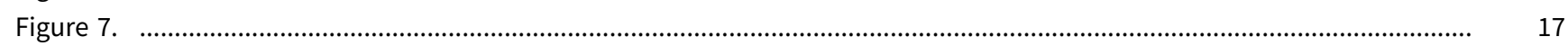

Figure 8.

Figure 9.

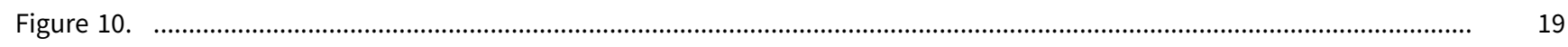

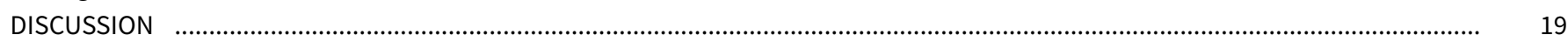

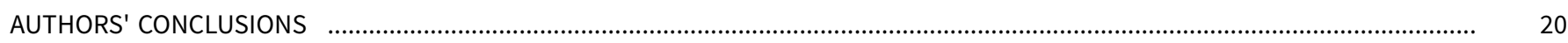

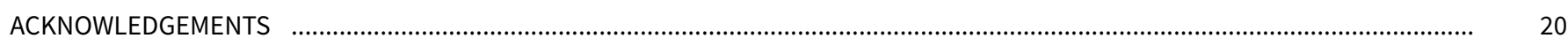

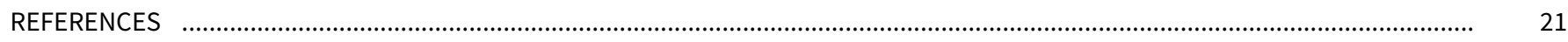

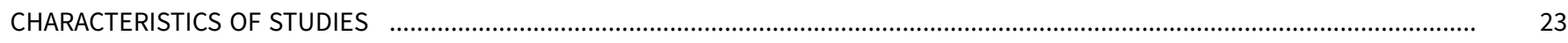

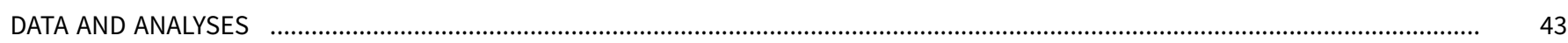

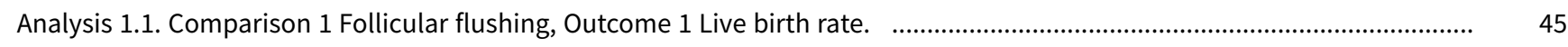

Analysis 1.2. Comparison 1 Follicular flushing, Outcome 2 Oocyte yield per woman randomised (normally distributed data). .. 45

Analysis 1.3. Comparison 1 Follicular flushing, Outcome 3 Oocyte yield per woman randomised (non-normally distributed 45

data).

Analysis 1.4. Comparison 1 Follicular flushing, Outcome 4 Duration of oocyte retrieval (normally distributed data; seconds). .. 46

Analysis 1.5. Comparison 1 Follicular flushing, Outcome 5 Time taken for procedure (non-normally distributed data). ............ 46

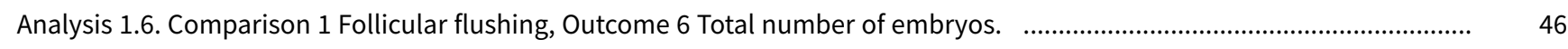

Analysis 1.7. Comparison 1 Follicular flushing, Outcome 7 Number of embryos cryopreserved per woman randomised. ......... 47

Analysis 1.8. Comparison 1 Follicular flushing, Outcome 8 Clinical pregnancy rate per woman randomised. ........................... 47

Analysis 1.9. Comparison 1 Follicular flushing, Outcome 9 Ongoing pregnancy rate per woman randomised. ............................ 47

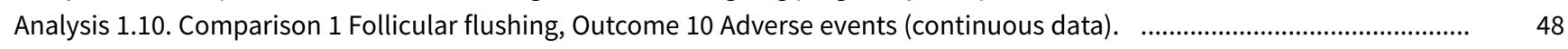

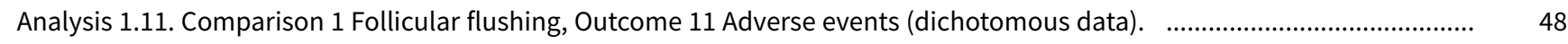

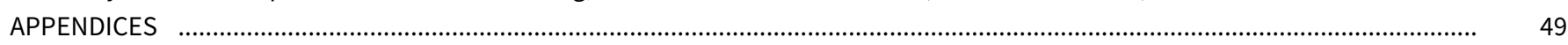

WHAT'S NEW

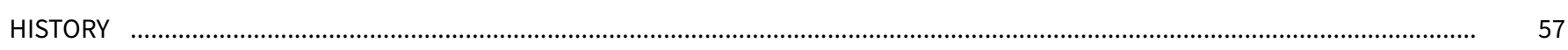

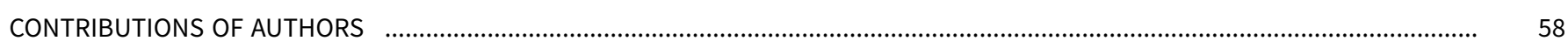

DECLARATIONS OF INTEREST

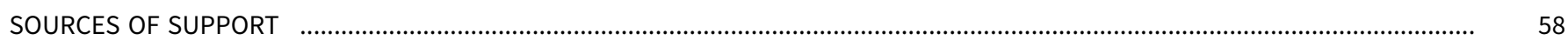

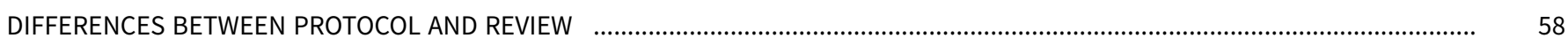

INDEX TERMS 
[Intervention Review]

\section{Follicular flushing during oocyte retrieval in assisted reproductive techniques}

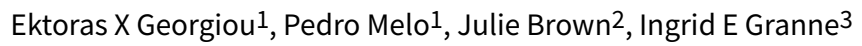

1Women's Centre, John Radcliffe Hospital, Oxford University Hospitals NHS Foundation Trust, Oxford, UK. 2Auckland, New Zealand.

${ }^{3}$ Nuffield Department of Obstetrics \& Gynaecology, John Radcliffe Hospital, Oxford, UK

Contact: Ektoras X Georgiou, Women's Centre, John Radcliffe Hospital, Oxford University Hospitals NHS Foundation Trust, Headley Way, Headington, Oxford, OX3 9DU, UK. Hector.Georgiou@ouh.nhs.uk.

Editorial group: Cochrane Gynaecology and Fertility Group.

Publication status and date: New search for studies and content updated (no change to conclusions), published in Issue 4, 2018.

Citation: Georgiou EX, Melo P, Brown J, Granne IE. Follicular flushing during oocyte retrieval in assisted reproductive techniques. Cochrane Database of Systematic Reviews 2018, Issue 4. Art. No.: CD004634. DOI: 10.1002/14651858.CD004634.pub3.

Copyright @ 2018 The Cochrane Collaboration. Published by John Wiley \& Sons, Ltd.

\section{A B S T R A C T}

\section{Background}

Follicular aspiration under transvaginal ultrasound guidance is routinely performed as part of assisted reproductive technology (ART) to retrieve oocytes for in vitro fertilisation (IVF). However, controversy as to whether follicular flushing following aspiration yields a larger number of oocytes and hence is associated with greater potential for pregnancy than aspiration only is ongoing.

\section{Objectives}

To assess the safety and efficacy of follicular flushing as compared with aspiration only performed in women undergoing ART.

\section{Search methods}

We searched the following electronic databases up to 18 July 2017: Cochrane Gynaecology and Fertility Group (CGF) Specialised Register of Controlled Trials, the CENTRAL Register of Studies Online (CRSO), MEDLINE, Embase, PsycINFO, and the Cumulative Index to Nursing and Allied Health Literature (CINAHL). We also searched the trial registries ClinicalTrials.gov and the World Health Organization (WHO) International Clinical Trials Registry Platform to identify ongoing and registered trials up to 4 July 2017. We reviewed the reference lists of reviews and retrieved studies to identify further potentially relevant studies.

\section{Selection criteria}

We included randomised controlled trials (RCTs) that compared follicular aspiration and flushing with aspiration alone in women undergoing ART using their own gametes. Primary outcomes were live birth rate and miscarriage rate per woman randomised.

\section{Data collection and analysis}

Two independent review authors assessed studies against the inclusion criteria, extracted data, and assessed risk of bias. A third review author was consulted if required. We contacted study authors as required. We analysed dichotomous outcomes using Mantel-Haenszel odds ratios (ORs), 95\% confidence intervals (Cls), and a fixed-effect model, and we analysed continuous outcomes using mean differences (MDs) between groups presented with $95 \% \mathrm{Cls}$. We examined the heterogeneity of studies via the $\mathrm{I}^{2}$ statistic. We assessed the quality of evidence by using GRADE (Grades of Recommendation, Assessment, Development and Evaluation) criteria.

\section{Main results}

We included ten studies, with a total of 928 women. All included studies reported outcomes per woman randomised. We assessed no studies as being at low risk of bias across all domains and found that the main limitation was lack of blinding. Using the GRADE method, 
we determined that the quality of the evidence ranged from moderate to very low, and we identified issues arising from risk of bias, imprecision, and inconsistency.

Comparing follicular flushing to aspiration alone revealed probably little or no difference in the live birth rate $(\mathrm{OR} 0.95,95 \% \mathrm{Cl} 0.58$ to 1.56 ; three RCTs; $n=303 ; 1^{2}=30 \%$; moderate-quality evidence). This suggests that with a live birth rate of approximately $41 \%$ with aspiration alone, the equivalent live birth rate with follicular flushing is likely to lie between $29 \%$ and $52 \%$. None of the included studies reported on the primary outcome of miscarriage rate.

Data show probably little or no difference in oocyte yield (MD -0.28 oocytes, $95 \% \mathrm{Cl}-0.64$ to $0.09 ;$ six RCTs; $\mathrm{n}=708 ; \mathrm{I}^{2}=0 \%$; moderate-quality evidence). Very low-quality evidence suggests that the duration of oocyte retrieval was longer in the follicular flushing group than in the aspiration only group (MD 166.01 seconds, $95 \% \mathrm{Cl} 141.96$ to 190.06 ; six RCTs; $n=714 ; \mathrm{I}^{2}=88 \%$ ). We found no evidence of a difference in the total number of embryos per woman randomised (MD -0.10 embryos, $95 \% \mathrm{Cl}-0.34$ to 0.15 ; two RCTs; $n=160 ; I^{2}=58 \%$; low-quality evidence) and no evidence of a difference in the number of embryos cryopreserved (meta-analysis not possible). Data show probably little or no difference in the clinical pregnancy rate (OR $1.07,95 \% \mathrm{Cl} 0.78$ to 1.46 ; five RCTs; $n=704 ; 12=49 \%$; moderate-quality evidence). Only two studies reported on adverse outcomes: One reported no differences in patient-reported adverse outcomes (depression, anxiety, and stress), and the other reported no differences in needle blockage, vomiting, and hypotension. No studies reported on safety.

\section{Authors' conclusions}

This review suggests that follicular flushing probably has little or no effect on live birth rates compared with aspiration alone. None of the included trials reported on effects of follicular aspiration and flushing on the miscarriage rate. Data suggest little or no difference between follicular flushing and aspiration alone with respect to oocyte yield, total embryo number, or number of cryopreserved embryos. In addition, follicular flushing probably makes little or no difference in the clinical pregnancy rate. Evidence was insufficient to allow any firm conclusions with respect to adverse events or safety.

\section{PLAIN LANGUAGE SUMMARY}

\section{Follicular flushing during oocyte retrieval in assisted reproductive technology}

\section{Review question}

Cochrane authors sought to assess the safety and efficacy of flushing follicles as part of egg collection in women undergoing interventions to help them get pregnant, termed assisted reproductive technology (ART).

\section{Background}

Couples who have difficulty becoming pregnant naturally may choose to have interventions to help them get pregnant. These interventions are known as assisted reproductive technology (ART). One of these interventions is in vitro fertilisation (IVF), or a variant of IVF, called intracytoplasmic sperm injection (ICSI). During IVF, controlled ovarian stimulation uses hormones to stimulate multiple eggs to develop in the ovaries. After ovarian stimulation, a needle guided by ultrasound is used to collect these eggs that are inside follicles. Instead of using only suction to obtain the contents of follicles (aspiration), it has been proposed that flushing the follicles after aspiration may lead to collection of more eggs and higher chances of becoming pregnant and having a baby. This technique is called follicular flushing.

\section{Study characteristics}

This review included ten research studies that randomly assigned a total of 928 women to follicular aspiration alone or follicular flushing after aspiration. To see if there was a difference between the two techniques, we wanted to look at the main results of live birth rate (number of babies born per 1000 women) and miscarriage rate (number of miscarriages per 1000 women). We carried out a comprehensive search to identify all relevant research in this field available in July 2017.

\section{Key results}

Three studies reported on the main result of live birth rate and noted that follicular flushing probably has little or no effect on live birth rate compared with aspiration alone (moderate-quality evidence). This suggests that if a live birth rate of approximately $41 \%$ is seen with aspiration alone, the equivalent live birth rate with follicular flushing is likely to lie between $29 \%$ and $52 \%$. None of the included studies reported on the miscarriage rate.

Studies also found that follicular flushing probably makes little or no difference in the number of eggs retrieved, the number of embryos, or the clinical pregnancy rate compared with aspiration alone. Although the quality of evidence was very low, it appears that follicular flushing takes much longer to perform than aspiration alone. Evidence was insufficient to permit any firm conclusions with respect to adverse events or safety.

More research is needed to find out whether any specific patient groups would benefit from follicular flushing.

\section{Quality of the evidence}

Follicular flushing during oocyte retrieval in assisted reproductive techniques (Review)

Copyright (c) 2018 The Cochrane Collaboration. Published by John Wiley \& Sons, Ltd. 
The quality of evidence for the main outcome of live birth rate was moderate. The quality of evidence for the other outcomes ranged from very low to moderate. The main limitations of included studies were lack of blinding (the process whereby women participating in the trial as well research staff are not aware of the intervention used), inconsistency (differences between different studies), and imprecision (insufficient data). 


\section{SUMMARY OF FINDINGS}

\section{Summary of findings for the main comparison. Follicular flushing compared with placebo in assisted reproductive techniques}

\section{Follicular flushing compared with placebo in assisted reproductive techniques}

Patient or population: assisted reproductive techniques

Setting: ART clinic

Intervention: follicular flushing

Comparison: placebo

\begin{tabular}{|c|c|c|c|c|c|c|}
\hline \multirow[t]{2}{*}{ Outcomes } & \multicolumn{2}{|c|}{ Anticipated absolute effects ${ }^{\star}(95 \% \mathrm{Cl})$} & \multirow{2}{*}{$\begin{array}{l}\text { Relative effect } \\
(95 \% \mathrm{CI})\end{array}$} & \multirow{2}{*}{$\begin{array}{l}\text { No. of partici- } \\
\text { pants } \\
\text { (studies) }\end{array}$} & \multirow{2}{*}{$\begin{array}{l}\text { Quality of the } \\
\text { evidence } \\
\text { (GRADE) }\end{array}$} & \multirow[t]{2}{*}{ Comments } \\
\hline & $\begin{array}{l}\text { Risk with aspira- } \\
\text { tion only }\end{array}$ & $\begin{array}{l}\text { Risk with follicular } \\
\text { flushing }\end{array}$ & & & & \\
\hline Live birth rate & 414 per 1000 & $\begin{array}{l}401 \text { per } 1000 \\
\text { ( } 290 \text { to } 524)\end{array}$ & $\begin{array}{l}\text { OR } 0.95 \\
\text { (0.58 to } 1.56)\end{array}$ & $\begin{array}{l}303 \\
\text { (3 RCTs) }\end{array}$ & $\begin{array}{l}\oplus \oplus \oplus \ominus \\
\text { MODERATE } a\end{array}$ & \\
\hline Miscarriage rate & not estimable & & & (0 studies) & - & $\begin{array}{l}\text { No data for this outcome were reported in } \\
\text { any of the included studies. }\end{array}$ \\
\hline Oocyte yield & $\begin{array}{l}\text { Mean oocyte yield } \\
\text { was } 7.13 \text {. }\end{array}$ & $\begin{array}{l}\text { MD } 0.02 \text { lower } \\
\text { ( } 0.1 \text { lower to } 0.07 \text { high- } \\
\text { er) }\end{array}$ & - & $\begin{array}{l}708 \\
(6 \mathrm{RCTs})\end{array}$ & $\begin{array}{l}\oplus \oplus \oplus \ominus \\
\text { MODERATE } a\end{array}$ & \\
\hline $\begin{array}{l}\text { Duration of } \\
\text { oocyte retrieval }\end{array}$ & $\begin{array}{l}\text { Mean duration of } \\
\text { oocyte retrieval } \\
\text { was } 285.33 \text { sec- } \\
\text { onds. }\end{array}$ & $\begin{array}{l}\text { MD } 70.29 \text { higher } \\
\text { ( } 62.15 \text { higher to } 78.44 \\
\text { higher) }\end{array}$ & - & $\begin{array}{l}714 \\
(6 \mathrm{RCTs})\end{array}$ & $\begin{array}{l}\oplus \ominus \odot \odot \\
\text { VERY LOWa,b,c }\end{array}$ & \\
\hline $\begin{array}{l}\text { Total number of } \\
\text { embryos }\end{array}$ & $\begin{array}{l}\text { Mean total num- } \\
\text { ber of embryos was } \\
1.50 \text {. }\end{array}$ & $\begin{array}{l}\text { MD } 0 \\
\text { ( } 0.05 \text { lower to } 0.04 \text { high- } \\
\text { er) }\end{array}$ & - & $\begin{array}{l}160 \\
(2 \mathrm{RCTs})\end{array}$ & $\begin{array}{l}\oplus \oplus \ominus \ominus \\
\text { LOWa,b }\end{array}$ & \\
\hline $\begin{array}{l}\text { Clinical preg- } \\
\text { nancy rate }\end{array}$ & 362 per 1000 & $\begin{array}{l}378 \text { per } 1000 \\
\text { (307 to } 453)\end{array}$ & $\begin{array}{l}\text { OR } 1.07 \\
\text { (0.78 to } 1.46)\end{array}$ & $\begin{array}{l}704 \\
(5 \mathrm{RCTs})\end{array}$ & $\begin{array}{l}\oplus \oplus \oplus \ominus \\
\text { MODERATE } a\end{array}$ & \\
\hline Adverse events & & & - & (2 RCTs) & $\begin{array}{l}\oplus \oplus \oplus \ominus \\
\text { MODERATE } a\end{array}$ & $\begin{array}{l}\text { One study reported no differences in pa- } \\
\text { tient-reported adverse outcomes (depres- } \\
\text { sion, anxiety, and stress). } \\
\text { Another study reported higher doses of } \\
\text { analgesia required in the follicular flushing }\end{array}$ \\
\hline
\end{tabular}


${ }^{\star}$ The risk in the intervention group (and its 95\% confidence interval) is based on the assumed risk in the comparison group and the relative effect of the intervention (and its $95 \% \mathrm{Cl})$.

Cl: confidence interval; MD: mean difference; OR: odds ratio; RCT, randomised controlled trial.

\section{GRADE Working Group grades of evidence.}

High certainty: We are very confident that the true effect lies close to that of the estimate of the effect.

Moderate certainty: We are moderately confident in the effect estimate: The true effect is likely to be close to the estimate of the effect, but there is a possibility that it is substantially different.

Low certainty: Our confidence in the effect estimate is limited: The true effect may be substantially different from the estimate of the effect.

Very low certainty: We have very little confidence in the effect estimate: The true effect is likely to be substantially different from the estimate of effect.

aRisk of bias - incorporates at least one open-label study. Downgraded one level

Inconsistency - high degree of heterogeneity. Downgraded one level

CImprecision - wide confidence intervals. Downgraded one level 


\section{B A C K G R O U N D}

\section{Description of the condition}

Assisted reproductive technology (ART) requires handling oocytes and embryos outside the woman's body. The technique involves ovarian stimulation, monitoring of follicular growth, oocyte recovery, sperm preparation and insemination, embryo culture, embryo transfer, and luteal support. Other variables, particularly female age, can significantly affect the number of oocytes retrieved and the success rate of ART.

\section{Description of the intervention}

Once maturity of the follicles is achieved, human chorionic gonadotropin (hCG) or recombinant luteinising hormone ( $\mathrm{LLH}$ ) is used to trigger oocyte maturation. Oocyte pickup is performed approximately 36 hours later. Technical details of oocyte recovery vary between fertility centres, especially with regard to type of anaesthesia (local, sedation, or general), type of aspiration needle (wide or narrow bore, single or double channel), route of retrieval (transvaginal or abdominal), aspiration alone or aspiration with follicular flushing, type of flushing medium, and the collecting system.

The number of embryos obtained is dependent on the number of oocytes retrieved (Wood 2000). To maximise the number of oocytes recovered, investigators have suggested follicular aspiration followed by a single 2-mL flush (el Hussein 1992). Waterstone and Parson reported that use of double-lumen needles and flushing yielded $20 \%$ more oocytes (Waterstone 1992). On the contrary, other studies found no difference in number of oocytes collected, fertilisation rate, embryo quality, or pregnancy rate (Haydardedeoglu 2011; Haydardedeoglu 2017; Kara 2012; Kingsland 1991; Knight 2001; Levens 2009; Mok-Lin 2013; Tan 1992; von Horn 2017). Tan 1992 suggested that aspiration without flushing reduced operative time and decreased the amount of anaesthetic required.

\section{How the intervention might work}

The place of follicular flushing during oocyte recovery in ART remains uncertain. Benefits of flushing include the possibility of obtaining more oocytes and subsequently more embryos. Whether this translates into higher pregnancy and live birth rates remains controversial. However, flushing may be associated with longer operative time and larger amounts of required anaesthetics and analgesics. From the patient's perspective, it could also mean higher costs. Moreover, anaesthetics such as propofol could have detrimental effects on embryos, at least in the mouse model (Janssenwillen 1997; Tatone 1998). Flushing could remove some of the follicular cells that might have an important endocrine luteal support function.

\section{Why it is important to do this review}

The prevalence of subfertility and the significant costs of assisted conception make assessment of ART techniques imperative to establish which are more effective in terms of attaining a live birth, and which are cost-beneficial, with a view toward improving treatment outcomes. This review provides information for women and clinicians and identifies aspects that require future study.

\section{O B JECTIVES}

To assess the safety and efficacy of follicular flushing as compared with aspiration only performed in women undergoing ARTs.

\section{METHODS}

\section{Criteria for considering studies for this review \\ Types of studies}

Randomised controlled trials (RCTs) were eligible for inclusion. We included cross-over trials only when pre-cross-over data were extractable for analysis. We included conference abstracts and handled these in the same way as full publications.

\section{Types of participants}

Participants were women who underwent assisted conception treatment by in vitro fertilisation (IVF) or intracytoplasmic sperm injection (ICSI) using their own gametes.

\section{Types of interventions}

We included trials if they investigated any form of follicular aspiration and flushing during oocyte retrieval and compared effects of follicular flushing versus a control procedure by which only aspiration was performed.

We included trials in which investigators replaced embryos resulting from oocytes derived from mixed groups of flushed and unflushed follicles in the same woman. We performed sensitivity analysis for inclusion or exclusion of these trials, when appropriate.

For inclusion in the review, trials had to report that all recruited women had undergone only one cycle of treatment within the context of the trial and had had embryos replaced in the uterine cavity in fresh or frozen-thawed cycles. We did not exclude trials where embryo replacement did not take place because of failure of fertilisation or failure of the embryo to divide further (cleavage arrest).

We excluded trials that directly compared different methods of follicular flushing (without an aspiration only control group).

\section{Types of outcome measures}

\section{Primary outcomes}

1. Live birth rate per woman randomised, with live birth defined as per the International Committee for Monitoring Assisted Reproductive Technology (ICMART) as "the complete expulsion or extraction from a woman of a product of fertilization, after 22 completed weeks of gestational age; which, after such separation, breathes or shows any other evidence of life, such as heart beat, umbilical cord pulsation or definite movement of voluntary muscles, irrespective of whether the umbilical cord has been cut or the placenta is attached. A birth weight of 500 grams or more can be used if gestational age is unknown" (Zegers-Hochschild 2017)

2. Miscarriage rate per woman randomised

\section{Secondary outcomes}

1. Oocyte yield, defined as number of oocytes retrieved per woman randomised 
2. Duration of oocyte retrieval

3. Total number of embryos per woman randomised

4. Number of cryopreserved embryos per woman randomised

5. Clinical pregnancy rate per woman randomised, defined per ICMART as the presence of one or more gestational sacs on ultrasound or definitive clinical signs of pregnancy (ZegersHochschild 2017)

6. Ongoing pregnancy rate per woman randomised, defined as a pregnancy of 12 or more weeks' gestation

7. Adverse events as defined by trialists (patient-reported outcomes and surgical complications including needle blockage, vomiting, and hypotension)

\section{Search methods for identification of studies}

\section{Electronic searches}

We used the following search strategy to obtain all reports that described (or might have described) RCTs of follicular flushing.

1. Cochrane Gynaecology and Fertility Group (CGFG) Specialised Register of Controlled Trials, PROCITE platform (searched 18 July 2017) (Appendix 1).

2. Cochrane Central Register of Controlled Trials; via the Cochrane Register of Studies Online, CRSO Web platform (searched 18 July 2017) (Appendix 2).

3. MEDLINE Ovid (searched from 1946 to 18 July 2017) (Appendix 3).

4. Embase Ovid (searched from 1980 to 18 July 2017) (Appendix 4).
5. PsycINFO Ovid (searched from 1806 to 18 July 2017) (Appendix 5).

6. Cumulative Index to Nursing and Allied Health Literature (CINAHL) Ebsco (from 1961 to 18 July 2017) (Appendix 6).

\section{Searching other resources}

1. We handsearched reference lists of relevant trials and systematic reviews retrieved by the search and contacted experts in the field to obtain additional data

2. We handsearched relevant journals and conference abstracts that were not covered in the CGFG register, in liaison with the Information Specialist

3. We searched for ongoing and registered trials on clinical trials.gov (http://www.clinicaltrials.gov) and the World Health Organization International Clinical Trials Registry Platform (WHO ICTRP) search portal (http://www.who.int/trialsearch/ Default.aspx) (all "other resources" searched 4 July 2017)

\section{Data collection and analysis}

\section{Selection of studies}

After an initial screen of titles and abstracts retrieved by the search (EG and PM), review authors retrieved the full text of all potentially eligible studies. Two review authors (EG and PM) independently examined these full texts for compliance with the inclusion criteria (Appendix 7) and selected eligible studies. We corresponded with study investigators as required to clarify study eligibility. We resolved disagreements by discussion or through arbitration by a third review author (IG). We documented the selection process using a PRISMA flow chart (Figure 1). 
Figure 1. Study flow diagram.

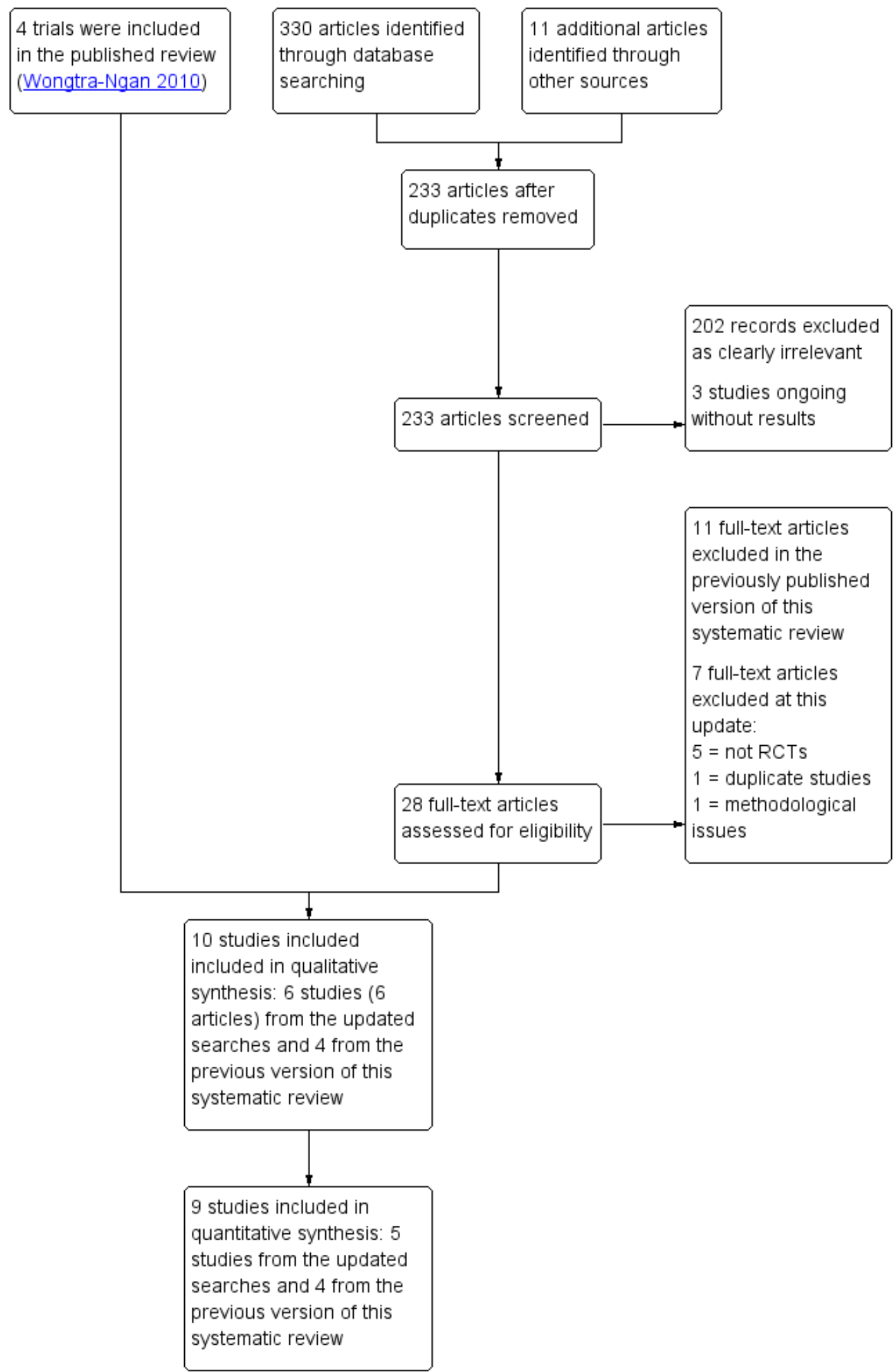




\section{Data extraction and management}

Two review authors (EG and PM) independently extracted data from eligible studies using the data extraction proforma that had been designed and pilot-tested by the review authors (Appendix 8) and resolved disagreements by discussion or through arbitration by a third review author (IG). Data extracted included study characteristics and outcome data. When studies had multiple publications, we collated multiple reports of the same trial under a single study ID with multiple references. We corresponded with study investigators to ask for further data or methods and/or results, as required.

\section{Assessment of risk of bias in included studies}

Two review authors ( $E G$ and $P M$ ) independently assessed the included studies for risk of bias using the Cochrane risk of bias assessment tool to assess the following: selection (random sequence generation and allocation concealment); performance (blinding of participants and personnel); detection (blinding of outcome assessors); attrition (incomplete outcome data); reporting (selective reporting); and other bias (Higgins 2011). We assigned judgement as recommended in the Cochrane Handbook for Systematic Reviews of Interventions, Chapter 8.5 (Higgins 2011b) and resolved disagreements by discussion or through arbitration by a third review author (IG). We described all judgements fully, presented conclusions in the risk of bias tables, and incorporated this information into our interpretation of review findings by performing sensitivity analyses.

\section{Measures of treatment effect}

We performed statistical analysis in accordance with Cochrane guidelines. For dichotomous data (e.g. live births), we used the number of events in each group to calculate Mantel-Haenszel odds ratios (ORs) with $95 \%$ confidence intervals (Cls), then combined these for meta-analysis using RevMan 5.3 software and a fixedeffect model. For continuous data, we calculated mean differences (MDs) between treatment groups and presented these along with 95\% Cls.

\section{Unit of analysis issues}

The primary analysis was per woman randomised. We summarised in an additional table data that did not allow valid analysis (e.g. 'per cycle' data, per pregnancy data) but did not include these data in a meta-analysis. We counted a multiple birth as a single live birth event. If we identified any cross-over trials, we planned to use only first-phase data.

\section{Dealing with missing data}

We analysed data on an intention-to-treat basis as far as possible and attempted to obtain missing data from the original trialists. When these were unobtainable, we undertook imputation of individual values for live birth only: We assumed that live birth did not occur in participants without reported outcomes. We analysed other outcomes using only available data. Any imputation undertaken was subjected to sensitivity analysis.

When studies reported sufficient detail to allow calculation of mean differences but provided no information on associated standard deviation (SD), we assumed that the outcome had a standard deviation equal to the highest standard deviation provided by other studies included within the same analysis.

\section{Assessment of heterogeneity}

We used statistical heterogeneity, ascertained by measure of the $1^{2}$, to determine whether the clinical and methodological characteristics of included studies were sufficiently similar for meta-analysis. We regarded an 12 measurement greater than $50 \%$ as indicating substantial heterogeneity (Higgins 2011). We explored substantial heterogeneity by conducting planned subgroup analyses as detailed below.

\section{Assessment of reporting biases}

In view of the difficulty of detecting and correcting for publication bias and other reporting biases, review authors aimed to minimise the potential for bias by searching multiple databases and grey literature. We planned that if at least 10 studies were included in the same analysis, we would produce a funnel plot to assess publication bias.

\section{Data synthesis}

We combined data from the primary studies using a fixed-effect model for the comparison of aspiration/flush versus aspiration only.

We did not stratify data. In meta-analyses, we graphically displayed an increase in the risk of a particular outcome that may be beneficial (e.g. live birth) or detrimental (e.g. miscarriage) to the right of the centre line and a decrease in the risk of an outcome to the left of the centre line.

\section{Subgroup analysis and investigation of heterogeneity}

When data were available, we conducted subgroup analyses to obtain separate evidence for primary outcomes within the following subgroups.

1. Age: women younger or older than 40 years.

2. Poor ovarian reserve: as determined by follicle-stimulating hormone (FSH) levels, anti-Müllerian hormone (AMH) levels, and/or antral follicle count (AFC). We used cutoff values for subgrouping as defined by trialists, or, in cases for which individual data were reported, we used the following cutoffs: FSH $10 \mathrm{IU} / \mathrm{L}, \mathrm{AMH} 0.8 \mathrm{ng} / \mathrm{mL}$, and AFC 6 follicles.

3. Poor response to ovarian stimulation: development of fewer than five mature follicles following controlled ovarian stimulation for IVF or ICSI versus normal response; alternatively, poor response as defined by trialists.

When possible, we extracted data on these subgroups directly from the included trials. When not reported, we used mean trial data (e.g. mean trial FSH level) to place the whole trial into one of these subgroups.

We performed a post hoc subgroup analysis for the outcomes of live birth rate and miscarriage rate, while taking statistical heterogeneity into account. When we detected substantial heterogeneity $(12>50 \%)$, we sought clinical and methodological differences between studies that may have accounted for this.

\section{Sensitivity analysis}

We conducted sensitivity analyses for primary outcomes to determine whether conclusions were robust to arbitrary decisions 
made regarding eligibility and analysis. These analyses included consideration of whether review conclusions would have differed if:

1. eligibility had been restricted to studies without high risk of bias (defined as studies at low risk of selection bias and with no domains at high risk of bias);

2. a random effects model had been adopted;

3. alternative imputation strategies had been implemented; or

4. we had included only fully published trials.

\section{Overall quality of the body of evidence: 'Summary of findings' table}

We prepared a 'Summary of findings' table using GRADEpro and Cochrane methods to evaluate the overall quality of the body of evidence found for main review outcomes for the main review comparison of follicular aspiration + flushing versus aspiration only (GRADEpro GDT 2015). We assessed the quality of evidence by using GRADE criteria: risk of bias, consistency of effect, imprecision, indirectness, and publication bias. Two review authors (EG and PM) who worked independently made judgements about evidence quality (high, moderate, low, or very low) and resolved disagreements by discussion or through arbitration by a third review author (IG). We justified, documented, and incorporated judgements into reporting of results for each outcome.

We used the following outcomes for GRADE assessment.

1. Live birth rate.

2. Miscarriage rate.

3. Oocyte yield.

4. Duration of oocyte retrieval.

5. Total number of embryos.

6. Clinical pregnancy rate.

7. Adverse events.

\section{RES U L T S}

\section{Description of studies}

\section{Results of the search}

For the 2018 update, our electronic search on 18 July 2017 yielded 330 articles. We identified 11 additional articles via other sources: 10 by searching trial registries and 1 by reviewing the reference list of another article. After removal of duplicates, we kept 233 articles for screening. Of these, we excluded 202 records as they were clearly not relevant (Characteristics of excluded studies). Three studies were ongoing trials that had not yet reported their results (Characteristics of ongoing studies). We obtained and reviewed the full text for the remaining 28 articles.

We identified 28 trials that provided data on follicular flushing during oocyte retrieval in assisted reproductive cycles (Avila 2013; Aydin 2017; Bagtharia 2005; Biljan 1997; Dean 1997; el Hussein 1992; Faller 2010; Ghosh 2002; Gordon 2002; Haines 1989; Haydardedeoglu 2011; Haydardedeoglu 2017; Kara 2012; Khalifa 1999; Kingsland 1991; Knight 2001; Lenz 1987; Levens 2009; Mehri 2014; Mendez Lozano 2008; Mok-Lin 2013; Neyens 2016; Pirrello 2011; Scott 1989; Tan 1992; von Horn 2017; Waterstone 1992; Ziebe 2000), along with three ongoing trials (NCT01329302; NCT02277210; NCT02641808). See Characteristics of ongoing studies.
Ten studies met the inclusion criteria for this review (Haines 1989; Haydardedeoglu 2011; Haydardedeoglu 2017; Kara 2012; Kingsland 1991; Levens 2009; Mok-Lin 2013; Scott 1989; Tan 1992; von Horn 2017). Of these, we included four in our qualitative synthesis (Haines 1989; Kingsland 1991; Mok-Lin 2013; Tan 1992), and we included nine in our quantitative analysis (metaanalysis) (Haydardedeoglu 2011; Haydardedeoglu 2017; Kara 2012; Kingsland 1991; Levens 2009; Mok-Lin 2013; Scott 1989; Tan 1992; von Horn 2017). We have presented the trial flow diagram in Figure 1 .

\section{Included studies}

\section{Study design and setting}

We included ten parallel-design randomised controlled trials, all of which have been published as full articles. All were singlecentre studies and three were carried out in the USA (Levens 2009; Mok-Lin 2013; Scott 1989); three in Turkey (Haydardedeoglu 2011; Haydardedeoglu 2017; Kara 2012); two in the UK (Kingsland 1991; Tan 1992); one in Australia (Haines 1989); and one in Germany (von Horn 2017).

\section{Participants}

The ten included studies included a total of 928 participants: 477 women in the intervention group and 451 in the control group.

Four studies recruited women with poor ovarian response (Haydardedeoglu 2017; Levens 2009; Mok-Lin 2013; von Horn 2017), and each study defined poor ovarian response differently. Levens 2009 defined it as a cumulative follicle count of 4-8 follicles greater than or equal to $12 \mathrm{~mm}$ with at least 2 follicles greater than 16 $\mathrm{mm}$; Mok-Lin 2013, it was defined as 4 or fewer follicles greater than or equal to $12 \mathrm{~mm}$; in Haydardedeoglu 2017, it was defined as 5 or fewer follicles greater than or equal to $13 \mathrm{~mm}$ in size and serum progesterone less than $1.5 \mathrm{ng} / \mathrm{ml}$; and von Horn 2017 as five or fewer follicles greater than $10 \mathrm{~mm}$. Apart from poor ovarian response, all patients included in Haydardedeoglu 2017 also had poor ovarian reserve, as defined by an antral follicle count (AFC) less than 6 and an anti-Müllerian hormone (AMH) level less than 0.8 $\mathrm{ng} / \mathrm{mL}$. One study recruited patients with tubal damage (Kingsland 1991). Five studies did not specify any inclusion criteria (Haines 1989; Haydardedeoglu 2011; Kara 2012; Scott 1989; Tan 1992).

Two studies excluded patients with poor ovarian response or high ovarian response (Haydardedeoglu 2011; Tan 1992). Other exclusion factors were natural IVF - as reported in Mok-Lin 2013 and Haydardedeoglu 2017 - and absent ovary or ovary(/ies) predicted to be difficult to access - as reported in von Horn 2017. Four studies did not specify any exclusion criteria (Haines 1989; Kara 2012; Kingsland 1991; Scott 1989).

\section{Interventions}

One study used clomiphene citrate to achieve ovarian hyperstimulation (Haines 1989). All other studies employed gonadotropin-releasing hormone agonist in a long-luteal protocol (Kingsland 1991), a low-dose luteal agonist protocol (Haydardedeoglu 2017; Kara 2012), an antagonist protocol (Haydardedeoglu 2011; Haydardedeoglu 2017; Mok-Lin 2013), a long-follicular protocol (Tan 1992), an FSH antagonist protocol (Haydardedeoglu 2017), a long-luteal or microdose follicular flare protocol (Levens 2009), or a long unspecified protocol (Scott 1989). 
Some studies induced final oocyte maturation with 5000 IU hCG (Haines 1989; Kingsland 1991; von Horn 2017), and others with 10,000 IU hCG (Haydardedeoglu 2017; Kara 2012; Levens 2009; MokLin 2013; Tan 1992). One study did not specify the dose of hCG used (Haydardedeoglu 2011), and another did not clarify whether hCG was used (Scott 1989).

Two studies used the same type of double-lumen needle: Kingsland 1991 without and Tan 1992 with removal of the inner channel to convert it to a single-channel needle. The other studies used single- or double-lumen needles that were - in Levens 2009, Haydardedeoglu 2011, Mok-Lin 2013, and Haydardedeoglu 2017 - or were not - in Haines 1989, Scott 1989, and Kara 2012 standardised for length plus/minus diameter, to control for flow dynamics within the needle. One study used a $17 \mathrm{G}$ Steiner-Tan Needle, which is described as a single-lumen needle surrounded by a plastic tube that allows passage of flushing medium for follicular flushing, and a 17G Gynetics single-lumen needle in the control arm (von Horn 2017).

Three studies used IVF (Kingsland 1991; Scott 1989; Tan 1992), and three studies used ICSI (Haydardedeoglu 2011; Haydardedeoglu 2017; Kara 2012) for fertilisation. Three studies used both IVF and ICSI (Levens 2009; Mok-Lin 2013; von Horn 2017). One study did not specify how fertilisation occurred (Haines 1989).

Two studies transferred up to three embryos (Kingsland 1991; Tan 1992), and two studies up to four embryos (Haydardedeoglu 2011; Kara 2012). Six studies did not specifically comment on the number of embryos transferred (Haines 1989; Haydardedeoglu 2017; Levens 2009; Mok-Lin 2013; Scott 1989; von Horn 2017), although the mean number in Haydardedeoglu 2017 was less than two, and in Levens 2009 and Mok-Lin 2013 was less than three.

\section{Outcomes}

\section{Primary outcomes}

Three studies reported on the primary outcome of live birth rate per woman randomised (Haydardedeoglu 2011; Mok-Lin 2013; Haydardedeoglu 2017). None of the included studies reported on the primary outcome of miscarriage per woman randomised.

\section{Secondary outcomes}

Six studies reported on oocyte yield (Haydardedeoglu 2011; Haydardedeoglu 2017; Kara 2012; Levens 2009; Scott 1989; von Horn 2017), and eight studies on duration of oocyte retrieval (Haydardedeoglu 2011; Haydardedeoglu 2017; Kara 2012; Kingsland 1991; Levens 2009; Mok-Lin 2013; Tan 1992; von Horn 2017).

Two studies reported on the total number of embryos per woman randomised (Haydardedeoglu 2017; von Horn 2017); two on the number of cryopreserved embryos per woman randomised (Haydardedeoglu 2011; Mok-Lin 2013); five on the clinical pregnancy rate (Haydardedeoglu 2011; Haydardedeoglu 2017; Kara 2012; Mok-Lin 2013; Tan 1992); four on the ongoing pregnancy rate (Kara 2012; Kingsland 1991; Levens 2009; von Horn 2017); one on adverse events including blockage of the needle, vomiting, and hypotension (Tan 1992); and one on adverse events including patient depression, anxiety, and stress (von Horn 2017).

\section{Author correspondence}

We contacted Haydardedeoglu 2017 and von Horn 2017 to further clarify some of the data included in the original papers. To date, we have received a response only from von Horn 2017.

\section{Excluded studies}

The previously published version of this systematic review excluded 11 studies (Bagtharia 2005; Biljan 1997; Dean 1997; el Hussein 1992; Gordon 2002; Khalifa 1999; Knight 2001; Lenz 1987; Mendez Lozano 2008; Waterstone 1992; Ziebe 2000). This update excluded seven additional studies (Avila 2013; Aydin 2017; Faller 2010; Ghosh 2002; Mehri 2014; Neyens 2016; Pirrello 2011).

Of the studies excluded from this update, five were not RCTs (Avila 2013; Aydin 2017; Ghosh 2002; Mehri 2014; Neyens 2016). Two studies incorporated the same population of patients, and we excluded both owing to trial author-reported issues with study ethics and inclusion criteria (Faller 2010; Pirrello 2011).

\section{Risk of bias in included studies}

We assessed risk of bias in all included studies as demonstrated in Figure 2 and Figure 3. Detailed information can be found in Characteristics of included studies. 
Figure 2. Methodological quality graph: review authors' judgements about each methodological quality item presented as percentages across all included studies.

Random sequence generation (selection bias)

Allocation concealment (selection bias)

Blinding of participants and personnel (performance bias)

Blinding of outcome assessment (detection bias)

Incomplete outcome data (attrition bias)

Selective reporting (reporting bias)

Other bias

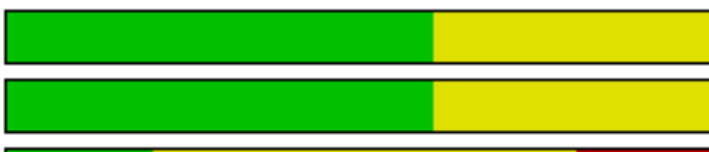

L
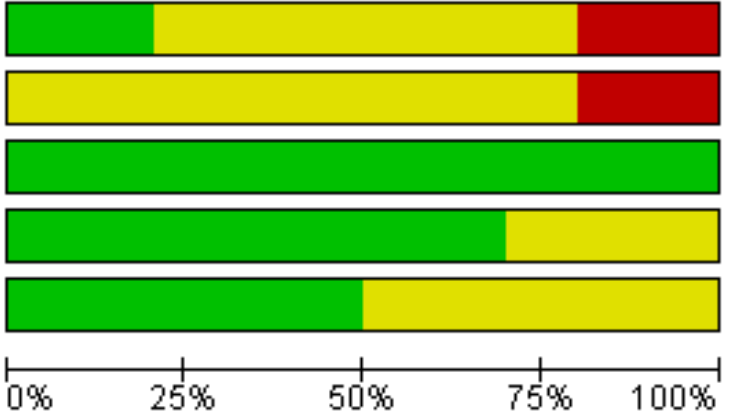

Low risk of bias

Unclear risk of bias

High risk of bias 
Figure 3. Methodological quality summary: review authors' judgements about each methodological quality item for each included study.

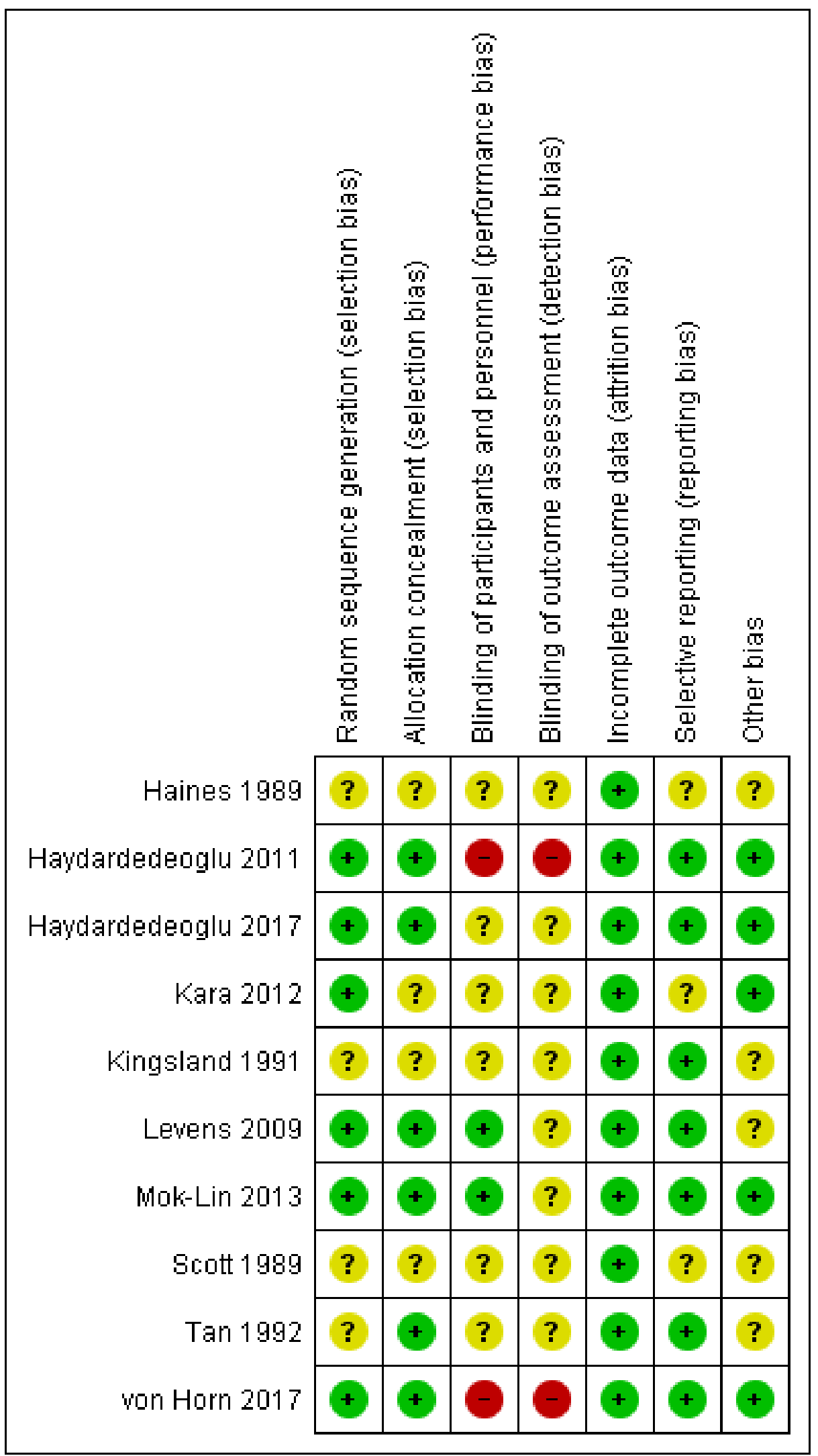




\section{Allocation}

\section{Random sequence generation}

Six studies used adequate methods for random sequence generation, such as random numbers tables or computergenerated randomisation sequences, and hence we deemed these studies to be at low risk of bias (Haydardedeoglu 2011; Haydardedeoglu 2017; Kara 2012; Levens 2009; Mok-Lin 2013; von Horn 2017). The remaining four studies did not provide details on whether or how they carried out randomisation, and hence we judged them to be at unclear risk of bias (Haines 1989; Kingsland 1991; Scott 1989; Tan 1992).

\section{Allocation concealment}

Six studies reported adequate methods used for allocation concealment, such as numbered sealed, opaque envelopes, and hence we deemed these trials to be at low risk of bias (Haydardedeoglu 2011; Haydardedeoglu 2017; Levens 2009; MokLin 2013; Tan 1992; von Horn 2017). The remaining four studies provided no relevant details, and hence were judged them to be at unclear risk of bias (Haines 1989; Kara 2012; Kingsland 1991; Scott 1989).

\section{Blinding}

\section{Blinding of participants and personnel (performance bias)}

Two studies reported blinding of participants and personnel (Levens 2009; Mok-Lin 2013). Two studies were open-label, and hence we judged these studies to be high risk of bias (Haydardedeoglu 2011; von Horn 2017). The remaining studies did not report on blinding, and hence we judged them to be at unclear risk of bias (Haines 1989; Haydardedeoglu 2017; Kara 2012; Kingsland 1991; Scott 1989; Tan 1992).

\section{Blinding of outcome assessment (detection bias)}

With the exception of Haydardedeoglu 2011 and von Horn 2017, both of which were open-label and hence at high risk of bias, none of the other studies reported on blinding of outcome assessors, and hence we judged these studies to be at uncertain risk of bias.

\section{Incomplete outcome data}

All trials analysed all randomised women.

\section{Selective reporting}

Seven studies reported on a priori outcomes, and we judged these studies to be at low risk of bias (Haydardedeoglu 2011; Haydardedeoglu 2017; Kingsland 1991; Levens 2009; Mok-Lin 2013; Tan 1992; von Horn 2017). The remaining three studies did not include an a priori statement of outcomes to be studied, and hence we deemed them to be at unclear risk of bias (Haines 1989; Kara 2012; Scott 1989).

\section{Other potential sources of bias}

We deemed six studies to be at low risk of other bias (Haydardedeoglu 2011; Haydardedeoglu 2017; Kara 2012; Levens 2009; Mok-Lin 2013; von Horn 2017), whereas we deemed the remaining studies to be at unclear risk of bias owing to lack of information (Haines 1989; Kingsland 1991; Scott 1989; Tan 1992).

\section{Effects of interventions}

See: Summary of findings for the main comparison Follicular flushing compared with placebo in assisted reproductive techniques

\section{Follicular flushing versus aspiration alone}

See Summary of findings for the main comparison.

\section{Primary outcomes}

\subsection{Live birth rate}

We found no evidence of a difference in live birth rate (OR 0.95 , $95 \% \mathrm{Cl} 0.58$ to 1.56 ; three RCTs; $\mathrm{n}=303 ; \mathrm{I}^{2}=30 \%$; moderate-quality evidence). This suggests that with a live birth rate of approximately $41 \%$ (414 per 1000) with aspiration alone, the equivalent live birth rate with follicular flushing lies between $29 \%$ and 52\% (290 to 524 per 1000).

Sensitivity analysis that excluded studies at high risk of bias - Haydardedeoglu 2011 - similarly showed no evidence of a difference in live birth rate (OR $0.60,95 \% \mathrm{Cl} 0.25$ to 1.47 ; two RCTs; $n=130 ;\left.\right|^{2}=44 \%$; high-quality evidence). Sensitivity analysis based on a random-effects model showed estimates similar to those obtained with the fixed-effect model (OR $0.89,95 \% \mathrm{Cl} 0.44$ to 1.81 ; three RCTs; $\left.\right|^{2}=30 \%$; moderate-quality evidence). We carried out no sensitivity analyses on alternative imputation strategies nor only on fully published trials, as these were not applicable. See Analysis 1.1 and Figure 4. 
Figure 4. Forest plot of comparison: 1 Follicular flushing, outcome: 1.1 Live birth rate.

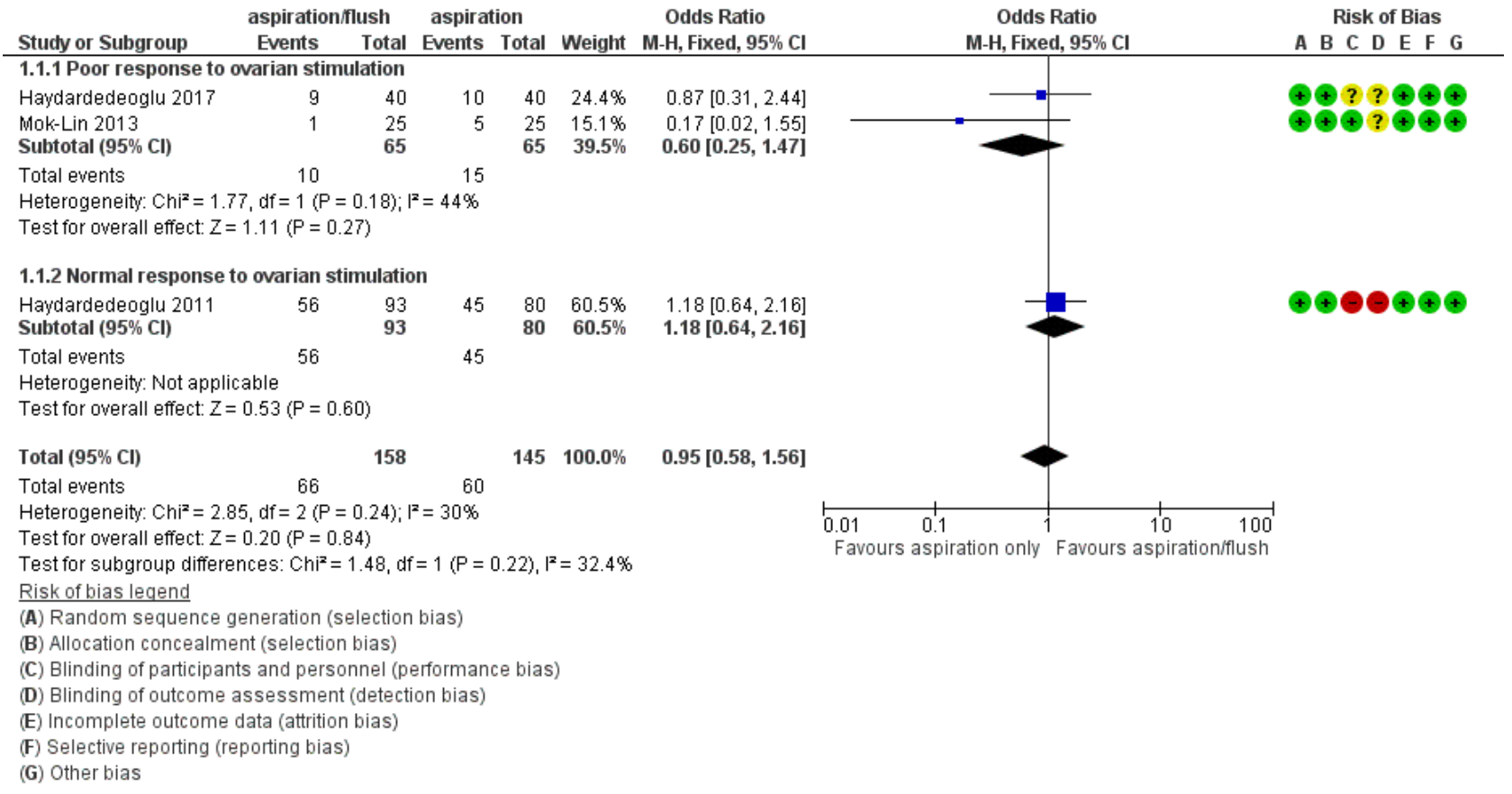

\subsubsection{Subgroup analysis: age}

No studies reported on this outcome.

\subsubsection{Subgroup analysis: poor ovarian reserve}

No studies specifically reported on this comparison. The women included in Haydardedeoglu 2017 had both poor ovarian reserve and poor response to ovarian stimulation. The review authors agreed to include them under 'poor response to ovarian stimulation' for the purposes of subgroup analysis.

\subsubsection{Subgroup analysis: poor response to ovarian stimulation}

We found no evidence of a difference in live birth rate among participants with poor ovarian response (OR $0.60,95 \% \mathrm{Cl} 0.25$ to 1.47; two RCTs; $n=130 ; 1^{2}=44 \%$; high-quality evidence).

\subsection{Miscarriage rate}

No studies reported on this outcome.

\section{Secondary outcomes}

\subsection{Oocyte yield}

We found no evidence of a difference in oocyte yield per woman randomised (mean difference (MD) -0.28 oocytes, $95 \% \mathrm{Cl}-0.64$ to 0.09 ; six RCTs; $n=708 ; 12=0 \%$; moderate-quality evidence). See Analysis 1.2 and Figure 5. One of the studies in this analysis reported very small standard deviations (SDs), which varied markedly from those reported in other papers (Haydardedeoglu 2017). We are attempting to contact the trial authors and whilst awaiting response have assumed the SD to be in fact standard error (SE); we recalculated this accordingly.

Figure 5. Forest plot of comparison: 1 Follicular flushing, outcome: 1.2 Oocyte yield per woman randomised (normally distributed data).

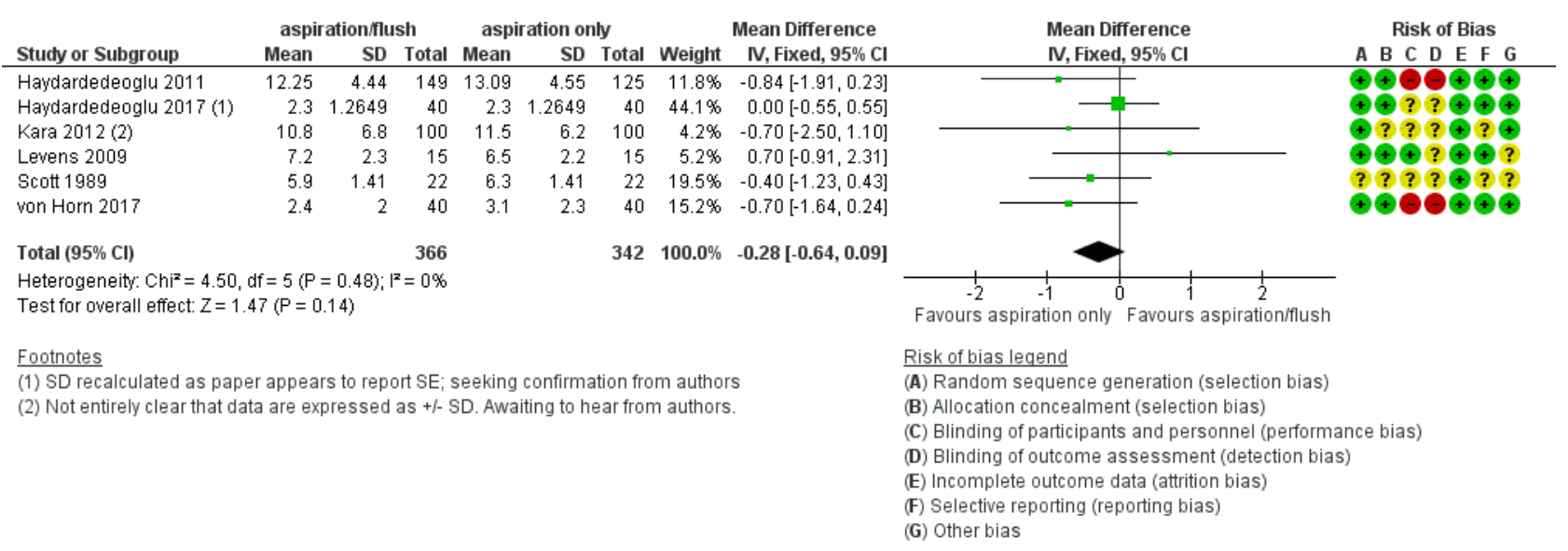


None of the studies providing data that could not be included in the meta-analysis provided any evidence of a difference in oocyte yield between the two groups (Haines 1989; Kingsland 1991; MokLin 2013; Tan 1992). See Analysis 1.3.

\subsection{Duration of oocyte retrieval}

The duration of oocyte retrieval was markedly longer in the aspiration/flush group than in the aspiration only group (MD 166,01 seconds, $95 \% \mathrm{Cl} 141.96$ to 190.06 ; six RCTs; $\mathrm{n}=714 ; \mathrm{I}^{2}=88 \%$; very low-quality evidence). See Analysis 1.4 and Figure 6. One of the studies in this analysis reported very small SDs, which varied markedly compared with those reported in other papers (Haydardedeoglu 2017). We are attempting to contact the study authors and whilst awaiting response have assumed the SD to be in fact SE; we have recalculated this accordingly.

\section{Figure 6. Forest plot of comparison: 1 Follicular flushing, outcome: 1.4 Duration of oocyte retrieval (normally} distributed data; seconds).

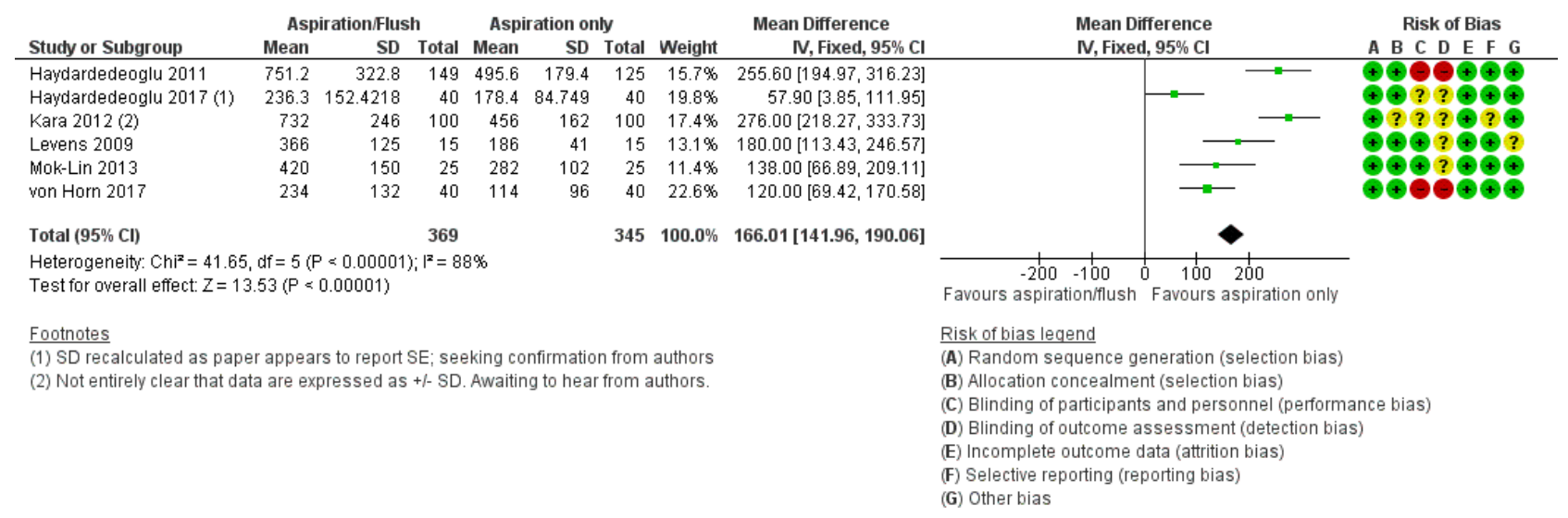

Sensitivity analysis with removal of the study reporting markedly different SD showed similar results (Haydardedeoglu 2017) (MD 192.70 seconds, $95 \% \mathrm{Cl} 165.85$ to 219.56 ; five RCTs; $n=634$; five RCTs; $12=82 \%$; very low-quality evidence).

Both studies providing data that could not be included in the metaanalysis yielded evidence of aspiration/flush lasting longer than aspiration alone (Kingsland 1991; Tan 1992). See Analysis 1.5.

\subsection{Total number of embryos}

We found no evidence of a difference in the total number of embryos per woman randomised (MD -0.10 embryos, $95 \% \mathrm{Cl}-0.34$ to 0.15 ; two RCTs; $n=160 ; 1^{2}=58 \%$; low-quality evidence). See Analysis 1.6.

\subsection{Number of cryopreserved embryos}

Two studies reported on the number of cryopreserved embryos per woman randomised. However, meta-analysis was not possible, as the mean number in the aspiration/flush group in Mok-Lin 2013 was 0 . See Analysis 1.7. The other study in this analysis reported very small SDs, which varied markedly from those reported in other papers (Haydardedeoglu 2017). We are attempting to contact study authors and whilst awaiting response have assumed the SD to be in fact SE; we have recalculated this accordingly.

\subsection{Clinical pregnancy rate}

We found no evidence of a difference in clinical pregnancy rate per woman randomised (OR 1.07, 95\% $\mathrm{Cl} 0.78$ to 1.46; five RCTs; $\mathrm{n}=704$; $\mathrm{I}^{2}=49 \%$; moderate-quality evidence). See Analysis 1.8 and Figure 7. 
Figure 7. Forest plot of comparison: 1 Follicular flushing, outcome: 1.8 Clinical pregnancy rate per woman randomised.

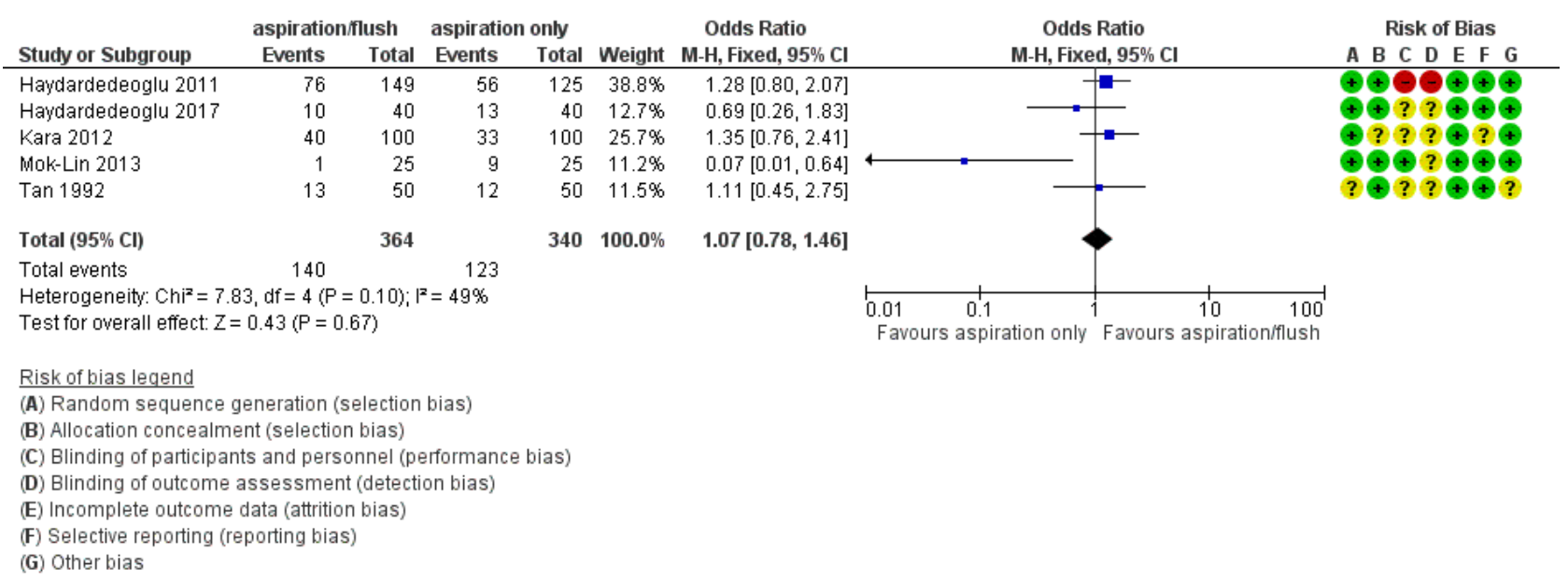

\subsection{Ongoing pregnancy rate}

We found no evidence of a difference in ongoing pregnancy rate per woman randomised (OR 1.21, 95\% $\mathrm{Cl} 0.73$ to 2.02; four RCTs; $\mathrm{n}=344$; $\mathrm{I}^{2}=0 \%$; moderate-quality evidence). See Analysis 1.9 and Figure 8.

\section{Figure 8. Forest plot of comparison: 1 Follicular flushing, outcome: 1.9 Ongoing pregnancy rate per woman} randomised.

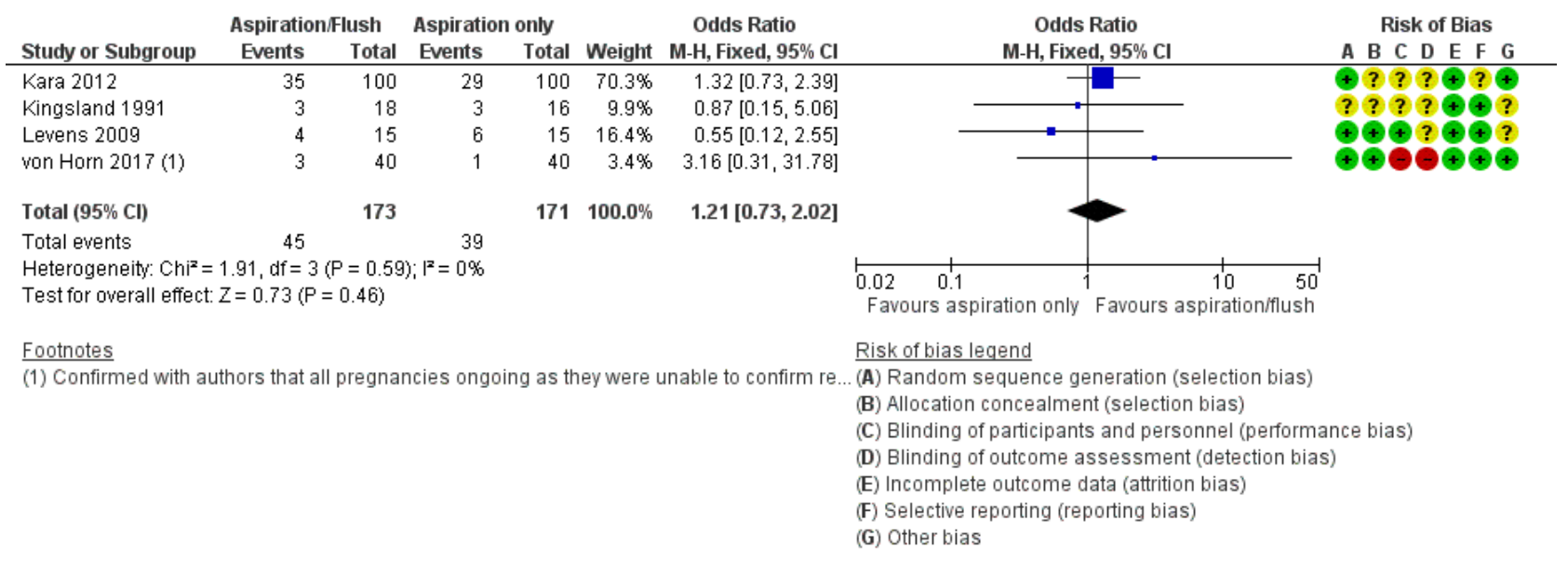

\subsection{Adverse events}

von Horn 2017 reported no evidence of a difference on the Depression Anxiety and Stress Scale (DASS)-21 in depression (MD
0.60 points, $95 \% \mathrm{Cl}-0.66$ to 1.86 ; one $\mathrm{RCT} ; \mathrm{n}=80$ ), anxiety (MD 0.00 points, $95 \% \mathrm{Cl}-0.60$ to 0.60 ; one RCT, $\mathrm{n}=80$ ), or stress (MD 1.10 points, $95 \% \mathrm{Cl}-0.42$ to $2.62 ; n=80$; moderate-quality evidence). See Analysis 1.10 and Figure 9. 
Figure 9. Forest plot of comparison: 1 Follicular flushing, outcome: 1.10 Adverse events (continuous data).

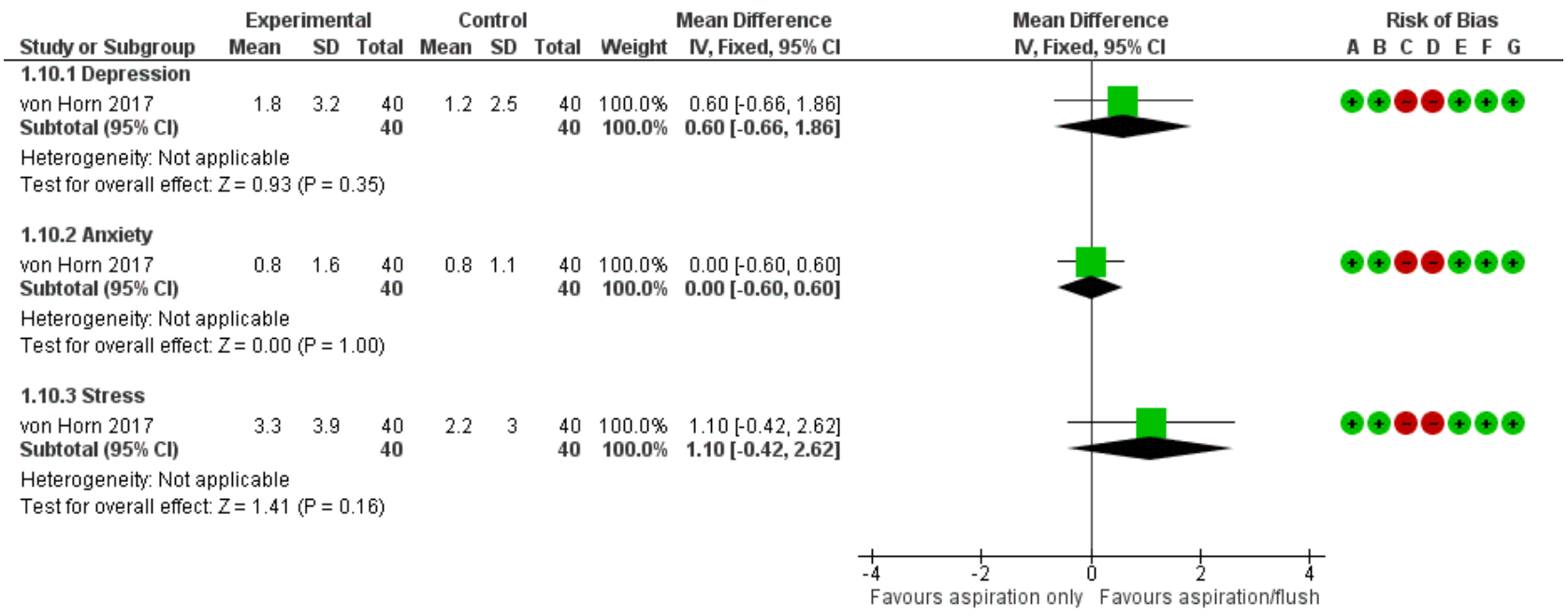

\footnotetext{
Risk of bias legend

(A) Random sequence generation (selection bias)

(B) Allocation concealment (selection bias)

(C) Blinding of participants and personnel (performance bias)

(D) Blinding of outcome assessment (detection bias)

(E) Incomplete outcome data (attrition bias)

(F) Selective reporting (reporting bias)

(G) Other bias
}

Tan 1992 reported on three adverse events: blockage of the needle (OR 7.44, $95 \% \mathrm{Cl} 0.37$ to 147.92 ; one RCT; $\mathrm{n}=100$ ), vomiting (OR $5.21,95 \% \mathrm{Cl} 0.24$ to 111.24 ; one RCT; $n=100$ ), and hypotension (OR 5.21, 95\% Cl 0.24 to 111.24; one RCT; $\mathrm{n}=100$ ). We found no evidence of a difference between aspiration/flush compared with aspiration alone for any of these outcomes (Analysis 1.11; Figure
10). Tan 1992 reported that significantly less analgesia was required with the aspiration alone procedure compared with added flushing (median $50 \mathrm{mg}$, range 50 to $100 \mathrm{mg}$ for aspiration alone; median 100 $\mathrm{mg}$, range 50 to $100 \mathrm{mg}$ for aspiration/flushing). It should be noted that event rates are low and were derived from a single study, hence caution is advised in interpreting these data. 
Figure 10. Forest plot of comparison: 1 Follicular flushing, outcome: 1.11 Adverse events (dichotomous data).

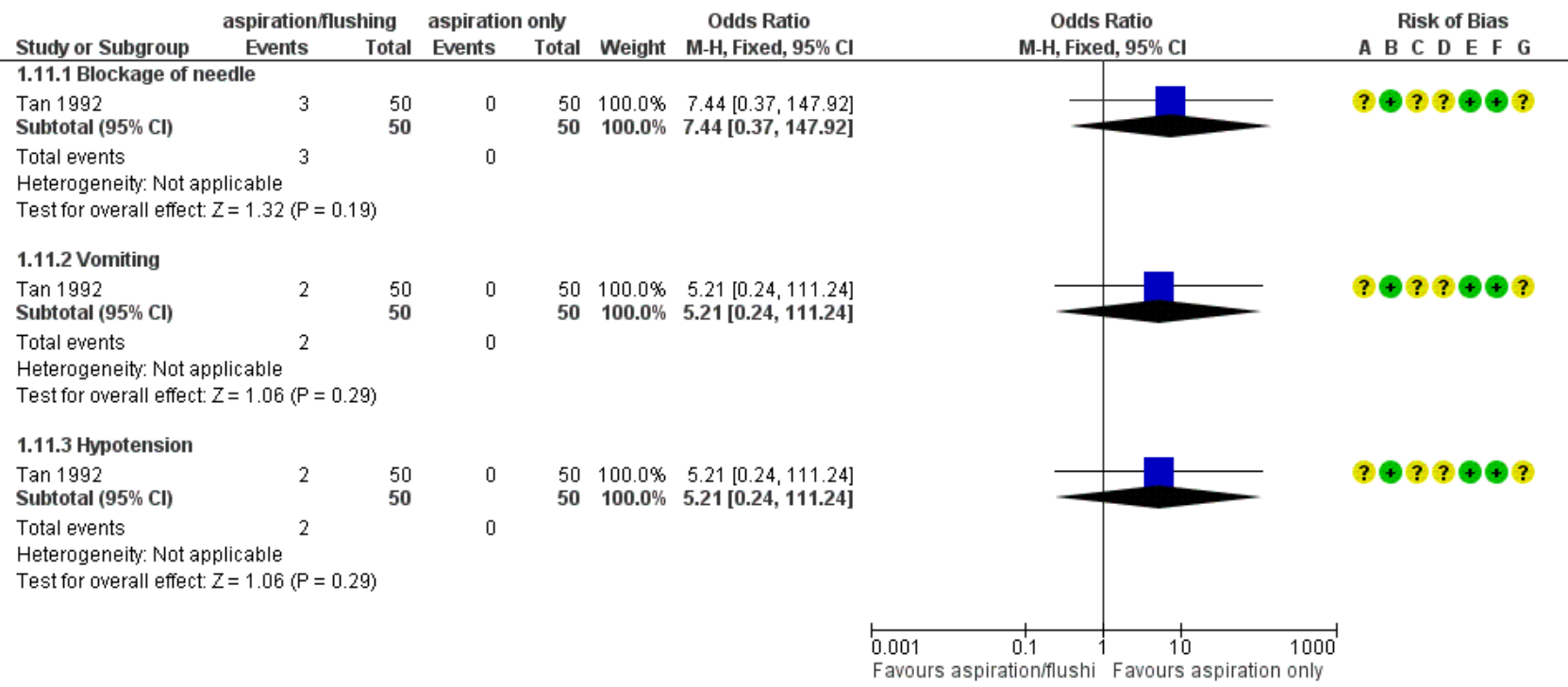

Risk of bias legend

(A) Random sequence generation (selection bias)

(B) Allocation concealment (selection bias)

(C) Blinding of participants and personnel (performance bias)

(D) Blinding of outcome assessment (detection bias)

(E) Incomplete outcome data (attrition bias)

(F) Selective reporting (reporting bias)

(G) Other bias

No study provided data on safety.

\section{DISCUSSION}

\section{Summary of main results}

This Cochrane review aimed to evaluate the effectiveness of follicular flushing (aspiration/flush) compared with aspiration alone in women undergoing in vitro fertilisation (IVF) or intracytoplasmic sperm injection (ICSI). Moderate-quality evidence shows probably little or no difference in the primary outcome of live birth with follicular flushing. No studies reported on the primary outcome of miscarriage. Moderate-quality evidence shows probably little or no difference in oocyte yield with follicular flushing compared with aspiration alone. The oocyte retrieval process was noted to last significantly longer with follicular flushing than with aspiration alone, although this evidence is of very low quality. No differences were noted in total number of embryos, number of embryos cryopreserved, or clinical or ongoing pregnancy rates (Summary of findings for the main comparison). Evidence was insufficient to allow firm conclusions with respect to adverse events or safety.

\section{Overall completeness and applicability of evidence}

Only three of the included studies reported on live birth rate, which is likely to be the most important outcome for women embarking on fertility treatment. Furthermore, none of the studies reported a miscarriage rate. No studies reported on this review's subgroup of maternal age. Additionally, only one study focussed on women with poor ovarian reserve (Haydardedeoglu 2017). However all participants in this study also had a poor response to ovarian stimulation; we decided to include these patients in this subgroup as it represents the more clinically relevant subgroup. Two studies looked at poor response to ovarian stimulation and noted no difference in the live birth rate (Haydardedeoglu 2017; Mok-Lin 2013); we deemed this to be high-quality evidence.

Most of the included papers focussed on oocyte yield and four studies incorporated data that could not be used for metaanalysis (Haines 1989; Kingsland 1991; Mok-Lin 2013; Tan 1992). Nevertheless, these studies reported no change in oocyte yield with follicular flushing. In addition, two studies incorporated data on duration of oocyte retrieval that could not be incorporated into the meta-analysis (Kingsland 1991; Tan 1992). These data mirrored data presented in the meta-analysis, suggesting increased procedure length with follicular flushing. It appears that follicular flushing is associated with a significantly longer procedure compared with aspiration alone. Nevertheless, these data should be interpreted with caution, as we found a high degree of heterogeneity, mainly attributable to one study (Haydardedeoglu 2017).

Although the included studies provided few data on adverse events, von Horn 2017 reported no differences in depression, anxiety, or stress in either group, and Tan 1992 reported no differences in needle blockage, vomiting, or hypotension. Data on adverse events should be interpreted with caution, as individual studies are relatively small and event rates low.

A study carried out in the early 2000s reported that more than $50 \%$ of fertility units routinely perform follicular flushing (Knight 2001). Although changes in clinical practice are usually slow to be implemented, this Cochrane review provides evidence suggesting no benefit for follicular flushing and hence would encourage a shift away from it. 


\section{Quality of the evidence}

For this review, we identified and included only published data originating from ten RCTs and incorporating 928 women. We have summarised in Figure 2 and Figure 3 risk of bias for individual studies.

We rated the quality of evidence on the basis of GRADE criteria. The quality of the evidence ranged from very low to moderate, with issues arising as the result of lack of blinding, imprecision, and inconsistency. Although lack of blinding was a feature of several included studies, and blinding of the operator was not possible, we suggest that this was not essential, as study outcomes were objective. See Summary of findings for the main comparison.

\section{Potential biases in the review process}

Review authors aimed to reduce the risk of publication bias by conducting systematic searches of multiple databases and trial registries to identify ongoing studies. We contacted trial authors to request further information when applicable, and unfortunately we did not receive a response in all cases. Subgroup analysis was not possible for subgroups of age and poor ovarian reserve owing to lack of data. As prespecified, we performed sensitivity analysis for the primary outcome of live birth. We were unable to construct a funnel plot owing to the small number of included studies.

\section{Agreements and disagreements with other studies or reviews}

Older studies, which were not randomised controlled trials (RCTs), have suggested that oocyte yield increases with follicular flushing. For example, Bagtharia 2005 found $40 \%$ of oocytes in primary aspiration without flushing of the follicle and retrieved up to $82 \%$ of oocytes with two flushes and up to $97 \%$ with four flushes. Mendez Lozano 2008 observed a $46.8 \%$ oocyte recovery rate with aspiration only compared with $84.6 \%$ with additional follicular flushing in 165 infertile women with low ovarian reserve who were undergoing 271 consecutive minimal stimulation IVF cycles.

However, data from this systematic review contradict these findings and show no increase in oocyte yield nor in the more clinically relevant outcome of live birth. In addition, the two most recent systematic reviews on this topic, which date to 2012 (Levy 2012; Roque 2012), reported findings that are similar to those presented in this systematic review. Both of these systematic reviews incorporated studies that we have included here.

\section{AUTHORS' CONCLUSIONS}

\section{Implications for practice}

This review suggests that follicular flushing probably has little or no effect on live birth rates compared with aspiration alone. None of the included trials reported on effects of follicular aspiration and flushing on the miscarriage rate. Data suggest little or no difference between follicular flushing and aspiration alone with respect to oocyte yield, total embryo number, or number of cryopreserved embryos. In addition, follicular flushing probably makes little or no difference in the clinical pregnancy rate. Evidence was insufficient to allow any firm conclusions with respect to adverse events or safety.

\section{Implications for research}

Although the body of evidence against use of follicular flushing is growing, further research predominantly centred on population selection and outcomes is required. Study design could be improved by blinding participants, the embryologist, and those assessing outcomes.

\section{Population}

Most research so far has not focussed on specific populations that may benefit from follicular flushing. Future directions could involve focussing on populations such as older women, women with poor ovarian reserve, and women with a poor response to ovarian stimulation.

\section{Outcomes}

Although more recent studies have focused on the outcome of live birth rate, this remains an underreported outcome. Further research should make this the primary outcome. In addition, data on the miscarriage rate associated with follicular flushing are required.

\section{ACKNOWLEDGEMENTS}

We wish to thank the CGFG editorial group for patience and kind support provided. In particular, we would like to thank Helen Nagels for assistance with all of our queries, and Marian Showell for help in conducting these searches. 


\section{RE F E R E N C E S}

\section{References to studies included in this review}

Haines 1989 \{published data only\}

Haines CJ, Emes AL, O'Shea RT, Weiss TJ. Choice of needle for ovum pickup. Journal of In Vitro Fertilisation and Embryo Transfer 1989;6(2):111-2.

\section{Haydardedeoglu 2011 \{published data only\}}

Haydardedeoglu B, Cok T, Kilicdag EB, Parlakgumus AH, Simsek E, Bagis T. In vitro fertilization-intracytoplasmic sperm injection outcomes in single- versus double-lumen oocyte retrieval needles in normally responding patients: a randomized trial. Fertility and Sterility 2011;95(2):812-4.

Haydardedeoglu 2017 \{published data only\}

Haydardedeoglu B, Gjemalaj F, Aytac PC, Kilicdag EB. Direct aspiration versus follicular flushing in poor responders undergoing intracytoplasmic sperm injection: a randomised controlled trial. British Journal of Obstetrics and Gynaecology 2017;124(8):1190-6.

\section{Kara 2012 \{published data only\}}

Kara M, Aydin T, Turktekin N. Is follicular flushing really effective? A clinical study. Archives of Gynecology and Obstetrics 2012;286(4):1061-4.

\section{Kingsland 1991 \{published data only\}}

Kingsland CR, Taylor CT, Aziz N, Bickerton N. Is follicular flushing necessary for oocyte retrieval? A randomized trial. Human Reproduction 1991;6(3):382-3.

Levens 2009 \{published data only\}

Levens ED, Whitcomb BW, Payson MD, Larsen FW. Ovarian follicular flushing among low-responding patients undergoing assisted reproductive technology. Fertility and Sterility 2009;91 Suppl(4):1381-4

\section{Mok-Lin 2013 \{published data only\}}

Mok-Lin E, Brauer AA, Schattman G, Zaninovic N, Rosenwaks Z, Spandorfer S. Follicular flushing and in vitro fertilization outcomes in the poorest responders: a randomized controlled trial. Human Reproduction 2013;28(11):2990-5. [DOI: 10.1093/ humrep/det350]

\section{Scott 1989 \{published data only\}}

Scott RT, Hofmann GE, Muasher SJ, Acosta AA, Kreiner DK, Rosenwaks Z. A prospective randomized comparison of single- and double-lumen needles for transvaginal follicular aspiration. Journal of In Vitro Fertilization and Embryo Transfer 1989;6(2):98-100.

\section{Tan 1992 \{published data only\}}

Tan SL, Waterstone J, Wren M, Parsons J. A prospective randomized study comparing aspiration only with aspiration and flushing for transvaginal ultrasound-directed oocyte recovery. Fertility and Sterility 1992;58(2):356-60. von Horn 2017 \{published and unpublished data\}

von Horn K, Depenbusch M, Schultze-Mosgau A, Griesinger G. Randomized, open trial comparing a modified double-lumen needle follicular flushing system with a single-lumen aspiration needle in IVF patients with poor ovarian response. Human Reproduction 2017;32(4):832-5.

\section{References to studies excluded from this review}

Avila 2013 \{published data only\}

Avila A, Diaz-Spndola P, Santos-Haliscak R, Obeso-Montoya I, Davila-Garza A, Garcia-Villafaña G. Follicle flushing does not improve reproductive outcomes in art program. Fertility and Sterility 2013;100(3 Suppl):S499-S500.

\section{Aydin 2017 \{published data only\}}

Aydin A, Taplamaciogly F, Gokce F. What is the effect of follicle flushing on oocyte yield and quality in ART cycles of poor responders?. Human Reproduction Abstract Book of the 33rd Annual Meeting of the ESHRE, Switzerland 2017;32:i246-7.

Bagtharia 2005 \{published data only\}

Bagtharia S, Haloob ARK. Is there a benefit from routine follicular flushing for oocyte retrieval?. Journal of Obstetrics and Gynaecology 2005;25(4):374-6.

Biljan 1997 \{published data only\}

Biljan MM, Dean N, Hemmings R, Bissonnette F, Tan SL. Prospective randomized trial of the effect of two flushing media on oocyte collection and fertilization rates after in vitro fertilization. Fertility and Sterility 1997;68(6):1132-4.

Dean 1997 \{published data only\}

Dean N, Biljan MM, Hemmings R, Bissonette F, Tan SL. Prospective randomized trial on effects of different flushing media on collection and fertilization rates in IVF procedures. Journal of Reproduction and Fertility 1992;19:22 (Abstract No. 44).

\section{el Hussein 1992 \{published data only\}}

el Hussein E, Balen AH, Tan SL. A prospective study comparing the outcome of oocytes retrieved in the aspirate with those retrieved in the flush during transvaginal ultrasound directed oocyte recovery for in-vitro fertilization. British Journal of Obstetrics and Gynaecology 1992;99(10):841-4.

Faller 2010 \{published and unpublished data\}

Faller E, Pirrello O, Wittemer C, Ohl J. Follicular flushing with double-lumen needle among low responder patients: preliminary study of 79 cases. Human Reproduction, Abstract Book of the 26th Annual Meeting of the ESHRE, Rome 2010;25 Suppl 1:i153.

\section{Ghosh 2002 \{published data only\}}

Ghosh S, Chatterjee R, Goswami S, Chakraborty BN. Follicular flushing at OCR - should we do away with it?. Human Reproduction Abstract Book of the 18th Annual Meeting of 
the ESHRE, Vienna, July 1-3, 2002. 2002;17 Suppl 1(Abstract O-145):51.

\section{Gordon 2002 \{published data only\}}

Gordon AC, Gadd SC, Kendrew H, Spearman P, Williams C, Walker $\mathrm{D}$, et al. Prospective randomized comparison of two commercially prepared flushing media for IVF/ICSI. Human Reproduction, Abstract Book of the 18th Annual Meeting of the ESHRE, Vienna, July 1-3, 2002. 2002;17 Suppl 1(Abstract P-4810):163.

\section{Khalifa 1999 \{published data only\}}

Khalifa EAM, Buraidah KFSH. Routine use of normal saline as flushing media has no impact on fertilization, embryo development and pregnancy rates in assisted reproductive technologies. Fertility and Sterility 1999;72 Suppl 1:193-4.

Knight 2001 \{published data only\}

Knight DC, Tyler JP, Driscoll GL. Follicular flushing at oocyte retrieval: a reappraisal. Australian \& New Zealand Journal of Obstetrics \& Gynaecology 2001;41(2):210-3.

\section{Lenz 1987 \{published data only\}}

Lenz S, Lindenberg S, Fehilly C, Petersen K. Are ultrasonicguided follicular aspiration and flushing safe for the oocyte?. Journal of In Vitro Fertilization and Embryo Transfer 1987;4(3):159-61.

\section{Mehri 2014 \{published data only\}}

Mehri S, Levi Setti PE, Greco K, Sakkas D, Martinez G, Patrizio P. Correlation between follicular diameters and flushing versus no flushing on oocyte maturity, fertilization rate and embryo quality. Journal of Assisted Reproduction and Genetics 2014;31(1):73-7.

\section{Mendez Lozano 2008 \{published data only\}}

Mendez Lozano DH, Scheffer JB, Frydman N, Fay S, Fanchin R, Frydman R. Optimal reproductive competence of oocytes retrieved through follicular flushing in minimal stimulation IVF. RBM Online 2008;16(1):119-23.

\section{Neyens 2016 \{published data only\}}

Neyens S, De Neubourg D, Peeraer K, De Jaegher N, Spiessens C, Debrock $S$, et al. Is there a correlation between the number of follicular flushings, oocyte/embryo quality and pregnancy rate in assisted reproductive technology cycles? Results from a prospective study. Gynecologic and Obstetric Investigation 2016;81(1):34-40.

\section{Pirrello 2011 \{published data only\}}

Pirrello O, Faller E, Catherine R, Jeanine O, Laurence M, Brigitte $F$, et al. Follicular flushing with double lumen needle among low responder patients: a preliminary study. Human Fertility (Abstract of the 7th Biennial Conference of the UK Fertility Societies: The Association of Clinical Embryologists, British Fertility Society and the Society for Reproduction and Fertility. Also Participating: Irish Clinical Embryologists Association, ICE and the Irish Fertility Society 2011;14(2):143.

\section{Waterstone 1992 \{published data only\}}

Waterstone JJ, Parsons JH. A prospective study to investigate the value of flushing follicles during transvaginal ultrasound-directed follicle aspiration. Fertility and Sterility 1992;57(1):221-3.

\section{Ziebe 2000 \{published data only\}}

Ziebe S, Sunde A, Erb K. Evaluation of a new fully synthetic flushing medium in a prospective randomised multi-centre study. Human Reproduction 2000;15:74 (Abstract of the 16th ESHRE, Bologna, 25-28 June 2000; 0-0185).

\section{References to ongoing studies}

NCT01329302 \{unpublished data only\}

NCT01329302. Benefit of follicular flushing during oocyte retrieval for poor responder patient in an assisted reproductive technology program. Available from https://clinicaltrials.gov/ ct2/show/NCT01329302. First posted 5 April 2011.

\section{NCT02277210 \{unpublished data only\}}

NCT02277210. Follicular flushing in patients with suboptimal responses. Available from https://clinicaltrials.gov/ct2/show/ NCT02277210. First posted 28 October 2014.

\section{NCT02641808 \{unpublished data only\}}

NCT02641808. Does follicular flushing improve the outcome in monofollicular IVF therapy? (Flushing). Available from https:// clinicaltrials.gov/ct2/show/NCT02641808. First posted 29 December 2015.

\section{Additional references}

\section{GRADEpro GDT 2015 [Computer program]}

GRADE Working Group, McMaster University. GRADEpro GDT. Version accessed 23 October 2017. Hamilton (ON): GRADE Working Group, McMaster University, 2015.

\section{Higgins 2011}

Higgins JPT, Green S (editors). Cochrane Handbook for Systematic Reviews of Interventions Version 5.1.0 (updated March 2011). The Cochrane Collaboration 2011. Available from handbook.cochrane.org.

\section{Higgins 2011b}

Higgins JPT, Altman DG, Sterne JAC. Chapter 8: Assessing risk of bias in included studies. In: Higgins JP, Green S, editor(s). Cochrane Handbook for Systematic Reviews of Interventions Version 5.1.0 (updated March 2011). The Cochrane Collaboration, 2011. Available from handbook.cochrane.org.

\section{Janssenwillen 1997}

Janssenswillen, C. Christiaens, F. Camu, F. Van Steirteghem, A. The effect of propofol on parthenogenetic activation, in vitro fertilization and early development of mouse oocytes. Fertility and Sterility 1997;67:769-74.

\section{Levy 2012}

Levy G, Hill MJ, Ramirez Cl, Correa L, Ryan ME, DeCherney AH, et al. The use of follicle flushing during oocyte retrieval in assisted 
reproductive technologies: a systematic review and metaanalysis. Human Reproduction 2012;27(8):2373-9. [DOI: 10.1093/ humrep/des174]

\section{Roque 2012}

Roque M, Sampaio M, Geber S. Follicular flushing during oocyte retrieval: a systematic review and meta-analysis. Journal of Assisted Reproduction and Genetics 2012;29(11):1249-54. [DOI: 10.1007/s10815-012-9869-9]

\section{Tatone 1998}

Tatone C, Francion A, Marinangeli F, Lottan M, Varrassi G, Colonna R. An evaluation of propofol toxicity on mouse oocytes and preimplantation embryos. Human Reproduction 1998;13:430-5.

\section{Wood 2000}

Wood C, Trounson AO. Historical perspectives of IVF. In: Trounson AO, Gardner DK editor(s). Handbook of In Vitro Fertilization. Second Edition. New York: CRC Press, 2000:4.

\section{CHARACTERISTICS OF STUDIES}

Characteristics of included studies [ordered by study ID]

\section{Zegers-Hochschild 2017}

Zegers-Hochschild F, Adamson GD, Dyer S, Racowsky C, de Mouzon J, Sokol R, et al. The International Glossary on Infertility and Fertility Care, 2017. Fertility and Sterility 2017;108(3):393-406. [DOI: 10.1016/j.fertnstert.2017.06.005]

\section{References to other published versions of this review Wongtra-ngan 2004}

Wongtra-ngan S, Edi-Osagie ECO, Vutyavanich T. Follicular flushing during oocyte retrieval in assisted reproductive techniques. Cochrane Database of Systematic Reviews 2004, Issue 1. [DOI: 10.1002/14651858.CD004634]

\section{Wongtra-Ngan 2010}

Wongtra-Ngan S, Vutyavanich T, Brown J. Follicular flushing during oocyte retrieval in assisted reproductive techniques. Cochrane Database of Systematic Reviews 2010, Issue 8. [DOI: 10.1002/14651858.CD004634.pub2]

Haines 1989

\begin{tabular}{ll}
\hline Methods & Parallel randomised trial \\
\hline Participants & Country: Australia \\
Site: Flinders University, Flinders Medical Centre, Adelaide \\
Patients: 36 patients undergoing IVF treatment \\
Mean age + SD: not specified \\
Inclusion: not specified \\
Exclusion: not specified
\end{tabular}

Interventions

Ovarian hyperstimulation was achieved with clomiphene citrate (Clomid, Merrell Dow), 50 mg twice daily on days 5 to 9 of the cycle, and human menopausal gonadotropin (Humegon, Organon), 2 ampoules daily from day 6 and continued according to response. Human chorionic gonadotropin (Profasi, Serono), $5000 \mathrm{IU}$, was administered when the dominant follicle reached $18 \mathrm{~mm}$ in the presence of appropriate oestradiol levels.

Oocyte pickup was performed with the patient under intravenous analgesia via a single-lumen (W.A. Cook, Australia; 17 G, 23.5 cm, K-OPS-1023-RWH) or double-lumen (W.A. Cook, Australia; 17 G, 25 cm; KOPSD-1725) needle. Flushing was performed up to 5 times. The single-lumen oocyte pickup represented the control group $(n=18)$, and the double-lumen oocyte pickup represented the intervention group $(n=18)$.

$\begin{array}{ll}\text { Outcomes } & \text { Number of follicles aspirated (mean + range) } \\ & \text { Fertilisation rate (\%) }\end{array}$

Notes

No statement regarding competing interests. No declaration of funding source(s), if any

\section{Risk of bias}


Haines 1989 (Continued)

\begin{tabular}{lll} 
Bias & Authors' judgement & Support for judgement \\
\hline $\begin{array}{l}\text { Random sequence genera- } \\
\text { tion (selection bias) }\end{array}$ & Unclear risk & No details \\
\hline $\begin{array}{l}\text { Allocation concealment } \\
\text { (selection bias) }\end{array}$ & Unclear risk & No details \\
\hline $\begin{array}{l}\text { Blinding of participants } \\
\text { and personnel (perfor- } \\
\text { mance bias) }\end{array}$ & Unclear risk & No details \\
All outcomes & \\
\hline $\begin{array}{l}\text { Blinding of outcome as- } \\
\text { sessment (detection bias) } \\
\text { All outcomes }\end{array}$ & Unclear risk & No details \\
\hline $\begin{array}{l}\text { Incomplete outcome data } \\
\text { (attrition bias) } \\
\text { All outcomes }\end{array}$ & Low risk & All randomised women were analysed. \\
\hline $\begin{array}{l}\text { Selective reporting (re- } \\
\text { porting bias) }\end{array}$ & Unclear risk & No details \\
\hline \begin{tabular}{l} 
Other bias \\
\hline
\end{tabular} & Unclear risk & No details \\
\hline
\end{tabular}

Haydardedeoglu 2011

Methods Prospective parallel randomised trial

Participants Country: Turkey

Site: Department of Obstetrics and Gynaecology, Baskent University Adana

Patients: 274 women undergoing ICSI treatment

Mean age \pm SD: $30.58 \pm 4.66$ in the single-lumen needle group, $30.75 \pm 4.96$ in the double-lumen needle group

Inclusion: not specified

Exclusion: patients with a poor response ( $<6$ follicles over $12 \mathrm{~mm}$ on the day of $\mathrm{hCG}$ ), patients undergoing a microdose flare protocol, patients with a high response (polycystic ovarian syndrome and polycystic ovaries)

Interventions

Patients underwent luteal down-regulation with $1.0 \mathrm{mg}$ leuprolide acetate (Lucrin; Abbott, Istanbul, Turkey) for at least 10 days until day 2 to 3 of menses, at which point baseline ultrasonography and blood tests were carried out. If there were no cysts $\geq 2 \mathrm{~cm}$ and estradiol (E2) levels were $<50 \mathrm{pg} / \mathrm{mL}$, gonadotrophin stimulation was performed with 150 to $225 \mathrm{IU}$ gonadotropin (Puregon; Organon, Turkey). E2 monitoring began on the morning of stimulation day 5 .

Other patients underwent a GnRH antagonist cycle with baseline ultrasonography and blood tests. If there were no cysts $\geq 2 \mathrm{~cm}$ and the progesterone level was $<1 \mathrm{ng} / \mathrm{mL}$, gonadotropin stimulation was performed with 150 to $225 \mathrm{IU}$ gonadotropin. E2 monitoring began on the morning of stimulation day 5 . GnRH antagonist (Orgalutran; Organon) was added on day 6. Ultrasound and E2 monitoring continued until hCG administration criteria were met: at least 3 follicles with maximum diameter $>17 \mathrm{~mm}$. 
Haydardedeoglu 2011 (Continued)

In the single-lumen needle group ( $\mathrm{n}=125)$, a 17-gauge needle (Cook Ireland Ltd., Limerick, Ireland) was used to aspirate the follicles. A 17-gauge needle was used in the double-lumen needle group $(n=149) ; 2$ $\mathrm{mL}$ flush medium was injected and was aspirated once for each punctured follicle. Oocyte-corona complexes were denuded and intracytoplasmic sperm injection performed after 2 hours of incubation. Embryos were transferred on day 3 with individualised transfer protocols for poor-grade embryos. All participants had luteal support with $90 \mathrm{mg}$ progesterone (8\% gel, Crinon; Serono, Istanbul, Turkey) administered vaginally each day after embryo transfer.

Nutcomes
Number of metaphase Il oocytes (mean \pm SD)
Number of germinal vesicles (mean \pm SD)
Duration of oocyte retrieval (min, mean \pm SD)
Fertilisation rate (\%, mean \pm SD)
Number of transferred embryos (mean \pm SD)
Biochemical pregnancy rate (mean \pm SD)
Clinical pregnancy rate (mean \pm SD)
Live birth rate (mean \pm SD)
Rate of patients hospitalised with ovarian hyperstimulation syndrome (\%)
Cancellation rate (\%)

Notes

Using a baseline live birth rate for normal-responding participants with ICSI of $35 \%$ with detectable difference between groups at 5\%, a sample size of 1471 participants in each group was required to achieve 0.80 power. Recruitment was terminated after 13 months, when it became evident it would not be possible to recruit this number of participants at a single centre.

No statement regarding competing interests. No declaration of funding source(s), if any

\section{Risk of bias}

\section{Bias}

Random sequence genera- Low risk tion (selection bias)

\section{Authors' judgement Support for judgement}

Quote: "allocation sequence generated from a random numbers table"

\begin{tabular}{|c|c|c|}
\hline $\begin{array}{l}\text { Allocation concealment } \\
\text { (selection bias) }\end{array}$ & Low risk & Quote: "use of consecutively numbered opaque, sealed envelopes" \\
\hline $\begin{array}{l}\text { Blinding of participants } \\
\text { and personnel (perfor- } \\
\text { mance bias) } \\
\text { All outcomes }\end{array}$ & High risk & Quote: "open-label, randomized controlled trial" \\
\hline $\begin{array}{l}\text { Blinding of outcome as- } \\
\text { sessment (detection bias) } \\
\text { All outcomes }\end{array}$ & High risk & Quote: "open-label, randomized controlled trial" \\
\hline $\begin{array}{l}\text { Incomplete outcome data } \\
\text { (attrition bias) } \\
\text { All outcomes }\end{array}$ & Low risk & All randomised women were analysed. \\
\hline
\end{tabular}


Haydardedeoglu 2011 (Continued)
Selective reporting (re-
Low risk
All a priori outcomes were reported. porting bias)

Other bias

Low risk

No differences in basal participant characteristics. No statement regarding

conflicts of interest

Haydardedeoglu 2017

\begin{tabular}{ll}
\hline Methods & Prospective parallel randomised trial \\
\hline Participants & Country: Turkey
\end{tabular}

Participants Country: Turkey

Site: Division of Reproductive Endocrinology and IVF Unit, Department of Obstetrics and Gynaecology, Baskent University Adana

Patients: 80 women undergoing ICSI treatment

Mean age \pm SD: $34.3 \pm 5.4$ in the single-lumen needle group, $36.2 \pm 3.9$ in the double-lumen needle group

Inclusion: women aged 20 to 43 years with poor ovarian response defined as 5 or fewer follicles $\geq 13$ $\mathrm{mm}$ in size, serum progesterone level $<1.5 \mathrm{ng} / \mathrm{mL}$ on the day of hCG administration, and known poor functional ovarian reserve to predict a poor ovarian response to gonadotropin stimulation diagnosed by an antral follicle count (AFC) $<6$ in both ovaries together with an anti-Müllerian hormone (AMH) level $<0.8 \mathrm{ng} / \mathrm{mL}$

Exclusion: monofollicular ovarian response, natural in vitro fertilisation (IVF) cycle programme, and presence of ovarian endometrioma

Interventions

Approximately half of poor responders took part in a low-dose luteal GnRH agonist programme consisting of a luteal dose of $0.5 \mathrm{mg}$ leuprorelin acetate (Lucrin; Abbott, Paris, France) until day 2 or 3 following menses. After ovarian suppression was achieved, the dose was reduced to $0.25 \mathrm{mg}$ until the date of 10,000 IU hCG (Pregnyl ampoule; MSD) administration. If there were no cysts $\geq 2 \mathrm{~cm}$ and the estradiol (E2) level was $<50 \mathrm{pg} / \mathrm{mL}$, then gonadotropin stimulation with $300 \mathrm{IU}$ (Puregon; MSD, Oss, the Netherlands) was performed. Ultrasound and blood E2 monitoring continued until administration of 10,000 IU hCG when at least 2 follicles had reached maximum diameter $>17 \mathrm{~mm}$.

The GnRH antagonist protocol involved administration of letrozole (Femara; Novartis, Basel, Switzerland) and rFSH (Puregon; MSD). On day 2 or 3 of menses, letrozole $5 \mathrm{mg} / \mathrm{d}$ was started and continued for 5 days. Administration of gonadotropins was started on the same day with 150 IU rFSH plus 150 IU pure human menopausal gonadotropin (hMG) (Menopur; Ferring Pharmaceuticals, Lozan Saint-Prex, Switzerland). A GnRH antagonist (Orgalutran; MSD) was added to this regimen when the leading follicle had reached $14 \mathrm{~mm}$. Ultrasound and blood E2 monitoring continued until the hCG administration criterion was met, with at least 2 follicles having a maximum diameter of $>17 \mathrm{~mm}$.

Four participants were placed on the FSH + pure hMG/GnRH antagonist protocol, which administered gonadotropins and started on day 2 or 3 of menses with $150 \mathrm{IU}$ rFSH plus $150 \mathrm{IU}$ pure hMG. Orgalutran was added to this regimen when the leading follicle reached $14 \mathrm{~mm}$. After the leading follicle reached > $17 \mathrm{~mm}, 10,000 \mathrm{IU}$ of $\mathrm{hCG}$ and $0.2 \mathrm{mg} / \mathrm{mL}$ triptorelin were injected.

Allocation sequence was done using a random numbers table to assign participants to single-lumen (direct aspiration) or double-lumen (follicular flushing) needle groups. Consecutively numbered opaque, sealed envelopes were used on the day of oocyte retrieval. All participants were blinded to randomisation for the duration of the study. Clinicians performing the oocyte retrieval procedure were notified of treatment allocation on the day of retrieval to record duration of the procedure and were given anaesthetic drug amounts.

Transvaginal ultrasound-guided oocyte retrieval was performed 36 hours after trigger under sedation with $1 \%$ propofol (Fresenius Kabi, Homburg, Germany). For the single-lumen needle group $(n=40)$, 
Haydardedeoglu 2017 (Continued)

a 17-gauge needle (Cook Ireland, Limerick, Ireland) was used to aspirate follicles. A 17-gauge needle (Cook Ireland) was also used in the double-lumen needle group ( $n=40)$, and $2 \mathrm{~mL}$ was injected into each follicle via a manually pressed syringe containing $10 \mathrm{~mL}$ of culture medium warmed to $37^{\circ} \mathrm{C}$ and re-aspirated and re-injected 3 times for each punctured follicle. The pressure at which we aspirated the follicles was strictly maintained at $80 \mathrm{mmHg}$.

The oocyte-corona complexes were denuded, and intracytoplasmic sperm injection was performed after a 2-hour incubation. Embryos were transferred on day 3. All participants received luteal support with daily intravaginal $90 \mathrm{mg}$ progesterone (Crinone $8 \%$ gel; Merck Serono, Darmstadt, Germmany) and $0.1 \mathrm{mg} / \mathrm{ml}$ triptorelin on the third day after embryo transfer.

\begin{tabular}{|c|c|}
\hline \multirow[t]{9}{*}{ Outcomes } & Number of metaphase II oocytes retrieved (mean \pm SD) \\
\hline & Number of punctured follicles ( $n$ ) \\
\hline & Number of retrieved oocytes ( $n$ ) \\
\hline & Fertilisation rate $(\%$, mean \pm SD) \\
\hline & Implantation rate $(\%$, mean \pm SD) \\
\hline & Duration of procedure (seconds, mean \pm SD) \\
\hline & Total use of anaesthetic (mean \pm SD) \\
\hline & Clinical pregnancy rate (\%) \\
\hline & Live birth date (\%) \\
\hline
\end{tabular}

Notes

No competing interests. Funding by Baskent University Faculty of Medicine

\section{Risk of bias}

\begin{tabular}{lll}
\hline Bias & Authors' judgement & Support for judgement \\
\hline $\begin{array}{l}\text { Random sequence genera- } \\
\text { tion (selection bias) }\end{array}$ & Low risk & $\begin{array}{l}\text { Quote: "Using a random numbers table, the 80 eligible patients were assigned } \\
\text { randomly" }\end{array}$ \\
\hline $\begin{array}{l}\text { Allocation concealment } \\
\text { (selection bias) }\end{array}$ & Low risk & $\begin{array}{l}\text { Quote: "using consecutively numbered opaque, sealed envelopes on the day } \\
\text { of oocyte retrieval" }\end{array}$ \\
\hline $\begin{array}{l}\text { Blinding of participants } \\
\text { and personnel (perfor- } \\
\text { mance bias) }\end{array}$ & Unclear risk & $\begin{array}{l}\text { Quote: "All patients were blinded to the randomisation for the duration of the } \\
\text { study" }\end{array}$ \\
\hline $\begin{array}{l}\text { All outcomes } \\
\text { Rinding }\end{array}$ & \\
\hline
\end{tabular}

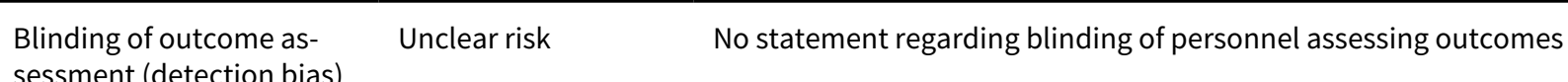
sessment (detection bias)

All outcomes

Incomplete outcome data Low risk All randomised women were analysed.
(attrition bias)
All outcomes

Selective reporting (re- Low risk $\quad$ All a priori outcomes were reported.
porting bias)

\begin{tabular}{ll}
\hline Other bias Low risk & $\begin{array}{l}\text { No differences in basal patient characteristics. No competing interests de- } \\
\text { clared }\end{array}$
\end{tabular}


Kara 2012

\begin{tabular}{ll}
\hline Methods & Prospective parallel randomised trial \\
\hline Participants & Country: Turkey \\
Site: Department of Obstetrics and Gynecology, Bozok University Medical Faculty, \\
Patients: 200 patients undergoing ICSI treatment \\
Mean age \pm SD: $28.1 \pm 5.5$ in the aspiration group, $30.1 \pm 5.3$ in the aspiration group \\
Inclusion: not specified \\
Exclusion: not specified
\end{tabular}

Interventions

In all participants, the pituitary was down-regulated with $0.5 \mathrm{mg}$ leuprolide acetate (Lucrin, Abbott, USA), starting on the $21 \mathrm{st}$ day of the previous cycle. The dose was reduced to $0.25 \mathrm{mg}$ and was continued until the day of hCG injection. Controlled ovarian stimulation was performed with FSH on cycle day 3. The starting FSH dose was $300 \mathrm{IU}$, and this was individually adjusted on the basis of previous treatment cycles, BMI, and age. Follicular development was monitored with E2 levels and ultrasonographic measurements. When 1 or 2 follicles reached $17 \mathrm{~mm}$, hCG (Pregnyl, Schering-Plough, USA) was administered. Transvaginal utrasound-guided needle aspiration of follicular fluid was carried out 35 to 36 hours after hCG administration.

For the aspiration only group (group 1), a single-lumen transvaginal oocyte retrieval needle (Otrieva Tapered Ovum Aspiration Needle, K-TIVM-172035-US, Cook Medical, Spencer, IN, USA) was used. In the flushing group (group 2), a double-lumen transvaginal oocyte retrieval needle (Echo Tip Double Lumen Aspiration Needle, K-OPSD-1635-A-L, Cook Medical, Spencer, IN, USA) was used. Flushing was with $2 \mathrm{~mL}$ flush medium. Women were anaesthetised with Propofol $1000 \mathrm{mg} / \mathrm{mL}$ (Abbott, USA) during the oocyte pickup procedure.

All women underwent intracytoplasmic sperm injection. Up to 4 embryos were transferred on day 2, 3, or 5 after oocyte retrieval using Rocket THin wall Transfer set (Rocket Medical, Hingham, MA, USA). Luteal support was provided by vaginal progesterone administration (Crinon $8 \%$ vaginal gel, Merck-Serono, Switzerland). Progesterone administration was initiated on the oocyte pickup day and continued for 12 days until the day of pregnancy testing. In cases of pregnancy, progesterone was continued until the 12 th gestational week.

All women were initially randomly numbered. Then, computer-assisted randomisation was utilised according to the instructions at www.randomization.com.

Outcomes Number of retrieved oocytes (likely mean, unclear if \pm SD)

Number of metaphase II oocytes (likely mean, unclear if \pm SD)

Number of metaphase I oocytes (likely mean, unclear if \pm SD)

Fertilisation rate (\%)

Clinical pregnancy rate $(\%)$

Ongoing pregnancy rate $(\%)$

Cancellation rate (\%)

Duration of procedure (min, likely mean, unclear if \pm SD) 
Kara 2012 (Continued)

Risk of bias

\begin{tabular}{|c|c|c|}
\hline Bias & Authors' judgement & Support for judgement \\
\hline $\begin{array}{l}\text { Random sequence genera- } \\
\text { tion (selection bias) }\end{array}$ & Low risk & Quote: "computer assisted randomization was utilized" \\
\hline $\begin{array}{l}\text { Allocation concealment } \\
\text { (selection bias) }\end{array}$ & Unclear risk & No details \\
\hline $\begin{array}{l}\text { Blinding of participants } \\
\text { and personnel (perfor- } \\
\text { mance bias) } \\
\text { All outcomes }\end{array}$ & Unclear risk & No details \\
\hline $\begin{array}{l}\text { Blinding of outcome as- } \\
\text { sessment (detection bias) } \\
\text { All outcomes }\end{array}$ & Unclear risk & No details \\
\hline $\begin{array}{l}\text { Incomplete outcome data } \\
\text { (attrition bias) } \\
\text { All outcomes }\end{array}$ & Low risk & All randomised women were analysed. \\
\hline $\begin{array}{l}\text { Selective reporting (re- } \\
\text { porting bias) }\end{array}$ & Unclear risk & No a priori statement regarding outcomes \\
\hline Other bias & Low risk & $\begin{array}{l}\text { No differences in basal participant characteristics. No competing interests de- } \\
\text { clared }\end{array}$ \\
\hline
\end{tabular}

Kingsland 1991

\begin{tabular}{ll}
\hline Methods & Prospective parallel randomised trial \\
\hline Participants & Country: UK \\
& Site: 34 women undergoing IVF \\
& Median age: 31 years for group 1, 30.5 years for group 2 \\
& Inclusion: aged 35 years or younger with tubal damage as the sole cause of infertility \\
& Exclusion: no details
\end{tabular}
menopausal gonadotropin, hCG administered when at least 3 follicles $>18 \mathrm{~mm}$ diameter

Transvaginal ultrasound-guided retrieval via JP6L double-channeled needle

Pain relief: $1 \mathrm{mg}$ lorazepam given orally on the evening before oocyte retrieval and repeated on the morning of aspiration. A single dose of $150 \mathrm{mg}$ pethidine was administered IM 20 minutes before aspiration. No participants required additional anaesthesia.

Group 1 had aspiration only

vs

Group 2 had follicles emptied, then flushed with $10 \mathrm{~mL}$ Earle's balanced salt solution (EBSS, Gibco, Paisley, UK) supplemented with pyruvate and bicarbonate and buffered with HEPES, if the oocyte was 
Kingsland 1991 (Continued)

not retrieved in the aspiration. A maximum of $2 \mathrm{~mL}$ of fluid was instilled into each follicle at each flush (maximum of 5 flushes per follicle).

All oocyte retrievals were done by the same operator. Oocytes were washed once in flushing medium, incubated at $37^{\circ} \mathrm{C}$ in $5 \% \mathrm{CO}_{2}$ in air, pre-equilibrated $1 \mathrm{~mL}$ drops of EBSS supplemented with $0.11 \mathrm{mg} /$ $\mathrm{mL}$ sodium pyruvate, $1 \%$ sodium bicarbonate, $0.02 \mathrm{mg}$ gentamicin, and $10 \% \mathrm{IMS}$.

\begin{tabular}{|c|c|c|}
\hline \multirow[t]{4}{*}{ Outcomes } & \multicolumn{2}{|c|}{ Number of oocytes obtained (median) } \\
\hline & \multicolumn{2}{|c|}{ Time taken for oocyte retrieval (min, median) } \\
\hline & \multicolumn{2}{|l|}{ Fertilization rate (\%) } \\
\hline & \multicolumn{2}{|c|}{ Ongoing pregnancy rate $(\mathrm{n})$} \\
\hline Notes & \multicolumn{2}{|c|}{ No statement regarding competing interests. No declaration of funding source(s), if any } \\
\hline \multicolumn{3}{|l|}{ Risk of bias } \\
\hline Bias & Authors' judgement & Support for judgement \\
\hline $\begin{array}{l}\text { Random sequence genera- } \\
\text { tion (selection bias) }\end{array}$ & Unclear risk & No details \\
\hline $\begin{array}{l}\text { Allocation concealment } \\
\text { (selection bias) }\end{array}$ & Unclear risk & No details \\
\hline $\begin{array}{l}\text { Blinding of participants } \\
\text { and personnel (perfor- } \\
\text { mance bias) } \\
\text { All outcomes }\end{array}$ & Unclear risk & No details \\
\hline $\begin{array}{l}\text { Blinding of outcome as- } \\
\text { sessment (detection bias) } \\
\text { All outcomes }\end{array}$ & Unclear risk & No details \\
\hline $\begin{array}{l}\text { Incomplete outcome data } \\
\text { (attrition bias) } \\
\text { All outcomes }\end{array}$ & Low risk & All randomised women were analysed. \\
\hline $\begin{array}{l}\text { Selective reporting (re- } \\
\text { porting bias) }\end{array}$ & Low risk & All a priori outcomes were reported. \\
\hline Other bias & Unclear risk & $\begin{array}{l}\text { No differences in baseline participant characteristics. No staten } \\
\text { conflicts of interest }\end{array}$ \\
\hline
\end{tabular}

Levens 2009

\begin{tabular}{ll}
\hline Methods & Prospective randomised study \\
\hline Participants & Patients: 30 poor responders undergoing ART \\
& Site: Walter Reed Army Medical Center ART Program, USA \\
& Mean age $37.1 \pm 3.2$ and $36.2 \pm 3.4$ years for single- and double-lumen groups, respectively $(P=0.48)$
\end{tabular}


Levens 2009 (Continued)

Inclusion criteria: low responders with a cumulative follicle count of 4 to 8 follicles $\geq 12 \mathrm{~mm}$ (with at least 2 follicles achieving $\geq 16 \mathrm{~mm}$ )

Interventions

Pretreatment with OCPs during the cycle preceding ovarian stimulation. A combination of $\mathrm{rFSH}$ (Gonal-F) and hMG (Repronex, Ferring) was given twice daily. Adequate follicular development was assessed by serial serum E2 ultrasound. hCG 10,000 IU was given, followed by transvaginal oocyte retrieval 34 to 36 hours later. Assignment to single- or double-lumen group was done immediately before oocyte retrieval. Computerised randomisation in blocks of 10 to 20 was used to ensure balanced group size. Concealment was achieved by using sequentially numbered, opaque envelopes that were opened in the OR after anaesthesia was administered. The length and diameter of retrieval needles were standardised $(35 \mathrm{~cm}, 16 \mathrm{G})$ to control flow dynamics within the needle that may affect oocyte recovery. Cook Echotip single-lumen (K-J-ANC-16R-35) and double-lumen (K-OPSD-1635-B-S) transvaginal oocyte retrieval needles were used. Suction pressure of 150 to $200 \mathrm{mmHg}$ (provided by Pioneer Pro-pump, GenX International, CT) was used under direct transvaginal ultrasound guidance (Acuson Sequoia 512 with an 8-MHz probe). Those in the single-lumen needle group did not undergo saline follicular flushing (direct aspiration), whereas those in the double-lumen group had each aspirated follicle flushed once with $2 \mathrm{~mL}$ sterile PBS and subsequently re-aspirated.

Outcomes

Number of oocytes obtained (mean \pm SD)

Total oocytes mature, maturity (\%)

Fertilization rate (\%)

Implantation rate (\%)

Ongoing pregnancy rate (\%)

Retrieval times (sec, mean \pm SD)

No statement regarding competing interests. No declaration of funding source(s), if any

\section{Risk of bias}

\begin{tabular}{lll}
\hline Bias & Authors' judgement & Support for judgement \\
\hline $\begin{array}{l}\text { Random sequence genera- } \\
\text { tion (selection bias) }\end{array}$ & Low risk & $\begin{array}{l}\text { Quote: "randomly assigned" } \\
\text { Quote: "computerised randomization in blocks of } 10 \text { and } 20 \text { to ensure bal- } \\
\text { anced group size" }\end{array}$ \\
\hline $\begin{array}{l}\text { Allocation concealment } \\
\text { (selection bias) }\end{array}$ & Low risk & $\begin{array}{l}\text { Quote: "Allocation was performed by the Walter Reed Army Medical Center De- } \\
\text { partment of Clinical Investigation and concealed by using sequentially num- } \\
\text { bered, opaque envelopes that were opened in the operating theater after } \\
\text { anesthesia was administered" }\end{array}$ \\
\hline
\end{tabular}

$\begin{aligned} & \text { Blinding of participants } \\ & \text { and personnel (perfor- } \\ & \text { mance bias) }\end{aligned}$
$\begin{aligned} & \text { All outcomes } \\ & \text { blinded to the group assignments" }\end{aligned}$
$\begin{aligned} & \text { Quote: "The providers performing the oocyte retrieval remained blinded to the } \\ & \text { number of oocytes retrieved until the completion of the procedure" }\end{aligned}$

Blinding of outcome as- Unclear risk No details
sessment (detection bias) All outcomes

Incomplete outcome data Low risk $\quad$ All randomised women were analysed.
(attrition bias)

All outcomes 
Levens 2009 (Continued)

Selective reporting (re- Low risk A priori outcomes were reported.
porting bias)

Other bias

Unclear risk

No differences in basal participant characteristics. No statement regarding competing interests

Mok-Lin 2013

\begin{tabular}{ll}
\hline Methods & Prospective parallel randomised study \\
\hline Participants & Country: USA \\
Site: Ronald O. Perelman and Claudia Cohen Center for Reproductive Medicine of Weill Cornell Medical \\
College \\
Patients: 50 women undergoing IVF \\
Mean age \pm SD: $39.5 \pm 3.2$ in the direct aspiration group, $38.2 \pm 4.3$ in the flushing group \\
Inclusion: poor responders with 4 or fewer follicles $\geq 12 \mathrm{~mm}$ \\
Exclusion: patients without a planned fresh embryo transfer, patients undergoing natural IVF, patients \\
whose cycles were cancelled before hCG administration, patients offered enrolment or randomised in a \\
previous cycle
\end{tabular}

Interventions

Most poor responders utilised a GnRH antagonist protocol with luteal oestrogen priming. Participants were placed on a $0.1-\mathrm{mg}$ oestradiol patch every other day beginning 8 to 10 days after an LH surge, followed by controlled ovarian hyperstimulation $(\mathrm{COH})$ on day 2 of menses. Other protocols included use of a $\mathrm{GnRH}$ antagonist without priming, 5 days of clomiphene citrate or letrozole, and daily subcutaneous 40 micrograms leuprolide with $\mathrm{COH}$. $\mathrm{COH}$ was performed with rFSH and human menopausal gonadotropins. hCG 10,000 IU was administered intramuscularly when 1 to 2 follicles $\geq 17 \mathrm{~mm}$ were present.

Participants were randomised on the day of hCG administration to direct aspiration or flushing. Treatment allocation was performed via a computer-generated randomisation sequence. Allocation was concealed by sequentially numbered, opaque envelopes. All participants were blinded to randomisation. Embryologists were blinded to the allocation scheme. In the direct aspiration group, a 16-gauge single-lumen oocyte retrieval needle (Echotipwovum aspiration needle; Cook Medical; Bloomington, IN, USA) was used to aspirate follicles with transvaginal ultrasound guidance. In the flushing group, each aspirated follicle was flushed up to 4 times via a manually pressed syringe with $5 \mathrm{~mL}$ of culture media warmed to $37^{\circ} \mathrm{C}$ and was re-aspirated with a 16-gauge double-lumen needle (Echotip Double Lumen Aspiration Needle; Cook Medical). All embryos were transferred on day 3, and transferring physicians were blinded to the assigned intervention.

Outcomes

Number of oocytes retrieved (mean \pm SD)

Anaesthesia time (min, mean $\pm \mathrm{SD})$

Procedure time $(\mathrm{min}$, mean $\pm \mathrm{SD})$

Number of mature oocytes (mean \pm SD)

Number of embryos transferred (mean \pm SD)

Implantation rate (\%)

Clinical pregnancy rate (\%)

Live birth rate $(\%)$ 
Mok-Lin 2013 (Continued)

Notes No competing interests. No external funding for the study

\section{Risk of bias}

\begin{tabular}{|c|c|c|}
\hline Bias & Authors' judgement & Support for judgement \\
\hline $\begin{array}{l}\text { Random sequence genera- } \\
\text { tion (selection bias) }\end{array}$ & Low risk & $\begin{array}{l}\text { Quote: "Treatment allocation was performed using a computer-generated ran- } \\
\text { domization sequence" }\end{array}$ \\
\hline $\begin{array}{l}\text { Allocation concealment } \\
\text { (selection bias) }\end{array}$ & Low risk & $\begin{array}{l}\text { Quote: "Allocation was performed by the research team and concealed using } \\
\text { sequentially numbered, opaque envelopes" }\end{array}$ \\
\hline $\begin{array}{l}\text { Blinding of participants } \\
\text { and personnel (perfor- } \\
\text { mance bias) }\end{array}$ & Low risk & $\begin{array}{l}\text { Quote: "All patients were blinded to the randomization for the duration of the } \\
\text { study" }\end{array}$ \\
\hline \multirow[t]{2}{*}{ All outcomes } & & $\begin{array}{l}\text { Quote: "Determination of need for ICSI and selection of embryos for transfer } \\
\text { were performed by embryologists blinded to the allocation scheme" }\end{array}$ \\
\hline & & $\begin{array}{l}\text { Quote: "All embryos were transferred on Day } 3 \text { and transferring physicians } \\
\text { were blinded to the assigned intervention" }\end{array}$ \\
\hline
\end{tabular}

\begin{tabular}{lll}
$\begin{array}{l}\text { Blinding of outcome as- } \\
\text { sessment (detection bias) } \\
\text { All outcomes }\end{array}$ & Unclear risk & No statement regarding blinding of personnel assessing outcome \\
\hline $\begin{array}{l}\text { Incomplete outcome data } \\
\text { (attrition bias) } \\
\text { All outcomes }\end{array}$ & Low risk & All randomised women were analysed. \\
\hline $\begin{array}{l}\text { Selective reporting (re- } \\
\text { porting bias) }\end{array}$ & Low risk & All a priori outcomes were reported. \\
\hline Other bias & Low risk & $\begin{array}{l}\text { No differences in basal participant characteristics. No competing interests de- } \\
\text { clared }\end{array}$ \\
\hline
\end{tabular}

\section{Scott 1989}

\begin{tabular}{ll}
\hline Methods & Prospective parallel randomised study \\
\hline Participants & Country: USA \\
& Patients: 44 women undergoing IVF \\
& Median ages of both groups not given \\
& No inclusion or exclusion criteria given \\
\hline
\end{tabular}

Interventions All participants underwent gonadotropin stimulation via previously described protocols (in textbook, no details given in the paper).

Retrieval with single-lumen needle (SLN) $(n=22)$ was done with a Swe-Med needle (outer diameter 1.5 $\mathrm{mm}$, inner diameter $1 \mathrm{~mm}$ ). The follicle was aspirated with a hand-held $20-\mathrm{mL}$ syringe, and the needle was removed from the participant; this was followed by aspiration of an additional $2 \mathrm{~mL}$ of heparinised Dulbecco's solution through the system to wash fluid in the dead space back into the syringe.

The double-lumen needle (DLN; Swe-Med Lab, Frolunda, Sweden) had an inner diameter of the aspiration lumen of $1 \mathrm{~mm}$ and an outer diameter of $1.6 \mathrm{~mm}$. The follicle was aspirated, then 1 to $3 \mathrm{~mL}$ of heparinised Dulbecco's solution was injected into the follicle through the second port. This volume was 
Scott 1989 (Continued)

then aspirated back into the syringe. Lavage was performed 1 more time until the oocyte was recovered, or until the follicle was not re-expanding well, before proceeding to the next follicle.

Pain relief: method not mentioned

\begin{tabular}{|c|c|c|}
\hline Outcomes & \multicolumn{2}{|c|}{$\begin{array}{l}\text { Number of follicles aspirated and number of oocytes retrieved (mean } \pm \mathrm{SE} \text { ) } \\
\text { Incidence of fractured zona in both groups }(\%)\end{array}$} \\
\hline Notes & \multicolumn{2}{|c|}{ No statement regarding competing interests. No declaration of funding source(s), if any } \\
\hline \multicolumn{3}{|l|}{ Risk of bias } \\
\hline Bias & Authors' judgement & Support for judgement \\
\hline $\begin{array}{l}\text { Random sequence genera- } \\
\text { tion (selection bias) }\end{array}$ & Unclear risk & No details \\
\hline $\begin{array}{l}\text { Allocation concealment } \\
\text { (selection bias) }\end{array}$ & Unclear risk & No details \\
\hline $\begin{array}{l}\text { Blinding of participants } \\
\text { and personnel (perfor- } \\
\text { mance bias) } \\
\text { All outcomes }\end{array}$ & Unclear risk & No details \\
\hline
\end{tabular}

\begin{tabular}{lll}
\hline $\begin{array}{l}\text { Blinding of outcome as- } \\
\text { sessment (detection bias) } \\
\text { All outcomes }\end{array}$ & Unclear risk & No details \\
\hline $\begin{array}{l}\text { Incomplete outcome data } \\
\begin{array}{l}\text { (attrition bias) } \\
\text { All outcomes }\end{array}\end{array}$ & Low risk & All randomised women were analysed. \\
\hline $\begin{array}{l}\text { Selective reporting (re- } \\
\text { porting bias) }\end{array}$ & Unclear risk & Fertilisation rate and clinical pregnancy rate were not described. \\
\hline Other bias & Unclear risk & No details \\
\hline
\end{tabular}

Tan 1992

\begin{tabular}{|c|c|}
\hline Methods & Prospective parallel randomised study \\
\hline \multirow[t]{5}{*}{ Participants } & Country: UK \\
\hline & Site: 100 women undergoing IVF treatment at an assisted conception unit \\
\hline & Median age for group 1 was 32 ( 25 to 42 years), and for group 232.5 ( 23 to 43 years). \\
\hline & Inclusion: not specified \\
\hline & $\begin{array}{l}\text { Exclusion: women who had developed }>25 \text { or }<4 \text { follicles wider than } 14 \mathrm{~mm} \text { diameter on the day of } \\
\text { hCG administration }\end{array}$ \\
\hline Interventions & $\begin{array}{l}\text { Long follicular protocol, starting buserelin acetate (Suprefact; Hoechst, Hounslow, UK) was adminis- } \\
\text { tered intranasally ( } 200 \mathrm{\mu g} 4 \text {-hourly) on day } 1 \text { or } 2 \text { of the menstrual cycle. When serum oestradiol con- } \\
\text { centration was < } 200 \mathrm{pmol} / \mathrm{L} \text {, human menopausal gonadotropin (Pergonal; Serono, Welwyn Garden } \\
\text { City, UK) was started at } 2 \text { to } 6 \text { ampoules daily. hCG (Profasi; Serano) } 10,000 \text { IU was administered when }\end{array}$ \\
\hline
\end{tabular}


Tan 1992 (Continued)

there were at least 4 follicles $>14 \mathrm{~mm}$ in diameter and mean diameter of the largest follicle was $>20$ $\mathrm{mm}$.

Transvaginal ultrasound-guided follicle aspiration was performed 33 to 38 hours post hCG as an outpatient procedure. Pain relief was achieved with IV pethidine 50 to $100 \mathrm{mg}$ in bolus doses of $25 \mathrm{mg}$ as required.

Aspiration via JP6L double-channel needle (Casmed, Cheam, UK). Maximum aspiration pressure of 100 $\mathrm{mmHg}$ was used in both groups.

Group 1 (aspiration only; $\mathrm{n}=50$ ): inner channel of needle removed to convert it to a single-channel needle. Each follicle was aspirated until empty. The probe was moved around until all follicular fluid was aspirated as evidenced by some blood-stained fluid in the tubing. The same procedure was repeated until all follicles $>10 \mathrm{~mm}$ had been aspirated from the first ovary. After dead space in the needle was cleared, the procedure was repeated in the second ovary.

Group 2 (aspiration and flushing, $n=50$ ): double-channel needle used and the follicle aspirated through the inner channel. This initial aspirate was termed A1. Once the follicle had been emptied, the collecting tube was changed and, with the valve open, flushing medium was injected until $1.5 \mathrm{~mL}$ of fluid had been collected. This was termed A2. A1 and A2 were examined separately, and if no oocyte was observed, the follicle was flushed up to a maximum of 6 times.

One to three embryos were transferred 48 to 72 hours after oocyte recovery.

Outcomes

Number of follicles aspirated and number of oocytes obtained (median + range)

Time taken for oocyte aspiration (min, median + range)

Dose of pethidine required ( $\mathrm{mg}$, median + range)

Fertilization rate $(\%$, range)

Number of embryos transferred (median + range)

Clinical pregnancy rate $(\%$, range)

Notes

No statement regarding competing interests. No declaration of funding source(s), if any

\section{Risk of bias}

\section{Bias} Authors' judgement Support for judgement

Random sequence genera- Unclear risk Unclear as to how randomisation was performed
tion (selection bias)

\begin{tabular}{ll}
\hline $\begin{array}{l}\text { Allocation concealment } \\
\text { (selection bias) }\end{array} \quad$ Low risk & Randomised by drawing serially number sealed envelopes
\end{tabular}

\begin{tabular}{|c|c|c|}
\hline $\begin{array}{l}\text { Blinding of participants } \\
\text { and personnel (perfor- } \\
\text { mance bias) } \\
\text { All outcomes }\end{array}$ & Unclear risk & No details \\
\hline $\begin{array}{l}\text { Blinding of outcome as- } \\
\text { sessment (detection bias) } \\
\text { All outcomes }\end{array}$ & Unclear risk & No details \\
\hline $\begin{array}{l}\text { Incomplete outcome data } \\
\text { (attrition bias) } \\
\text { All outcomes }\end{array}$ & Low risk & Data for all women were reported. \\
\hline
\end{tabular}


Tan 1992 (Continued)

\begin{tabular}{lll}
$\begin{array}{l}\text { Selective reporting (re- } \\
\text { porting bias) }\end{array}$ & Low risk & A priori outcomes were reported. \\
\hline Other bias & Unclear risk & $\begin{array}{l}\text { No differences in basal participant characteristics. No statement on competing } \\
\text { interests }\end{array}$
\end{tabular}

von Horn 2017

Methods Prospective parallel randomised study

Participants

Country: Germany

Site: Department of Reproductive Endocrinology and Reproductive Medicine, University Hospital of Schleswig- Holstein, Lübeck

Patients: 80 women undergoing ICSI treatment

Mean age \pm SD: $38.7 \pm 5.0$ in the no flushing group, $37.5 \pm 4.3$ in the flushing group

Inclusion: $\mathrm{BMI}>18 \mathrm{~kg} / \mathrm{m} 2$ and $<35 \mathrm{~kg} / \mathrm{m} 2$, between the age of 18 and 45 , presenting with a total $\leq$ five follicles $>10 \mathrm{~mm}$ in both ovaries combined at the end of the follicular phase of the treatment cycle

Exclusion: 1 ovary absent (e.g. after ovarectomy) or 1/both ovaries foreseeably difficult to puncture (e.g. heterotopic site because of adhesions)

Interventions

IVF protocol used is not described in detail. Final oocyte maturation was induced by 5000 IU urinary hCG as soon as the leading follicle reached a mean diameter of $18 \mathrm{~mm}$ or the day thereafter, and oocyte pickup was scheduled $34-38 \mathrm{~h}$ thereafter.

On the day of the decision to trigger final oocyte maturation, participants were randomised to either study group (Steiner-Tan Needle) or control group (Gynetics). The Steiner-Tan needles and the flushing system were provided for free by the manufacturer.

Randomisation was performed by one of the doctors who performed sonographic monitoring by opening a sealed, opaque, and sequentially numbered envelope containing allocation of the participant. The random sequence was software-generated and was produced by one of the trial authors. Blocks of 4 were used.

In the study group $(n=40)$, all visible follicles were aspirated with suction pressure of $180 \mathrm{mmHg}$, then were flushed 3 times under ultrasound. In the control group $(n=40)$, all visible follicles were aspirated with suction pressure of $180 \mathrm{mmHg}$.

Intracytoplasmic sperm injection was performed as per standard operating procedure.

Outcomes

Number of cumulus-oocyte complexes (mean \pm SD) and oocyte retrieval rate

Number of metaphase II oocytes (mean \pm SD)

Number of fertilised oocytes (mean \pm SD)

Proportion of participants undergoing embryo transfer (\%)

Ongoing pregnancy rate $(\mathrm{n})$

Duration of procedure (min, mean $\pm S D$ )

Depression Anxiety and Stress Scale score (DASS-21)

Pain assessment by visual analogue scale 2 hours post procedure 
von Horn 2017 (Continued)

Notes

Steiner-Tan needles were provided for free by the manufacturer. Personal fees received by study authors were declared.

\section{Risk of bias}

\begin{tabular}{lll}
\hline Bias & Authors' judgement & Support for judgement \\
\hline $\begin{array}{l}\text { Random sequence genera- } \\
\text { tion (selection bias) }\end{array}$ & Low risk & $\begin{array}{l}\text { Quote: "The random sequence was software-generated and was produced by } \\
\text { one of the authors (G.G.). Blocks of four were used" }\end{array}$ \\
\hline $\begin{array}{l}\text { Allocation concealment } \\
\text { (selection bias) }\end{array}$ & Low risk & $\begin{array}{l}\text { Quote: "sealed, opaque and sequentially numbered envelope containing the } \\
\text { allocation of the patient" }\end{array}$ \\
\hline $\begin{array}{l}\text { Blinding of participants } \\
\begin{array}{l}\text { and personnel (perfor- } \\
\text { mance bias) } \\
\text { All outcomes }\end{array}\end{array}$ & High risk & Quote: "randomized, controlled, open, superiority trial" \\
\hline
\end{tabular}

\begin{tabular}{|c|c|c|}
\hline $\begin{array}{l}\text { Blinding of outcome as- } \\
\text { sessment (detection bias) } \\
\text { All outcomes }\end{array}$ & High risk & Quote: "randomized, controlled, open, superiority trial" \\
\hline $\begin{array}{l}\text { Incomplete outcome data } \\
\text { (attrition bias) } \\
\text { All outcomes }\end{array}$ & Low risk & All randomised women were analysed. \\
\hline $\begin{array}{l}\text { Selective reporting (re- } \\
\text { porting bias) }\end{array}$ & Low risk & All a priori outcomes were reported. \\
\hline Other bias & Low risk & $\begin{array}{l}\text { No differences in basal participant characteristics. Competing interests de- } \\
\text { clared }\end{array}$ \\
\hline
\end{tabular}

AFC: antral follicle count.

AMH: anti-Müllerian hormone.

ART: assisted reproductive technology.

BMI: body mass index.

DASS-21: Depression Anxiety and Stress Scale-21.

DLN: double-lumen needle.

E2: estradiol.

EBSS: Earle's balanced salt solution.

FSH: follicle-stimulating hormone.

GnRH: gonadotropin-releasing hormone.

hCG: human chorionic gonadotropin.

HEPES: 4-(2-hydroxyethyl)-1-piperazineethanesulfonic acid.

hMG: human menopausal gonadotropin.

ICSI: intracytoplasmic sperm injection.

IM: intramuscular.

IMS: inactivated maternal serum.

IVF: in vitro fertilisation.

OCPs: oral contraceptive pills.

PBS: phosphate-buffered saline.

rFSH: recombinant follicle-stimulating hormone.

SD: standard deviation.

SE: standard error.

SLN: single-lumen needle. 


\section{Characteristics of excluded studies [ordered by study ID]}

\section{Study Reason for exclusion}

Avila 2013

148 participants divided into 2 groups: 75 allocated to follicular flushing (case), 73 allocated to aspiration only (control). Total oocytes retrieved were $11.80 \pm 1.3$ in the flushing group vs $9.59 \pm 6.1$ ( $P$ $=0.691)$ in the control group. Further, no differences were reported in positive pregnancy test $(43 \%$ and $32 \%$, respectively) or fertilisation rate ( $55.5 \%$ and $55.85 \%$, respectively).

Reason for exclusion: retrospective, descriptive study

Aydin 2017

45 poor responders who all underwent aspiration followed by flushing up to 3 times. Trial authors reported an increase in the number of oocytes retrieved with sequential flushing.

Reason for exclusion: prospective cohort study, not a randomised study; no aspiration only group
All participants had repeated flushing of the follicles. Study compared number of oocytes obtained with each flushing after primary aspiration of the follicle. Study authors concluded that $40 \%$ of oocytes were retrieved with primary aspiration without flushing of the follicle, and up to $82 \%$ of oocytes were retrieved with 2 flushes and up to $97 \%$ with 4 flushes.

Study was excluded as it was not an RCT and no control (aspiration only) group was present.

35 participants were randomised to have the left or right ovary flushed with heparinised normal saline or heparinised culture medium. Oocytes obtained from each side were cultured separately and were assessed for fertilisation 18 to 21 hours after insemination. From the side flushed with saline, 185 oocytes were collected from 237 follicles, which was not significantly different from 181 oocytes collected from 244 follicles on the side flushed with culture medium (OR 1.23, 95\% Cl 0.79 to 1.92). No significant difference in fertilization rates was observed between oocytes obtained after saline (median $71.4 \%$ ) and culture medium flush (median $75 \%$ ) (OR 1.08, 95\% $\mathrm{Cl} 0.68$ to 1.72).

Reason for excluding from meta-analysis: no aspiration only group

\section{Dean 1997}

This was an abstract of the same study as Biljan MM et al (1997) - published in Fertility and Sterility 1997;68:1132-4.

Reason for exclusion: duplicate study (under different first trial author)

el Hussein 1992
Study evaluated 100 consecutive patients undergoing 100 cycles of IVF. Four patients were excluded because their embryos were electively cryopreserved. Study reported an overall oocyte recovery rate of $87.8 \%$. Of 1046 oocytes collected, $40.3 \%$ were from initial aspiration (A1), $41.3 \%$ from dead space in the collecting system (A2), $13.7 \%$ from the first 2-mL flush (F1), and $4.7 \%$ from the second 2-mL flush (F2). Comparable numbers of viable and fertilised oocytes and cleaved, transferred, and frozen embryos in tubes $A 1$ and $A 2$, but all these parameters were significantly lower in tubes $F 1$ and F2 $(P<0.0001)$. All these parameters were also significantly higher in $F 1$ compared with $F 2(P<$ 0.001 ), except for numbers of embryos frozen, which showed no difference. Overall pregnancy rate/ cycle was $28.1 \%$ and pregnancy rate per ET was $31 \%$. No pregnancy was reported in any of the cycles in which embryos originating from $\mathrm{F} 2$ were transferred, nor was pregnancy found in cycles in which only embryos from F1 were transferred. Study authors concluded that follicular aspiration together with one 2-mL flush maximises the recovery of oocytes that will result in pregnancies.

Reason for exclusion: not a randomised study. Aspiration done in all cases
Randomised study comparing aspiration alone (39 participants) vs aspiration and flushing (40 participants) in poor responders. In the flushing group, 123 oocytes were collected, whereas 106 were obtained from the aspiration alone group $(P=0.0594)$. No difference was found in fertilisation or pregnancy rates. 


\section{Study Reason for exclusion}

Reason for exclusion: study authors contacted owing to similarity with another conference abstract (Pirrello 2011) with differing participant numbers. Study authors clarified that issues were identified with study ethics and inclusion criteria.

Ghosh 2002

This is a comparative evaluation comparing aspiration alone (group A; 156 participants) vs repeated follicular flushing (group B; 172 participants) in women with tubal block. Study authors reported oocyte recovery of $5.2 \pm 1.1$ in group $A$ and $6.2 \pm 1.3$ in group B. Pregnancy rate was $34.6 \%$ in group $A$ and $34.9 \%$ in group $B$; miscarriage rates were $9.2 \%$ and 21.6 , respectively.

Reason for exclusion: not a randomised study

Gordon 2002

A randomised study comparing 2 flushing media (Medicult flushing medium 25 cases, SynVitroFlush 22 cases) for follicle irrigation of women undergoing IVF/ICSI treatment. Study authors observed no differences in numbers of oocytes retrieved, fertilisation rates, numbers of embryos replaced, and clinical pregnancy per oocyte collection ( $2 / 25$ or $8 \%$ vs $6 / 22$ or $27.2 \%$ for Medicult and SynVitroFlush medium, respectively; $\mathrm{P}=0.052$ ).

Reason for exclusion: no aspiration-only group for comparison

Study included 40 IVF cycles in cases with $>10$ follicles. Each case was randomised to the first half of follicles $(>14 \mathrm{~mm}$ ) flushed with non-heparinised EBSS and the second half with non-heparinised normal saline, or vice versa. 185 oocytes out of 276 follicles (67\%) were retrieved when EBSS was used (group I), and 187 out of 284 follicles (65.8\%) when normal saline was used (group II). Data show no significant differences in fertilisation (150/185, $81 \%$ vs $153 / 187,82 \%$; NS), cleavage rates (136/150, 90.6\% vs $141 / 153,92 \%$; NS), or grade I embryos at 48 hours (74\% vs $76 \%$ ) and 72 hours (68\% vs $67 \%)$ in groups I and II, respectively.

Reason for exclusion: no aspiration-only group for comparison tion plus flushing at City West IVF during 1991-1993. 23 women had failed collections in each group and were excluded (leaving only 1139 in each group). (Total number of participants in the abstract (2378) did not match that in the text $(1139+1139+23+23=2324)$.)

Reason for exclusion: historical comparison of aspiration alone and aspiration with additional flushing of each follicle. Not a randomised trial

Oocyte collection was done in 53 cases by ultrasonically guided abdominal puncture under local or epidural anaesthesia. After follicle aspiration, 2 to 6 flushes with culture medium were performed with a syringe. A total of 196 oocytes were collected, 84 of which (42.9\%) were found in the flushes. Mechanical damage was observed in $5.1 \%$ of oocytes. Cleavage rates in mature oocytes (157) after 48 hours in culture were similar in the aspirate group (56.5\%) and the flush group (54.2\%). 10 clinical pregnancies were reported, corresponding to a pregnancy rate of $18.9 \%$.

Reason for exclusion: TAS not TVS approach, only 1 group of aspiration with flushing lar flushing have different developmental competence. 49 cycles were studied; if an oocyte was not collected with aspiration alone, flushing would be conducted twice. Data show no difference in oocyte maturity between flushed and not flushed groups and no differences in fertilisation and cleavage rates.

Reason for exclusion: observational study

Study prospectively included 165 infertile women with low ovarian reserve, 20 to 37 years of age, undergoing 271 consecutive minimal stimulation IVF cycles from January 2005 to December 2006. Oocyte retrieval was performed 34 hours after hCG administration, rather than after 36 hours, to avoid risk of possible follicular rupture before aspiration. Follicular fluid was aspirated with a single-channel 16-gauge needle attached to a $10-\mathrm{mL}$ syringe. The aspiration needle was kept steady inside the follicle until the oocyte was found and isolated (follicular aspiration group; FA group). 


\title{
Study Reason for exclusion
}

In case of negative oocyte recovery, sequential flushings were performed via 10-mL syringes filled with $3 \mathrm{~mL}$ of Tyrode's salt solution. These oocytes were entered into the follicular flushing group (FF). Data show $46.8 \%$ oocyte recovery with aspiration only, compared with $84.6 \%$ with additional follicular flushings. In addition, oocytes retrieved by follicular flushing demonstrated better morphological quality (top-quality embryos $43 / 75$ or $59.7 \%$ vs $40 / 98$ or $41.2 \%$; $P=0.01$ ) and implantation outcomes (implantation rate $34.8 \%$ vs $20.4 \%$; $P=0.04$ ) for the corresponding embryo compared with those already present in follicular fluid.

Reason for exclusion: Recruited women underwent > 1 cycle of treatment. Not an RCT, as aspiration was followed by flushing only when no oocyte was obtained

138 patients undergoing IVF underwent aspiration (A) and up to 3 flushes (F1, F2, F3) and were inspected for the presence of oocyte-cumular complexes (OCCS). $91 \%$ of OCCs were obtained with aspiration only (A) after 1 flush (F1); significantly more mature oocytes were collected with aspiration only $(P=0.03)$. Fertilisation rates were similar in all groups. Clinical pregnancy rate and live birth rate were not affected by the first 2 flushes.

Reason for exclusion: observational study

A randomised study comparing aspiration alone (36 participants) with aspiration and flushing (38 participants) among poor responders. An equivalent number of oocytes was collected in both groups $(P=0.0594)$.

Reason for exclusion: study authors contacted regarding similarity with another conference abstract (Faller 2010) but with differing participant numbers. Study authors clarified that these data are duplicated in Faller 2010, and that differences in numbers were due to issues related to study ethics and inclusion criteria.

\section{Waterstone 1992}

All 50 participants had follicle aspiration with flushing. The origin of each oocyte was established - whether it had been obtained in the initial part of the aspirate, in the dead space aspirate, in the first to third flushes, or in the fourth to sixth flushes. Trialists concluded that $20 \%$ more oocytes were obtained than with aspiration alone.

Reason for exclusion: not an RCT; only 1 group included in follicle flushing. No adverse effects were noted during oocyte recovery in either of the 2 groups. Average numbers of oocytes collected $(8.2 \pm 2.8$ vs $8.3 \pm 2.9)$, recovery rates ( $86.8 \pm 14.6$ vs $82.8 \pm$ $15)$, cleavage rates $(60.7 \pm 30.3$ vs $61.1 \pm 28.2)$, implantation rates $(21.1 \%$ vs $18.3 \%)$, and ongoing pregnancy rates per completed cycle $(27.7 \%$ vs $27.5 \%)$ were similar with SynVitro and Medicult flushing media, respectively.

Reason for exclusion: no aspiration-only group for comparison

\author{
A: aspiration. \\ $\mathrm{Cl}$ : confidence interval. \\ EBSS: Earle's balanced salt solution. \\ ET: embryo transfer. \\ F: flushing. \\ FA: follicular aspiration. \\ FF: follicular flushing. \\ hCG: human chorionic gonadotropin. \\ ICSI: intracytoplasmic sperm injection. \\ IVF: in vitro fertilisation. \\ NS: not significant. \\ OCC: oocyte-cumulus complex. \\ OR: odds ratio. \\ $\mathrm{RCT}$ : randomised controlled trial. \\ TAS: transabdominal sonography.
}


TVS: transvaginal sonography.

Characteristics of ongoing studies [ordered by study ID]

NCT01329302

\begin{tabular}{|c|c|}
\hline Trial name or title & $\begin{array}{l}\text { Benefit of follicular flushing during oocyte retrieval for poor responder patient in an assisted repro- } \\
\text { ductive technology programme }\end{array}$ \\
\hline Methods & Prospective single-blind randomised controlled trial \\
\hline Participants & $\begin{array}{l}\text { - Patients undergoing IVF or ICSI treatment } \\
\text { - Long agonist, antagonist, or short stimulation protocol } \\
\text { - Fewer than } 5 \text { follicles of } 14 \mathrm{~mm} \text { or more per day of hCG } \\
\text { - } 18 \text { to } 43 \text { years old } \\
\text { - Patients within a married couple or who could prove a married life of over } 2 \text { years }\end{array}$ \\
\hline Interventions & $\begin{array}{l}\text { Direct aspiration with single-lumen needle Echo tip Cook, or follicular flushing with double-lumen } \\
\text { needle Echo tip Cook for double-lumen aspiration }\end{array}$ \\
\hline Outcomes & $\begin{array}{l}\text { Primary outcome measures: } \\
\text { - Number of mature oocytes collected } \\
\text { - Quality of embryos obtained } \\
\text { Secondary outcome measures: } \\
\text { - Number of embryos obtained } \\
\text { - Number of transferable embryos (transferred and frozen) } \\
\text { - Number of pregnancies obtained }\end{array}$ \\
\hline Starting date & March 2011 \\
\hline Contact information & $\begin{array}{l}\text { Dr. Olivier Pirrello } \\
\text { Centre d'Assistance Médicale à la Procréation, CMCO-SIHCUS } \\
\text { Schiltigheim } \\
\text { France, } 67300\end{array}$ \\
\hline Notes & Advised by study authors that the study is due to be submitted for peer review shortly \\
\hline
\end{tabular}

\section{NCT02277210}

Trial name or title

Methods

Follicular flushing in patients with suboptimal responses

Prospective single-blind randomised controlled trial

\section{Participants}

Age of women: $<43$ years

Normal uterine cavity on saline sonogram 
NCT02277210 (Continued)

Endometrial thickness $\geq 8 \mathrm{~mm}$ on the day of hCG

\begin{tabular}{ll}
\hline Starting date & October 2014 \\
\hline Contact information & Professor Ernest Hung-Yu Ng \\
& Department of Obstetrics and Gynaecology \\
& The University of Hong Kong \\
& Hong Kong \\
& PR China \\
\hline Notes & Estimated study completion date: September 2020 \\
\hline
\end{tabular}

NCT02641808

\begin{tabular}{ll}
\hline Trial name or title & Does follicular flushing improve the outcomes in monofollicular IVF therapy? \\
\hline Methods & Prospective open-label randomised controlled trial \\
\hline Participants & - Indication for in vitro fertilisation \\
& - Desire for natural cycle IVF and ICSI fertilisation \\
& - Regular menstrual cycle; both ovaries can be reached for follicle aspiration \\
& - 18 to 42 years \\
& - Size of follicle $\geq 16$ mm \\
- Max 2 previous embryo transfers \\
\hline Interventions & Experimental: follicular flushing group \\
\hline
\end{tabular}


NCT02641808 (Continued)

- Monofollicular IVF therapy with follicular flushing up to 5 times after aspiration of the follicle to the time of oocyte pickup

Active comparator: aspiration group

- Monofollicular IVF therapy with aspiration only at the time of oocyte pickup

\begin{tabular}{|c|c|}
\hline Outcomes & $\begin{array}{l}\text { Primary outcome measures: } \\
\text { - Proportion of mature oocytes retrieved } \\
\text { Secondary outcome measures: } \\
\text { - Number of flushings necessary to retrieve the oocyte (intervention arm only) } \\
\text { - Fertilisation rate } \\
\text { - Embryo quality (BLEFCO and ASEBIR scores) on day } 2 \text { after fertilisation } \\
\text { - Transfer rate } \\
\text { - Pregnancy rate } \\
\text { - Pain during intervention measured on a VAS scale } \\
\text { - Time taken for intervention }\end{array}$ \\
\hline Starting date & August 2016 \\
\hline Contact information & $\begin{array}{l}\text { Dr. Alexandra S. Kohl Schwartz } \\
\text { University Hospital Inselspital } \\
\text { University of Bern } \\
\text { Berne } \\
\text { Switzerland }\end{array}$ \\
\hline Notes & $\begin{array}{l}\text { Estimated primary completion date: July } 2018 \text { (final data collection date for primary outcome mea- } \\
\text { sure) }\end{array}$ \\
\hline
\end{tabular}

ASEBIR: classical EQC of the Spanish Society for the Study of Reproductive Biology.

BLEFCO: Biologistes des Laboratoires d'Etude de la Fécondation et de la Conservation de l'oeuf scale.

hCG: human chorionic gonadotropin.

ICSI: intracytoplasmic sperm injection.

IVF: in vitro fertilisation.

VAS: visual analogue scale.

\section{DATA AND ANALYSES}

Comparison 1. Follicular flushing

\begin{tabular}{lllll}
\hline Outcome or subgroup title & No. of studies & $\begin{array}{l}\text { No. of partici- } \\
\text { pants }\end{array}$ & Statistical method & Effect size \\
\hline 1 Live birth rate & 3 & 303 & $\begin{array}{l}\text { Odds Ratio (M-H, Fixed, 95\% } \\
\text { Cl) }\end{array}$ & $0.95[0.58,1.56]$ \\
\hline
\end{tabular}




\begin{tabular}{|c|c|c|c|c|}
\hline Outcome or subgroup title & No. of studies & $\begin{array}{l}\text { No. of partici- } \\
\text { pants }\end{array}$ & Statistical method & Effect size \\
\hline $\begin{array}{l}\text { 1.1 Poor response to ovarian stimu- } \\
\text { lation }\end{array}$ & 2 & 130 & $\begin{array}{l}\text { Odds Ratio (M-H, Fixed, 95\% } \\
\mathrm{Cl})\end{array}$ & $0.60[0.25,1.47]$ \\
\hline $\begin{array}{l}1.2 \text { Normal response to ovarian } \\
\text { stimulation }\end{array}$ & 1 & 173 & $\begin{array}{l}\text { Odds Ratio (M-H, Fixed, 95\% } \\
\mathrm{Cl})\end{array}$ & $1.18[0.64,2.16]$ \\
\hline $\begin{array}{l}2 \text { Oocyte yield per woman ran- } \\
\text { domised (normally distributed data) }\end{array}$ & 6 & 708 & $\begin{array}{l}\text { Mean Difference (IV, Fixed, } \\
95 \% \mathrm{Cl})\end{array}$ & $-0.28[-0.64,0.09]$ \\
\hline $\begin{array}{l}3 \text { Oocyte yield per woman ran- } \\
\text { domised (non-normally distributed } \\
\text { data) }\end{array}$ & & & Other data & No numeric data \\
\hline $\begin{array}{l}4 \text { Duration of oocyte retrieval (nor- } \\
\text { mally distributed data; seconds) }\end{array}$ & 6 & 714 & $\begin{array}{l}\text { Mean Difference (IV, Fixed, } \\
95 \% \mathrm{CI})\end{array}$ & $\begin{array}{l}166.01[141.96 \\
190.06]\end{array}$ \\
\hline $\begin{array}{l}5 \text { Time taken for procedure (non- } \\
\text { normally distributed data) }\end{array}$ & & & Other data & No numeric data \\
\hline 6 Total number of embryos & 2 & 160 & $\begin{array}{l}\text { Mean Difference (IV, Fixed, } \\
95 \% \mathrm{CI})\end{array}$ & $-0.10[-0.34,0.15]$ \\
\hline $\begin{array}{l}7 \text { Number of embryos cryopre- } \\
\text { served per woman randomised }\end{array}$ & 2 & 324 & $\begin{array}{l}\text { Mean Difference (IV, Fixed, } \\
95 \% \mathrm{Cl})\end{array}$ & $-0.44[-0.94,0.06]$ \\
\hline $\begin{array}{l}8 \text { Clinical pregnancy rate per woman } \\
\text { randomised }\end{array}$ & 5 & 704 & $\begin{array}{l}\text { Odds Ratio (M-H, Fixed, 95\% } \\
\mathrm{Cl} \text { ) }\end{array}$ & $1.07[0.78,1.46]$ \\
\hline $\begin{array}{l}9 \text { Ongoing pregnancy rate per } \\
\text { woman randomised }\end{array}$ & 4 & 344 & $\begin{array}{l}\text { Odds Ratio (M-H, Fixed, 95\% } \\
\mathrm{Cl})\end{array}$ & $1.21[0.73,2.02]$ \\
\hline 10 Adverse events (continuous data) & 1 & & $\begin{array}{l}\text { Mean Difference (IV, Fixed, } \\
95 \% \mathrm{CI})\end{array}$ & Subtotals only \\
\hline 10.1 Depression & 1 & 80 & $\begin{array}{l}\text { Mean Difference (IV, Fixed, } \\
95 \% \mathrm{CI})\end{array}$ & $0.60[-0.66,1.86]$ \\
\hline 10.2 Anxiety & 1 & 80 & $\begin{array}{l}\text { Mean Difference (IV, Fixed, } \\
95 \% \mathrm{Cl})\end{array}$ & $0.0[-0.60,0.60]$ \\
\hline 10.3 Stress & 1 & 80 & $\begin{array}{l}\text { Mean Difference (IV, Fixed, } \\
95 \% \mathrm{CI})\end{array}$ & $1.10[-0.42,2.62]$ \\
\hline $\begin{array}{l}11 \text { Adverse events (dichotomous da- } \\
\text { ta) }\end{array}$ & 1 & & $\begin{array}{l}\text { Odds Ratio (M-H, Fixed, 95\% } \\
\text { Cl) }\end{array}$ & Subtotals only \\
\hline 11.1 Blockage of needle & 1 & 100 & $\begin{array}{l}\text { Odds Ratio (M-H, Fixed, 95\% } \\
\mathrm{Cl})\end{array}$ & $7.44[0.37,147.92]$ \\
\hline 11.2 Vomiting & 1 & 100 & $\begin{array}{l}\text { Odds Ratio (M-H, Fixed, 95\% } \\
\mathrm{Cl})\end{array}$ & $5.21[0.24,111.24]$ \\
\hline 11.3 Hypotension & 1 & 100 & $\begin{array}{l}\text { Odds Ratio (M-H, Fixed, 95\% } \\
\mathrm{Cl})\end{array}$ & $5.21[0.24,111.24]$ \\
\hline
\end{tabular}


Analysis 1.1. Comparison 1 Follicular flushing, Outcome 1 Live birth rate.

\begin{tabular}{|c|c|c|c|c|c|}
\hline Study or subgroup & $\begin{array}{c}\text { aspira- } \\
\text { tion/flush } \\
n / N \\
\end{array}$ & $\begin{array}{c}\text { aspiration } \\
n / N \\
\end{array}$ & $\begin{array}{c}\text { Odds Ratio } \\
\text { M-H, Fixed, } 95 \% \mathrm{Cl}\end{array}$ & Weight & $\begin{array}{c}\text { Odds Ratio } \\
\text { M-H, Fixed, } 95 \% \mathrm{Cl}\end{array}$ \\
\hline \multicolumn{6}{|c|}{ 1.1.1 Poor response to ovarian stimulation } \\
\hline Haydardedeoglu 2017 & 9/40 & $10 / 40$ & $\longrightarrow$ & $24.37 \%$ & $0.87[0.31,2.44]$ \\
\hline Mok-Lin 2013 & $1 / 25$ & $5 / 25$ & & $15.1 \%$ & $0.17[0.02,1.55]$ \\
\hline Subtotal $(95 \% \mathrm{Cl})$ & 65 & 65 & & $39.47 \%$ & $0.6[0.25,1.47]$ \\
\hline \multicolumn{6}{|c|}{ Total events: 10 (aspiration/flush), 15 (aspiration) } \\
\hline \multicolumn{6}{|c|}{ Heterogeneity: $\mathrm{Tau}^{2}=0 ; \mathrm{Chi}^{2}=1.77, \mathrm{df}=1(\mathrm{P}=0.18) ; \mathrm{I}^{2}=43.51 \%$} \\
\hline \multicolumn{6}{|c|}{ Test for overall effect: $Z=1.11(P=0.27)$} \\
\hline \multicolumn{6}{|c|}{ 1.1.2 Normal response to ovarian stimulation } \\
\hline Haydardedeoglu 2011 & $56 / 93$ & $45 / 80$ & & $60.53 \%$ & $1.18[0.64,2.16]$ \\
\hline Subtotal $(95 \% \mathrm{Cl})$ & 93 & 80 & & $60.53 \%$ & $1.18[0.64,2.16]$ \\
\hline \multicolumn{6}{|c|}{ Total events: 56 (aspiration/flush), 45 (aspiration) } \\
\hline \multicolumn{6}{|c|}{ Heterogeneity: Not applicable } \\
\hline \multicolumn{6}{|c|}{ Test for overall effect: $Z=0.53(P=0.6)$} \\
\hline Total $(95 \% \mathrm{Cl})$ & 158 & 145 & & $100 \%$ & $0.95[0.58,1.56]$ \\
\hline \multicolumn{6}{|c|}{ Total events: 66 (aspiration/flush), 60 (aspiration) } \\
\hline \multicolumn{6}{|c|}{ Heterogeneity: $\operatorname{Tau}^{2}=0 ; \mathrm{Chi}^{2}=2.85, \mathrm{df}=2(\mathrm{P}=0.24) ; \mathrm{I}^{2}=29.9 \%$} \\
\hline \multicolumn{6}{|c|}{ Test for overall effect: $Z=0.2(P=0.84)$} \\
\hline \multicolumn{6}{|c|}{ Test for subgroup differences: $\mathrm{Chi}^{2}=1.48, \mathrm{df}=1(\mathrm{P}=0.22), \mathrm{I}^{2}=32.37 \%$} \\
\hline
\end{tabular}

Analysis 1.2. Comparison 1 Follicular flushing, Outcome 2 Oocyte yield per woman randomised (normally distributed data).

\begin{tabular}{|c|c|c|c|c|c|c|c|}
\hline \multirow[t]{2}{*}{ Study or subgroup } & \multicolumn{2}{|c|}{ aspiration/flush } & \multicolumn{2}{|c|}{ aspiration only } & \multirow{2}{*}{$\begin{array}{c}\text { Mean Difference } \\
\text { Fixed, } 95 \% \mathrm{Cl}\end{array}$} & \multirow[t]{2}{*}{ Weight } & \multirow{2}{*}{$\begin{array}{c}\text { Mean Difference } \\
\text { Fixed, } 95 \% \mathrm{Cl}\end{array}$} \\
\hline & $\mathbf{N}$ & Mean(SD) & $\mathbf{N}$ & Mean(SD) & & & \\
\hline Haydardedeoglu 2011 & 149 & $12.3(4.4)$ & 125 & $13.1(4.6)$ & -1 & $11.84 \%$ & $-0.84[-1.91,0.23]$ \\
\hline Haydardedeoglu 2017 & 40 & $2.3(1.3)$ & 40 & $2.3(1.3)$ & 1 & $44.08 \%$ & $0[-0.55,0.55]$ \\
\hline Kara 2012 & 100 & $10.8(6.8)$ & 100 & $11.5(6.2)$ & & $4.16 \%$ & $-0.7[-2.5,1.1]$ \\
\hline Levens 2009 & 15 & $7.2(2.3)$ & 15 & $6.5(2.2)$ & & $5.22 \%$ & $0.7[-0.91,2.31]$ \\
\hline Scott 1989 & 22 & $5.9(1.4)$ & 22 & $6.3(1.4)$ & & $19.51 \%$ & $-0.4[-1.23,0.43]$ \\
\hline 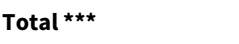 & 366 & & 342 & & & $100 \%$ & $-0.28[-0.64,0.09]$ \\
\hline \multicolumn{8}{|c|}{ Heterogeneity: $\mathrm{Tau}^{2}=0 ; \mathrm{Chi}^{2}=4.5, \mathrm{df}=5(\mathrm{P}=0.48) ; \mathrm{I}^{2}=0 \%$} \\
\hline \multicolumn{3}{|c|}{ Test for overall effect: $Z=1.47(P=0.14)$} & & & & & \\
\hline
\end{tabular}

\section{Analysis 1.3. Comparison 1 Follicular flushing, Outcome 3 Oocyte yield per woman randomised (non-normally distributed data).}

Oocyte yield per woman randomised (non-normally distributed data)

Study Aspiration/flush Aspiration only p value

\begin{tabular}{llll}
\hline Haines 1989 & Mean oocyte yield: 5.6 (range 2-15) & Mean oocyte yield: 6.8 (range 2-14) & $\mathrm{p}=0.22$ (NS) \\
\hline \hline
\end{tabular}

Follicular flushing during oocyte retrieval in assisted reproductive techniques (Review)

Copyright (c) 2018 The Cochrane Collaboration. Published by John Wiley \& Sons, Ltd. 


\begin{tabular}{|c|c|c|c|}
\hline \multicolumn{4}{|c|}{ Oocyte yield per woman randomised (non-normally distributed data) } \\
\hline Study & Aspiration/flush & Aspiration only & p value \\
\hline Kingsland 1991 & Median oocyte yield: 7 & Median oocyte retrieved: 8.5 & NS \\
\hline Mok-Lin 2013 & Median oocyte yield: 3 (IQR 2-5) & Median oocyte yield: 4 (IQR 2-6) & $p=0.41$ \\
\hline Tan 1992 & Median oocyte yield: 9 (range 1-22) & Median oocyte yield 11 (range: 1-24) & NS \\
\hline
\end{tabular}

Analysis 1.4. Comparison 1 Follicular flushing, Outcome 4 Duration of oocyte retrieval (normally distributed data; seconds).

\begin{tabular}{|c|c|c|c|c|c|c|c|c|}
\hline \multirow{3}{*}{$\begin{array}{l}\text { Study or subgroup } \\
\text { Haydardedeoglu } 2011\end{array}$} & \multicolumn{2}{|c|}{ Aspiration/Flush } & \multicolumn{2}{|c|}{ Aspiration only } & \multirow{2}{*}{\multicolumn{2}{|c|}{$\begin{array}{c}\text { Mean Difference } \\
\text { Fixed, } 95 \% \mathrm{Cl}\end{array}$}} & \multirow[t]{2}{*}{ Weight } & \multirow{2}{*}{$\begin{array}{c}\text { Mean Difference } \\
\text { Fixed, } 95 \% \mathrm{Cl}\end{array}$} \\
\hline & $\mathbf{N}$ & Mean(SD) & $\mathbf{N}$ & Mean(SD) & & & & \\
\hline & 149 & $\begin{array}{r}751.2 \\
(322.8)\end{array}$ & 125 & $\begin{array}{r}495.6 \\
(179.4)\end{array}$ & & $\longrightarrow$ & $15.74 \%$ & $255.6[194.97,316.23]$ \\
\hline Haydardedeoglu 2017 & 40 & $\begin{array}{r}236.3 \\
(152.4)\end{array}$ & 40 & $178.4(84.7)$ & & —- & $19.8 \%$ & $57.9[3.85,111.95]$ \\
\hline Kara 2012 & 100 & $732(246)$ & 100 & $456(162)$ & & $\longrightarrow$ & $17.36 \%$ & $276[218.27,333.73]$ \\
\hline Levens 2009 & 15 & $366(125)$ & 15 & $186(41)$ & & $\longrightarrow$ & $13.05 \%$ & $180[113.43,246.57]$ \\
\hline Mok-Lin 2013 & 25 & $420(150)$ & 25 & $282(102)$ & & $\longrightarrow$ & $11.44 \%$ & $138[66.89,209.11]$ \\
\hline von Horn 2017 & 40 & $234(132)$ & 40 & $114(96)$ & & — & $22.61 \%$ & $120[69.42,170.58]$ \\
\hline 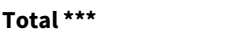 & 369 & & 345 & & & & $100 \%$ & $166.01[141.96,190.06]$ \\
\hline \multicolumn{9}{|c|}{ Heterogeneity: $\mathrm{Tau}^{2}=0 ; \mathrm{Chi}^{2}=41.65, \mathrm{df}=5(\mathrm{P}<0.0001) ; \mathrm{I}^{2}=87.99 \%$} \\
\hline \multicolumn{5}{|c|}{ Test for overall effect: $Z=13.53(P<0.0001)$} & & & & \\
\hline
\end{tabular}

Analysis 1.5. Comparison 1 Follicular flushing, Outcome 5 Time taken for procedure (non-normally distributed data).

\begin{tabular}{lll} 
& \multicolumn{2}{c}{ Time taken for procedure (non-normally distributed data) } \\
& \multicolumn{1}{c}{ Aspiration/flush } & \multicolumn{1}{c}{ Aspiration only } \\
\hline Kingsland 1991 & $\begin{array}{l}\text { Median time taken for procedure: } 35 \\
\text { minutes }\end{array}$ & $\begin{array}{l}\text { Median time taken for procedure: } 20 \\
\text { minutes }\end{array}$ \\
\hline Tan 1992 & $\begin{array}{l}\text { Median time taken: } 30 \text { minutes (range } \\
15 \text { to } 70 \text { minutes) }\end{array}$ & $\begin{array}{l}\text { Median time taken: } 15 \text { minutes (range } 4 \\
\text { to 30 minutes) }\end{array}$ \\
\hline
\end{tabular}

Analysis 1.6. Comparison 1 Follicular flushing, Outcome 6 Total number of embryos.

\begin{tabular}{|c|c|c|c|c|c|c|c|}
\hline \multirow[t]{2}{*}{ Study or subgroup } & \multicolumn{2}{|c|}{ aspiration/flushing } & \multicolumn{2}{|c|}{ aspiration only } & \multirow{2}{*}{$\begin{array}{c}\text { Mean Difference } \\
\text { Fixed, } 95 \% \mathrm{Cl} \\
\end{array}$} & \multirow[t]{2}{*}{ Weight } & \multirow{2}{*}{$\begin{array}{c}\text { Mean Difference } \\
\text { Fixed, } 95 \% \mathrm{Cl}\end{array}$} \\
\hline & $\mathbf{N}$ & $\operatorname{Mean}(S D)$ & $\mathbf{N}$ & $\operatorname{Mean}(S D)$ & & & \\
\hline Haydardedeoglu 2017 & 40 & $1.5(0.6)$ & 40 & $1.5(0.6)$ & - & $80.95 \%$ & $0[-0.28,0.28]$ \\
\hline von Horn 2017 & 40 & $1(1.2)$ & 40 & $1.5(1.4)$ & & $19.05 \%$ & $-0.5[-1.07,0.07]$ \\
\hline Total $\star \star \star ~$ & 80 & & 80 & & & $100 \%$ & $-0.1[-0.34,0.15]$ \\
\hline \multicolumn{8}{|c|}{ Heterogeneity: $\mathrm{Tau}^{2}=0 ; \mathrm{Chi}^{2}=2.38, \mathrm{df}=1(\mathrm{P}=0.12) ; \mathrm{I}^{2}=58 \%$} \\
\hline
\end{tabular}


Analysis 1.7. Comparison 1 Follicular flushing, Outcome 7 Number of embryos cryopreserved per woman randomised.

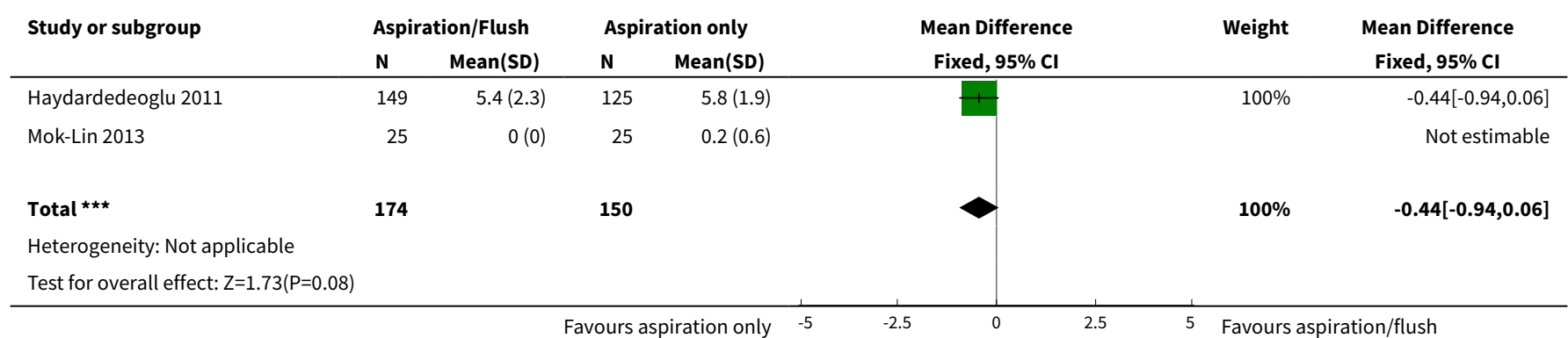

Analysis 1.8. Comparison 1 Follicular flushing, Outcome 8 Clinical pregnancy rate per woman randomised.

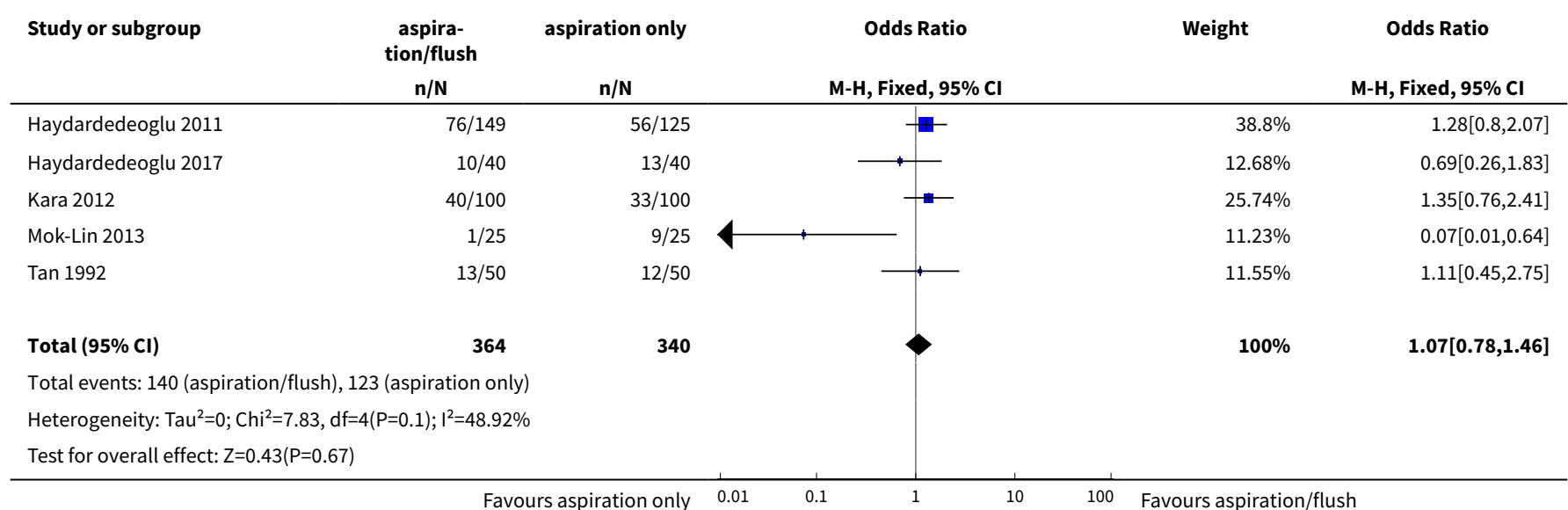

\section{Analysis 1.9. Comparison 1 Follicular flushing, Outcome 9 Ongoing pregnancy rate per woman randomised.}

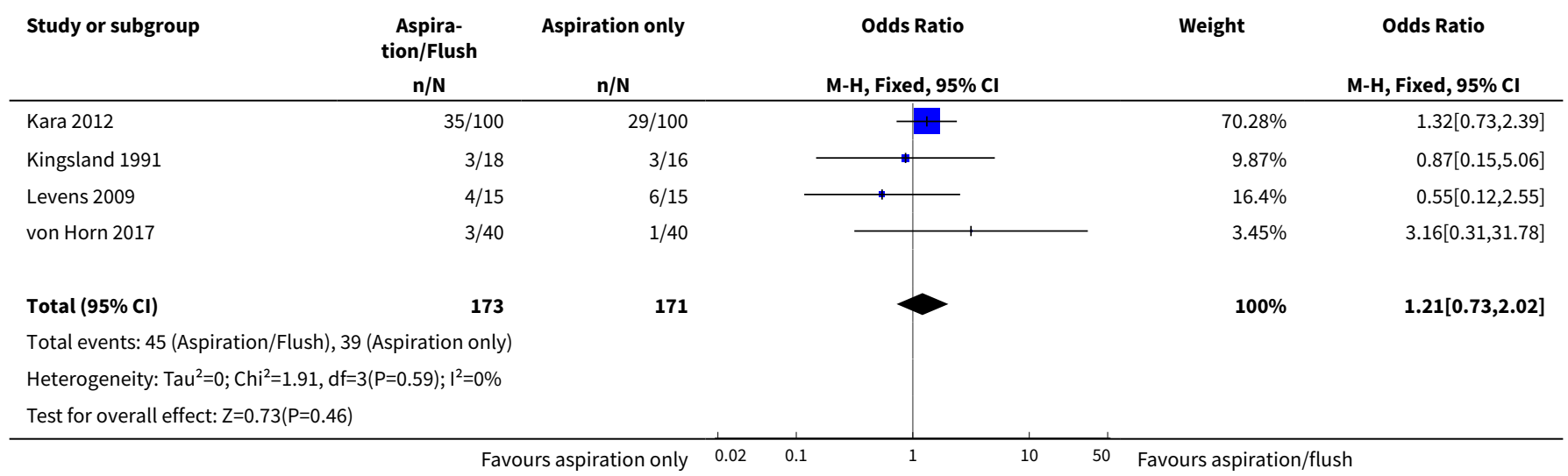


Analysis 1.10. Comparison 1 Follicular flushing, Outcome 10 Adverse events (continuous data).

\begin{tabular}{|c|c|c|c|c|c|c|c|}
\hline \multirow{3}{*}{$\begin{array}{l}\text { Study or subgroup } \\
1.10 .1 \text { Depression }\end{array}$} & \multicolumn{2}{|c|}{ Experimental } & \multicolumn{2}{|c|}{ Control } & \multirow{2}{*}{$\begin{array}{c}\text { Mean Difference } \\
\text { Fixed, 95\% Cl }\end{array}$} & \multirow[t]{2}{*}{ Weight } & \multirow{2}{*}{$\begin{array}{c}\text { Mean Difference } \\
\text { Fixed, } 95 \% \mathrm{Cl}\end{array}$} \\
\hline & \multirow[t]{2}{*}{$\mathbf{N}$} & \multirow[t]{2}{*}{ Mean(SD) } & \multirow[t]{2}{*}{$\mathbf{N}$} & \multirow[t]{2}{*}{ Mean(SD) } & & & \\
\hline & & & & & & & \\
\hline von Horn 2017 & 40 & $1.8(3.2)$ & 40 & $1.2(2.5)$ & & $100 \%$ & $0.6[-0.66,1.86]$ \\
\hline 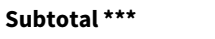 & 40 & & 40 & & & $100 \%$ & $0.6[-0.66,1.86]$ \\
\hline \multicolumn{8}{|c|}{ Heterogeneity: Not applicable } \\
\hline \multicolumn{8}{|c|}{ Test for overall effect: $Z=0.93(P=0.35)$} \\
\hline \multicolumn{8}{|l|}{ 1.10.2 Anxiety } \\
\hline von Horn 2017 & 40 & $0.8(1.6)$ & 40 & $0.8(1.1)$ & & $100 \%$ & $0[-0.6,0.6]$ \\
\hline Subtotal $* \star \star$ & 40 & & 40 & & & $100 \%$ & $0[-0.6,0.6]$ \\
\hline \multicolumn{8}{|c|}{ Heterogeneity: Not applicable } \\
\hline \multicolumn{8}{|c|}{ Test for overall effect: Not applicable } \\
\hline von Horn 2017 & 40 & $3.3(3.9)$ & 40 & $2.2(3)$ & & $100 \%$ & $1.1[-0.42,2.62]$ \\
\hline 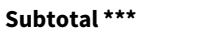 & 40 & & 40 & & & $100 \%$ & $1.1[-0.42,2.62]$ \\
\hline \multicolumn{8}{|c|}{ Heterogeneity: Not applicable } \\
\hline \multicolumn{8}{|c|}{ Test for overall effect: $Z=1.41(P=0.16)$} \\
\hline & & & dis & ation only & -2 & Favours & n/flush \\
\hline
\end{tabular}

Analysis 1.11. Comparison 1 Follicular flushing, Outcome 11 Adverse events (dichotomous data).

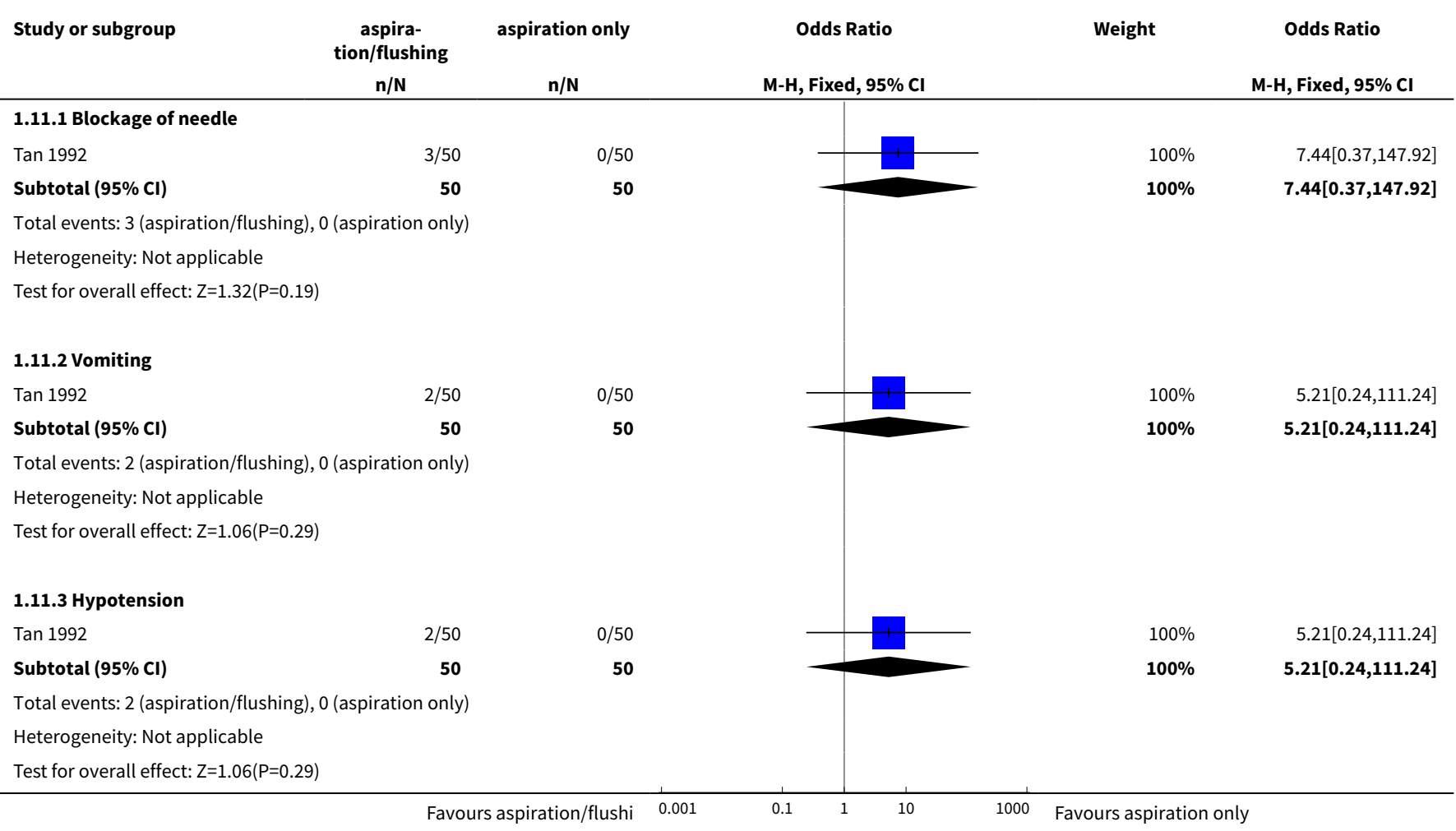




\section{APPENDICES}

\section{Appendix 1. Cochrane Gynaecology and Fertility Group (CGFG) specialised register search strategy}

Searched 18 July 2017

Procite platform

Keywords CONTAINS "follicular flushing" or "follicular rinsing" or "Flushing" or "flushing media" or "flushing outcome" or "tubal flushing" or "follicle aspiration" or "follicular aspiration" or "Flushing-Outcome" or "flushing media" or "Flushing" or Title CONTAINS "follicular flushing" or "follicular rinsing" or "Flushing" or "flushing media" or "flushing outcome" or "tubal flushing" or "follicle aspiration" or "follicular aspiration" or "Flushing-Outcome" or "flushing media" or "Flushing" (314 hits)

\section{Appendix 2. CENTRAL Register of Studies Online (CRSO) search strategy}

Searched 18 July 2017

Web platform

$\# 1$ (follic* adj15 flush ${ }^{\star}$ ):TI,AB,KY (27)

\#2 (follic* adj15 wash*):TI,AB,KY (6)

\#3 ((flush or wash^) adj15 oocyte*):TI,AB,KY (22)

\#4 (ovar* adj15 flush*):TI,AB,KY (13)

\#5 (ovar* adj15 wash*):TI,AB,KY (1)

\#6 \#1 OR \#2 OR \#3 OR \#4 OR \#5 (54)

\section{Appendix 3. MEDLINE search strategy}

Searched from 1946 to 18 July 2017

Ovid platform

1 (follic $\$$ adj15 flush\$).tw. (139)

2 (follic $\$$ adj15 wash\$).tw. (118)

3 ((flush\$ or wash\$) adj15 oocyte\$).tw. (400)

4 (ovar\$ adj15 flush\$).tw. (225)

5 (ovar\$ adj15 wash\$).tw. (308)

6 or/1-5 (1044)

7 randomized controlled trial.pt. (469461)

8 controlled clinical trial.pt. (94440)

9 randomized.ab. (411777)

10 randomised.ab. (80733)

11 placebo.tw. (196669)

12 clinical trials as topic.sh. (187425)

13 randomly.ab. (285289)

14 trial.ti. (184823)

15 (crossover or cross-over or cross over).tw. (76205)

16 or/7-15 (1207988)

17 exp animals/ not humans.sh. (4440485)

1816 not 17 (1114171)

196 and 18 (58)

\section{Appendix 4. Embase search strategy}

Searched from 1980 to 18 July 2017

Ovid platform

1 (follic $\$$ adj15 flush\$).tw. (168)

2 (follic\$ adj15 wash\$).tw. (161)

3 ((flush\$ or wash\$) adj15 oocyte\$).tw. (535) 
4 (ovar\$ adj15 flush\$).tw. (250)

5 (ovar\$ adj15 wash\$).tw. (425)

6 or/1-5 (1339)

7 Clinical Trial/ (930972)

8 Randomized Controlled Trial/ (459267)

9 exp randomization/ (74757)

10 Single Blind Procedure/ (28357)

11 Double Blind Procedure/ (138107)

12 Crossover Procedure/ (52384)

13 Placebo/ (296350)

14 Randomi?ed controlled trial\$.tw. (163117)

15 Rct.tw. (24914)

16 random allocation.tw. (1660)

17 randomly allocated.tw. (27801)

18 allocated randomly.tw. (2252)

19 (allocated adj2 random).tw. (781)

20 Single blind\$.tw. (19437)

21 Double blind\$.tw. (173262)

22 ((treble or triple) adj blind\$).tw. (695)

23 placebo\$.tw. (252265)

24 prospective study/ (390466)

25 or/7-24 (1766082)

26 case study/ (48502)

27 case report.tw. (333445)

28 abstract report/ or letter/ (1002945)

29 or/26-28 (1376884)

3025 not 29 (1720844)

316 and 30 (138)

\section{Appendix 5. PsycINFO search strategy}

Searched from 1806 to 18 July 2017

Ovid platform

1 (follic\$ adj15 flush\$).tw. (2)

2 (follic $\$$ adj15 wash\$).tw. (0)

3 ((flush\$ or wash\$) adj15 oocyte\$).tw. (1)

4 (ovar\$ adj15 flush\$).tw. (7)

5 (ovar\$ adj15 wash\$).tw. (2)

6 or/1-5 (11)

7 random.tw. (50386)

8 control.tw. (389567)

9 double-blind.tw. (20779)

10 clinical trials/ (10459)

11 placebo/ (4898)

12 exp Treatment/ (689504)

13 or/7-12 (1067763)

146 and 13 (3)

\section{Appendix 6. CINAHL search strategy}

Searched from 1961 to 18 July 2017

Ebsco Platform

\begin{tabular}{lll}
\hline$\#$ & Query & Results \\
\hline S19 & S6 AND S18 & 14 \\
\hline
\end{tabular}


(Continued)

\begin{tabular}{|c|c|c|}
\hline S18 & S7 OR S8 OR S9 OR S10 OR S11 OR S12 OR S13 OR S14 OR S15 OR S16 OR S17 & $1,147,142$ \\
\hline S17 & TX allocat ${ }^{\star}$ random $^{\star}$ & 7,005 \\
\hline S16 & (MH "Quantitative Studies") & 16,053 \\
\hline S15 & (MH "Placebos") & 10,235 \\
\hline S14 & TX placebo* & 46,640 \\
\hline S13 & TX random* allocat* & 7,005 \\
\hline S12 & (MH "Random Assignment") & 43,441 \\
\hline S11 & TX randomi $^{\star}$ control $^{\star}$ trial $^{\star}$ & 127,953 \\
\hline S10 & 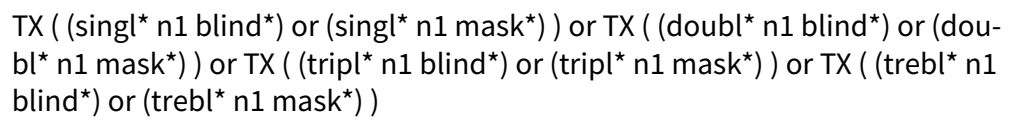 & 897,233 \\
\hline S9 & 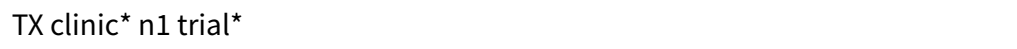 & 208,458 \\
\hline S8 & PT Clinical trial & 80,031 \\
\hline S7 & (MH "Clinical Trials+") & 217,256 \\
\hline S6 & S1 OR S2 OR S3 OR S4 OR S5 & 60 \\
\hline S5 & TX ovar* N15 wash* & 24 \\
\hline S4 & TX ovar* N15 flush* $^{\star}$ & 19 \\
\hline S3 & TX (flush* or wash*) N15 oocyte* & 7 \\
\hline S2 & TX follic* N15 wash* & 3 \\
\hline S1 & TX follic* N15 flush* & 13 \\
\hline
\end{tabular}

\section{Appendix 7. Inclusion criteria}

\begin{tabular}{ll}
\hline Date & \\
\hline Assessor & EG \\
& PM \\
\hline
\end{tabular}

First author

Publication year

Journal

Language

Follicular flushing during oocyte retrieval in assisted reproductive techniques (Review)

Copyright $\odot 2018$ The Cochrane Collaboration. Published by John Wiley \& Sons, Ltd. 


\section{Study design}

Q1: Is the study a randomised controlled trial?

Unclear

If 'no', trial excluded. If yes, then proceed to Q2.

\section{Participants}

Q2: Are the participants undergoing assisted conception treatment by IVF or ICSI?

Unclear

Q3: Did study participants use their own gametes?

Unclear

If 'no' to either Q2 or Q3, trial excluded. If yes, then proceed to Q4.

\section{Intervention}

Q4: Was the intervention follicular aspiration and flushing versus

Yes

follicular aspiration alone?

No

Unclear

\section{Final decision}

Study included if 'yes' to Q1, Q2, Q3, and Q4

Include

Exclude

\begin{tabular}{ll}
\hline Reasoning for exclusion & \\
\hline If 'unclear', action taken & Yes \\
\hline Both assessors in agreement? & No \\
\hline
\end{tabular}

If no, outcome of discussion and/or arbitration.

\section{Appendix 8. Data extraction form}




\section{Date}

Assessor

PM

\section{First author}

Publication year

\begin{tabular}{ll}
\hline Published & Yes
\end{tabular}

No

\section{Language}

Retrieval

Electronic search

Handsearched

\section{Study design}

$\begin{array}{ll}\text { Randomised controlled trial? } & \text { Yes } \\ \text { No }\end{array}$

What type of randomised controlled trial?

Parallel (intervention vs control)

Cross-over (participants used as intervention

and control groups)

Unclear

\section{Participants}

\section{Country}

Site (single or multiple centres, location)

\begin{tabular}{lc}
\hline Age & Mean+SD/Median+Range \\
& Intervention group \\
& Control group \\
\hline
\end{tabular}

\section{Inclusion criteria}

\section{Exclusion criteria}




\section{Study size}

Number recruited

Number randomised

Number excluded

Number analysed

Number lost to follow-up

\section{Interventions}

To include description of the ovarian stimulation protocol

(when appropriate), as well as details of follicular

aspiration and flushing procedures

\section{Primary outcomes}

Live birth rate

Occurrence of outcome

Non-occurrence of out-

come

Intervention group

Control group

Total (by event)

Miscarriage rate

Occurrence of outcome

Non-occurrence of outcome

Intervention group

Control group

Total (by event)

\section{Secondary outcomes}

$\begin{array}{lll}\text { Oocyte yield } & \text { Occurrence of outcome } & \begin{array}{l}\text { Non-occurrence of out- } \\ \text { come }\end{array}\end{array}$

Intervention group

Control group

Total (by event)

Duration of oocyte retrieval

Occurrence of outcome

Non-occurrence of outcome

Intervention group 
(Continued)

Control group

Total (by event)

Total number of embryos

Occurrence of outcome

Non-occurrence of outcome

Intervention group

Control group

Total (by event)

Number of embryos cryopreserved

Occurrence of outcome

Non-occurrence of outcome

Intervention group

Control group

Total (by event)

Ongoing pregnancy rate

Occurrence of outcome

Non-occurrence of out-

come

Intervention group

Control group

Total (by event)

Adverse event:

Occurrence of outcome

Non-occurrence of out-

come

Intervention group

Control group

Total (by event)

Adverse event:

Occurrence of outcome

Non-occurrence of outcome

Intervention group

Control group

Total (by event)

Adverse event:

Occurrence of outcome

Non-occurrence of outcome

Intervention group

Control group 
(Continued)

Total (by event)

\section{Subgroups:}

Age

\section{Poor ovarian reserve}

\section{Poor response to ovarian stimulation}

\begin{tabular}{lll}
\hline Live birth rate & Occurrence of outcome & $\begin{array}{l}\text { Non-occurrence of out- } \\
\text { come }\end{array}$
\end{tabular}

\footnotetext{
Intervention group
}

Control group

Total (by event)

\begin{tabular}{lll}
\hline Miscarriage rate & Occurrence of outcome & $\begin{array}{l}\text { Non-occurrence of out- } \\
\text { come }\end{array}$
\end{tabular}

Intervention group

Control group

Total (by event)

\section{Risk of bias assessment}

\begin{tabular}{|c|c|c|}
\hline \multirow[t]{2}{*}{ Selection bias } & $\begin{array}{l}\text { Was the allocation sequence adequately gen- } \\
\text { erated? } \\
\text { (adequate: computerised random number } \\
\text { generator; } \\
\text { random numbers table) }\end{array}$ & $\begin{array}{l}\text { Yes } \\
\text { No } \\
\text { Unclear }\end{array}$ \\
\hline & $\begin{array}{l}\text { Was participant allocation concealment ade- } \\
\text { quate? } \\
\text { (adequate: central computer randomisation; } \\
\text { sequentially numbered, sealed opaque en- } \\
\text { velopes) }\end{array}$ & $\begin{array}{l}\text { Yes } \\
\text { No } \\
\text { Unclear }\end{array}$ \\
\hline \multirow[t]{2}{*}{ Performance bias } & Were participants blinded? & $\begin{array}{l}\text { Yes } \\
\text { No } \\
\text { Unclear }\end{array}$ \\
\hline & Were personnel (embryologist) blinded? & $\begin{array}{l}\text { Yes } \\
\text { No } \\
\text { Unclear }\end{array}$ \\
\hline Detection bias & Were those assessing outcomes blinded? & $\begin{array}{l}\text { Yes } \\
\text { No }\end{array}$ \\
\hline
\end{tabular}


(Continued)

\section{Unclear}

\begin{tabular}{|c|c|c|}
\hline \multirow{5}{*}{$\begin{array}{l}\text { Attrition bias } \\
\text { (incomplete outcome data) }\end{array}$} & Was loss to follow-up accounted for? & Yes \\
\hline & & No \\
\hline & & Unclear \\
\hline & Was an intention-to-treat analysis performed? & Yes \\
\hline & & Unclear \\
\hline \multirow[t]{3}{*}{ Selective outcome reporting } & $\begin{array}{l}\text { Are reports of the study free of the suggestion } \\
\text { of }\end{array}$ & Yes \\
\hline & & No \\
\hline & selective outcome reporting? & Unclear \\
\hline
\end{tabular}

Other sources of bias

(high risk of bias: commercial funding source, early stopping, baseline

imbalances, poor choice of design)

WHAT'S NEW

\begin{tabular}{lll}
\hline Date & Event & Description \\
\hline 20 March 2018 & $\begin{array}{l}\text { New citation required but conclusions } \\
\text { have not changed }\end{array}$ & $\begin{array}{l}\text { The addition of } 6 \text { new studies has not led to a change in the con- } \\
\text { clusions of this review. }\end{array}$ \\
\hline 20 March 2018 & New search has been performed & $\begin{array}{l}\text { New searches have identified } 6 \text { studies at this update (Haines } \\
1989 ; \text { Haydardedeoglu 2011; Haydardedeoglu 2017; Kara 2012; } \\
\text { Mok-Lin 2013; von Horn 2017). }\end{array}$ \\
\hline
\end{tabular}

\section{H I S T ORY}

Protocol first published: Issue 1, 2004

Review first published: Issue 9, 2010

\begin{tabular}{lll}
\hline Date & Event & Description \\
\hline 31 March 2010 & New search has been performed & $\begin{array}{l}\text { This review has had a search run. One new study was identified } \\
\text { for the update, and formatting has been amended to include all } \\
\text { subheadings for RevMan 5. Amendments to the original protocol } \\
\text { have been made, and some outcomes and objectives have been } \\
\text { removed. }\end{array}$ \\
\hline 19 January 2010 & New search has been performed & Review completed, no changes to protocol \\
\hline 2 April 2008 & Amended & Converted to new review format \\
\hline
\end{tabular}




\begin{tabular}{lll}
\hline Date & Event & Description \\
\hline 11 November 2003 & $\begin{array}{l}\text { New citation required and major } \\
\text { changes }\end{array}$ & Substantive amendments \\
\hline
\end{tabular}

\section{CONTRIBUTIONS OF AUTHORS}

E. Georgiou was involved in preparing all sections of the review.

P. Melo was involved in data extraction for the review.

J. Brown made substantial editorial amendments to the review.

I. Granne was involved in preparing all sections of the protocol and made substantial editorial amendments to the review.

\section{DECLARATIONS OF INTEREST}

None known.

\section{SOURCES OF SUPPORT}

\section{Internal sources}

- None, Other.

\section{External sources}

- None, Other.

\section{DIFFERENCES BETWEEN PROTOCOLANDREVIEW}

\section{For the 2010 review}

The methods indicated that we planned to compare single versus multiple flushes, and different volumes for flushing, in terms of live births and ongoing pregnancies in women undergoing IVF and ICSI. However, as aspiration and aspiration with flushing do not yield any differences in clinical and ongoing pregnancies, nor in the number of oocytes obtained, this analysis becomes both irrelevant and unnecessary, and we removed the secondary objective from the final review.

Clinical pregnancy has been moved to be a primary outcome, with ongoing pregnancy.

We have removed several secondary outcomes from the protocol, as they did not contribute to the overall aim of the review, or they were potentially biased, as data not could not be analysed per woman randomised. These outcomes include fertilisation rate, rate of embryo cleavage, rates of congenital and chromosomal abnormalities, amount of anaesthetic required, and cost per oocyte retrieval procedure performed.

We have added the outcome of adverse events as a primary outcome.

\section{For the 2018 update}

We have updated primary and secondary outcomes. We have updated search methods and data collection and analysis in keeping with the most recent Cochrane Gynaecology and Fertility Group guidelines.

\section{INDEX TERMS}

\section{Medical Subject Headings (MeSH)}

*Ovarian Follicle; Fertilization in Vitro; Live Birth [epidemiology]; Oocyte Retrieval [*methods] [statistics \& numerical data]; Pregnancy Rate; Randomized Controlled Trials as Topic; Sperm Injections, Intracytoplasmic; Therapeutic Irrigation; Time Factors

\section{MeSH check words}

Female; Humans; Pregnancy 